\title{
X. LES PERMANENCES ET LES ÉVOLUTIONS DE LA CONSTITUTION DU SAINT-EMPIRE DE LA MORT DE CHARLES VI À LA VEILLE DE LA GUERRE DE SEPT ANS (1740-1756) ET L'OPINION DES FRANÇAIS À LEUR ÉGARD
}

Ce fut, à partir de 1740 , une véritable explosion de la production française de livres imprimés sur l'Empire qui se produit, et qui, dans l'espace d'une quinzaine d'années, de la mort de Charles VI à la veille de la guerre de Sept Ans, égala quantitativement toute la production antérieure sur ce sujet ${ }^{1}$. Explosion non seulement du nombre des publications, mais aussi de la cohérence des idées, les interprétations les plus différentes de la Constitution du Saint-Empire s'opposant désormais en France. Cette évolution des idées suit celle des réalités, marquées, d'un côté, par le dualisme de plus en plus aigu qui se faisait sentir entre l'Autriche et la Prusse (d'où une situation politique plus fragile et explosive, qui semblait mettre en danger le centre de gravité impérial que constituait Vienne) et, de l'autre, par la pérennisation d'une Constitution au fond restée inchangée ${ }^{2}$. La perception de ces réalités est, de ce fait, devenue beaucoup plus complexe, surtout aux moments cruciaux que constituent les élections d'empereur, où la maison d'Autriche a désormais plus de mal, voire ne parvient pas, à s'imposer. Si l'image qui se dégage à travers la lecture des mémoires politiques du dépôt des Affaires étrangères reste plus traditionnelle, les imprimés se prononcent souvent encore plus hardiment en faveur des droits des ordres et de leur (relative) indépendance face au pouvoir impérial. Ce sont cette diversification des idées, leurs fondements et leurs conséquences qui doivent être expliqués dans ce chapitre.

Par ordre chronologique, on voit paraître, en langue française, entre 1740 et 1756 (mis à part certains ouvrages particuliers sur la Bulle d'or et les capitulations impériales): en 1741, la »Description du gouvernement present du corps germanique « par Necker ${ }^{3}$, qui revêt aussi une certaine importance pour la connaissance du droit public allemand en Angleterre; également en 1741, un recueil

1 Même phénomène dans le domaine des manuscrits: les deux cinquièmes des mémoires manuscrits qui nous intéressent et que nous avons répertoriés, pour la période allant de 1648 à 1756, dans les archives et bibliothèques de Paris, Strasbourg, Londres, Vienne en Autriche, etc., datent des années 1740-1756.

2 Pour la Constitution allemande aux XVII et XVIII ${ }^{\mathrm{e}}$ siècle, cf. l'excellente synthèse de Burkhard, Vollendung und Neuorientierung. Pour un très bon résumé de l'image du SaintEmpire dans la littérature juridique et l'historiographie française au XVIII ${ }^{e}$ siècle, cf. également WREDE, Das Reich und seine Geschichte; ID., Die Reichsverfassung in der Perzeption. ${ }^{3}$ Charles-Frédéric NECKER, Description du gouvernement present du Corps germanique [...], Genève 1741; dédiée aux syndics et au conseil de Genève, qui avaient honoré Necker de la charge de professeur en droit public (p. $\left.{ }^{*} 2-[* 4]^{\prime}\right)$; autre édition, anonyme, s.l. 1741. 
de mémoires sur l'élection impériale par Jean Rousset, qui fut réédité en $1745^{4}$; en 1742, l'»Histoire de l'Empereur Charles VI« par Massuet ${ }^{5}$; également en 1742, une édition commentée de "La Capitulation de l'Empereur Charles VII" par Spon, rééditée en $1743^{6}$ et en $1746^{7}$; en 1748, la fameuse "Histoire générale $\mathrm{d}^{\prime}$ Allemagne ${ }^{8}{ }^{8}$ du père Joseph Barre ${ }^{9}$, entreprise d'une grande envergure, non seulement intellectuelle mais aussi financière ${ }^{10}$, et même traduite en allemand ${ }^{11}$; également en 1748, le »Traité historique et politique « de Le Coq de Villeray ${ }^{12}$; en 1749, »Le Droit public germanique « de Mauvillon ${ }^{13}$; en 1750, la traduction française de l'ouvrage de Müldener ${ }^{14}$; en 1751, un traité sur l'élection du roi des Romains ${ }^{15}$; entre 1751 et 1754 , les quatre volumes de Scheid; en 1753, les »Annales de l'Empire« de Voltaire'6; en 1754, la première édition de l'»Abrégé

4 [Jean RouSSET], Memoires instructifs, I. Sur la vacance du trone imperial. II. Les droits des electeurs et de l'Empire [...], 1 vol., Amsterdam 1741; 2 t. en 1 vol., ibid. 1745.

5 [Pierre MassueT], Histoire de l'Empereur Charles VI [...], 2 t., Amsterdam 1742.

6 [Jean-François, baron DE SPON], La Capitulation de l'Empereur Charles VII. Avec des remarques instructives touchant l'état et le gouvernement actuel de l'Empire, ainsi que sur les questions du droit public d'Allemagne les plus remarquables, Francfort/M. 1742; autre édition Francfort/M. 1743.

7 [ID.], La Capitulation [...], ibid. 1746 (BNF: M.4258); le Catalogue général des livres imprimés de la Bibliothèque nationale, t. 176 , col. 866-867, ici col. 867, remarque à juste titre qu'il s'agit d'une "réimpression de l'ouvrage précédent, en tête de laquelle ont été publiés des extraits de la Capitulation de l'empereur François I $\mathrm{I}_{\text {« }}$ et d'autres pièces.

8 BARRE, Histoire générale d'Allemagne.

${ }^{9}$ Sur cette passionnante figure, dont la plupart des papiers se trouvent aujourd'hui à la bibliothèque Sainte-Geneviève (BSG), voir ci-dessous. Le manuscrit BSG 2537 renferme la correspondance entre le père Barre et certains historiens et juristes allemands; il leur demande souvent des renseignements précis sur un certain sujet en vue de la rédaction de sa volumineuse Histoire d'Allemagne. On peut donc déterminer l'origine de certaines informations; cette correspondance éclaire surtout sur la diffusion des connaissances sur l'histoire et le droit de l'Allemagne via les relations personnelles entre savants. Le couvent du père Barre reçut certaines de ces personnalités échangeant des correspondances avec lui.

10 Témoin le projet de souscription (Paris 1744): le prix de souscription variait de 120 à 170 livres en fonction du papier choisi; la livraison était prévue au cours de l'année 1746 (bibliothèque Mazarine, ms. 1850 , pièce $n^{\circ} 9$; la $B S G$ possède aussi un exemplaire de ce prospectus, cote: $\mathrm{Z} 4^{\circ} 1117$ inv. 848).

11 [Joseph] BARRE, Allgemeine Geschichte von Deutschland, vor und nach Errichtung des Kaiserthums bis auf itzige Zeiten, 8 t., Leipzig 1749-1752; les cinq premiers tomes concernent l'histoire d'Allemagne de 648 à 1520; huit tomes ont été publiés, le reste manque. Cf. Le Journal des Sçavans (1751), p. 632, 668-669; ibid. (1752), p. 165-171, 443; ibid. (1754), p. 380.

12 LE CoQ, Traité.

13 [Éléazar de MauviLLoN], Le Droit public germanique. Où l'on voit l'état présent de l'Empire, ses principales loix \& constitutions [...], 2 vol., Amsterdam 1749; 2 vol., Amsterdam, Leipzig 1756.

14 [Johann Christian] Müldener, Capitulation harmonique [...], continuée jusqu'au tems présent: Ou traduction exactement litterale, et mot pour mot; et concordance generale de toutes les capitulations des Empereurs, Paris 1750.

15 Représentation impartiale de ce qui est juste à l'égard de l'élection d'un Roi des Romains [...], La Haye 1751.

${ }^{16}$ Les éditions en sont trop nombreuses pour être indiquées ici; pour les éditions antérieures 
chronologique « de Pfeffel ${ }^{17}$; en 1755, la version française du »Compendium iuris publici Sacri Romani Imperii« de Schmauss. Nous ne traiterons pas ces auteurs et ouvrages chronologiquement, mais par ordre thématique.

\section{Un cercle se referme: retour aux opinions de Jean Bodin chez Éléazar de Mauvillon}

Éléazar de Mauvillon, tout en étant un véritable Français par son origine, gagna cependant sa vie en Allemagne, comme secrétaire de l'électeur de Saxe, qui était en même temps roi de Pologne. Son »Droit public germanique «, une somme très brève, mais lucide sur le sujet et riche en détails, est profondément imprégné des idées de Jean Bodin et surtout de Chemnitz alias »Hippolitus a Lapide«. Selon Mauvillon, ce sont les "nouvelles Loix [sc. en particulier les traités de Westphalie et les capitulations impériales] qui ont ôté [à l'empereur] jusqu'à l'ombre de la Souveraineté dont il jouissoit avant la Paix d'Osnabruck«. Le pouvoir souverain, toujours selon Mauvillon, réside dans les états de l'Empire, "en les considérant dans la totalité «18. On croit entendre parler Bodin ${ }^{19}$.

Bien que cet auteur se soit vu accusé de partialité, pour son interprétation politique de la Constitution du Saint-Empire, son ouvrage a reçu l'approbation de nombreux contemporains, spécialistes du droit public, pour son savoir, sa connaissance des sources et la clarté de son traité. Dans sa traduction de la »Capitulation harmonique « de Müldener, Besset de La Chapelle ${ }^{20}$ fait un véritable éloge du »Droit public germanique «, dont l'auteur lui est inconnu ${ }^{21}$. En particulier, Besset atteste à cet écrivain »une précision rare« pour un jurisconsulte travaillant sur cette matière, »une exacte connoissance des Loix, Constitutions \& Actes publics de l'Empire, \& une lecture assidue des Auteurs qui ont, avant lui, couru la même carriere «22. Cependant, Besset soumet cet ouvrage à un examen sans complaisance, ne cachant pas son désaccord avec certaines assertions de Mauvillon. En particulier, il défend l'abbé de Fleury et le père Bougeant contre la critique de Mauvillon, qui, à son avis, est injustifiée. Il l'accuse notamment d'être »animé d'un zéle protestant contre le Pere Bougeant«, alors que les protestants eux-mêmes reconnaîtraient généralement les mérites de son ouvrage sur la paix de West-

à 1960, on se reportera au Catalogue général des livres imprimés de la Bibliothèque nationale, t. 214/1 et 214/2 (1978), pour les éditions plus récentes au catalogue BN Opale plus. 17 Pfefrel, Abrégé chronologique.

18 MaUvillon, Le Droit public germanique, p. 581-582.

19 La conformité entre Mauvillon et Bodin va jusque dans les citations que les deux auteurs allèguent; cf., par exemple, sur l'incompatibilité entre souveraineté et sujétion, MAUviLLoN, Le Droit public germanique, p. 576, et Bodin, République, p. 139.

20 Il s'agit probablement du premier commis Besset de La Chapelle (1700-1789), qui exerça sa charge de 1751 à 1754, cf. Piccioni, Les premiers commis, p. 238-241.

${ }^{21}$ Cf. MÜLDENER, Capitulation harmonique, discours préliminaire de Besset de La Chapelle, p. IIJ-V. Pour le reproche de sa partialité, cf. ibid., p. IV.

22 Ibid., p. IIJ-IV. 
phalie. Outre cela, Besset note certaines erreurs dans le traité de Mauvillon. Parmi les fautes les plus importantes, il note le fait que Mauvillon place dans le troisième collège de la diète certains états ecclésiastiques et des comtes immédiats, alors que, en réalité, ils faisaient partie du collège des princes. De plus, il observe que le prince de Salm a été admis à la diète de l'Empire dès 1654, tandis qu'en 1749 Mauvillon le met toujours au nombre de ceux qui n'ont pas été admis à siéger au collège des princes ${ }^{23}$. Or, le plus grave défaut que Mauvillon se voit reprocher, de la part de Besset, est la rapidité avec laquelle il passe sur certains points et la manière apodictique dont il présente ses conclusions, sans s'arrêter à un examen scrupuleux des opinions contraires ${ }^{24}$. Cependant, Besset de La Chapelle lui atteste un avantage que la critique allemande reconnaîtra également à son traité, c'està-dire "d'avoir donné le premier dans notre langue [française] un systême suivi du Droit public d'Allemagne $\ll^{25}$.

Retraçons, en quelques mots, les principales idées de l'auteur de ce "Droit public d'Allemagne«, au sujet de la Constitution du Saint Empire romain germanique. En parlant des princes de l'Empire, Mauvillon se sert du terme »supériorité territoriale«, mais il entend par là un pouvoir qui met les états "au rang des Souverains « ${ }^{26}$. Il n'en résulte pourtant pas que tous les états de l'Empire sont complètement indépendants, mais qu'ils participent à la souveraineté qui revient à l'ensemble des ordres, chaque ville et chaque prince particulier étant »co-impérant ${ }^{27}$. Si la vision du Saint-Empire dont fait preuve Mauvillon est donc très différente de celle que nous allons découvrir aux alentours de 1740 chez Necker, leurs ouvrages convergent en quelques points, par exemple en ce qui concerne le caractère de la capitulation impériale. La capitulation n'est pas, pour Mauvillon, un »Contract qu[e l'empereur] passe avec l'Empire avant que d'étre déclaré Empereur, et qu'il ratifie aprés avoir été proclamé tel«, comme la définit Heiss ${ }^{28}$, mais "une déclaration au Roi des Romains, sous quelle condition l'Empire consentoit de l'admettre à son gouvernement en qualité de Chef «29. L'empereur est réduit à un simple »dépositaire« du pouvoir auquel les états »communiquent [...] une portion du pouvoir Souverain qui réside en eux « 30 . Scheid, qui dénoncera les principes de Mauvillon, proches de ceux de Chemnitz et de Bodin, peu de temps après la publication du »Droit public germanique«, critique justement ces »abus si essentiels, qu'on en doit même être surpris, attendu le savoir de l'Auteur, par rapport à d'autres points ${ }^{31}$. Or, ce ne semble pas être le manque de connaissances qui amène Mauvillon à de tels jugements, mais bien plutôt son dogmatisme. En

${ }^{23}$ Cf. ibid., p. IV-V.

24 Cf. ibid., p. IV: "Le soin qu'il [Mauvillon] prend d'éviter la prolixité \& l'indécision qu'il reproche aux Jurisconsultes Allemands, le fait peut-être tomber dans un défaut contraire«.

25 Ibid., p. V.

26 Mauvillon, Le Droit public germanique, p. 579.

27 Ibid., p. 582.

28 HeISs, Histoire de l'Empire, deuxième édition (1685), t. II, p. 31.

29 MaUVILlon, Le Droit public germanique, p. 584.

30 Ibid., p. 582 et 584.

${ }^{31}$ SCHEID, Traité sistématique, t. I, introduction, p. [*6]. 
tant que successeur de Bodin, il n'est pourtant pas le plus fervent défenseur de l'indépendance des États territoriaux de l'Empire; la palme en ce domaine revient à Necker.

\section{L'Empire vu comme une confédération d'États indépendants par certains juristes français (Necker)}

Charles Frédéric Necker, publiciste d'origine allemande, qui professa à Genève ${ }^{32}$, publia une $»$ Description du gouvernement present du Corps germanique en 1741, ouvrage plutôt marqué par le dogmatisme de son auteur que par la précision des connaissances qu'il transmet. Mais l'ouvrage de Necker, ainsi que le souligne Scheid ${ }^{33}$, poursuit un but tout à fait différent de celui du »Traité sistématique«, ouvrage d'une grande érudition que ce dernier auteur devait publier entre 1751 et 1754. Il ne s'agit point de donner une idée complète de toutes les matières et de tous les aspects du droit public allemand, mais plutôt de défendre une certaine vision d'ensemble du Saint-Empire. Necker se veut, comme il le dit explicitement dans la préface de son ouvrage, successeur »de l'illustre Puffendorf « ${ }^{34}$. Et, effectivement, l'empreinte du maître est perceptible presque partout. Selon Necker, l'Empire est à ranger parmi les »Etats composez ou confedérez«; les différents membres qui en font partie »forment autant de veritables Souverainetez «. Il conçoit la souveraineté comme une puissance absolue et précise que »celui qui se dit Souverain doit être indépendant de toute Autorité Humaine« dans l'exercice de tous ses droits ${ }^{35}$. Necker admet bien que les états de l'Empire ne jouissent en principe que d'une supériorité territoriale, mais ce n'est pour lui qu'un nom »modeste" pour leur véritable "pouvoir Souverain«, et qui signifie au fond la même chose $^{36}$. La souveraineté des ordres n'est point incompatible avec leur qualité de vassaux, puisque le serment qu'ils prêtent à l'empereur »les engage seulement à ne pas exercer leurs Droits de Souveraineté au préjudice du bien commun de l'Empire« et que leurs fiefs ne relèvent pas à proprement parler de l'empereur, mais de l'Empire ${ }^{37}$. Même si l'on admettait cette thèse, l'argumentation ne serait pas convaincante, puisque même des fiefs relevant uniquement de l'Empire resteraient toujours des fiefs. L'ouvrage de Necker, qui se veut interprétation de l'article VIII du traité d'Osnabrück, fait violence à la Constitution de l'Empire par de nombreux aspects; mais c'est parce qu'il s'agit, en certains points, plutôt d'un écrit à caractère politique que d'une analyse juridique nuancée. Tout d'abord, Necker ne fonde son jugement que sur les princes, et exclut explicitement les états

32 Né à Custrin, mort à Genève en 1760 ; professeur de droit public allemand à Genève à partir de 1724. Cf. Nouvelle Biographie générale, t. 37, col. 575.

${ }^{33}$ SCHEID, Traité sistématique, t. I, p. *5.

34 NECKER, Description, préface, p. [*4'] (en général, nous citons l'édition de Genève).

35 Citations ibid., p. 1-2, 8 .

36 Ibid., p. 7 et 39.

37 Ibid., p. 156-157. 
de moindre puissance (villes, comtes, etc.) $)^{38}$, ce qui donne une fausse idée de l'ensemble. L'auteur, pour démontrer la compatibilité de la condition juridique des états avec leur qualité de souverains, se voit obligé de changer la nature de certaines institutions impériales et de certains pouvoirs de l'empereur limitant justement cette souveraineté. Ainsi, il transforme la mise au ban en »déclaration de guerre « et la compare au droit que les états auraient en contrepartie de déposer l'empereur au cas où celui-ci contreviendrait aux engagements pris dans sa capitulation $^{39}$. Dans ses prises de position, c'est pourtant - malgré quelques réserves que nous venons d'émettre - un ouvrage en partie convaincant et surtout rédigé par un esprit lucide, qui ne se limite pas à reproduire Pufendorf, mais va plus loin dans ses conclusions.

Si nous avons déjà attiré l'attention sur l'existence de cet ouvrage à deux reprises, il y a plusieurs années ${ }^{40}$, il reste intéressant de le confronter à un manuscrit, en fait un travail préparatoire, qu'en a laissé l'auteur ${ }^{41}$. L'inventaire des "King's Manuscripts « conservés à la British Library soupçonne à juste titre qu'il pourrait s'agir du projet ${ }^{42} \mathrm{du}$ livre que l'auteur, d'après sa préface, avait rédigé dix ans plus tôt, donc au début des années 1730 . Nous pouvons dater plus précisément ce manuscrit: Necker y évoque en effet l'»exemple tout récent« du traité de Hanovre ${ }^{43}$, conclu le 3 septembre 1725 ; le manuscrit date donc certainement lui aussi de 1725 ou bien des années suivantes ${ }^{44}$. Il convient par ailleurs de signaler que Necker avait été secrétaire privé de Sir Thomas Robinson, $1^{\text {er }}$ baron Grantham, ambassadeur britannique à Vienne et ensuite secretary of state, avant qu'il ne quittât son poste pour enseigner le droit public aux jeunes Anglais à Genève ${ }^{45}$.

38 Qui ont, d'après lui, les mêmes droits que les princes, mais pas les moyens suffisants pour les exercer librement, cf. ibid., p. 39-40.

${ }^{39}$ Ibid., p. 167 (citation), 169 et 173. Si les états ne portent pas leur précaution jusqu'à faire confirmer ce droit dans la capitulation, c'est par simple bienséance (ibid.).

40 Cf. BRaun, Traductions, p. 147.

41 Londres, British Library (BL), King's Manuscript 163, intitulé (fol. 1): „Réflexions sur le gouvemement de l'Allemagne « (voir ci-dessous); 83 feuillets, copie du XVIII ${ }^{e}$ siècle, aux armes du roi Georges III.

42 Necker lui-même parle d'»une ébauche « qu'il avait faite dix ans auparavant, après ses séjours à Ratisbonne et à Vienne, cf. NECKER, Description (édition de Genève), p. [*5], édition s.1., p. *2.

43 BL, King's Manuscript 163 fol. 6'. Necker revient sur le sujet de cette alliance défensive passée entre la Grande-Bretagne, la France et la Prusse évoqué dans la version imprimée: cf. NECKER, Description, p. 279-281.

44 Comme on sait, certaines puissances accédèrent au traité d'Hanovre en 1726 et en 1727. Cette version a apparemment aussi été lue en France. Du moins trouve-t-on un texte qui n'est pas toujours identique, mais très proche, à Paris ( $\mathrm{AE}, \mathrm{MD}$, All. 68); ce manuscrit anonyme daterait de 1730, d'après l'inventaire, et semble en effet être postérieur à celui de Londres, comme on le voit par certains remaniements stylistiques et une ample table des matières ajoutée à la fin (ibid., fol. 120-143). Cependant, nous comparerons seulement le texte de la $B L$ avec l'imprimé, les différences entre $B L$ et $A E$ ne paraissant pas aussi considérables.

45 Cette circonstance curieuse, et qui pourrait expliquer la présence du manuscrit dans la BL, n'est pas évoquée par l'article de la Nouvelle Biographie générale (voir ci-dessus), mais par D[avid] B[aynes] HoRN, The British Diplomatic Service 1689-1789, Oxford 1961, p. 38. 
Ce manuscrit diffère à certains égards de l'imprimé, bien que l'auteur n'ait pas changé d'une manière fondamentale ses idées. En premier lieu, il faut noter que le manuscrit est beaucoup plus bref. Il contient moins de réflexions sur la nature des États en général, ce qui fait qu'à travers sa lecture l'idée principale défendue par l'auteur devient plus claire; et cette idée est d'emblée exprimée, dans la première phrase du texte: »Pour avoir une juste idée du gouvernement de l'Allemagne, dit l'auteur, il ne faut pas la regarder comme un Estat simple, mais comme un Estat composé, c'est-à-dire, comme un corps politique formé par l'assemblage de plusieurs Estats souverains, à la manière, par exemple, des Provinces-Unies du PaysBas « ${ }^{46}$. Cette comparaison avec les Provinces-Unies, où chaque province est, rappelons-le, incontestablement indépendante depuis $1648^{47}$, est le leitmotiv du manuscrit ${ }^{48}$; si elle n'est pas complètement absente de l'imprimé, l'auteur n'en fait plus alors qu'un usage accessoire, et beaucoup plus nuancé. C'est ainsi que lorsque Necker définit les caractéristiques des États composés, dans la deuxième phrase du manuscrit, il reprend cette comparaison, soulignant que:

Les caractères essentiels d'un Estat composé sont, $1^{\circ}$ que chacun des Estats qui forment entre eux un mesme corps, conserve sa souveraineté et son gouvernement particulier; $2^{\circ}$ que touts ensemble tiennent des délibérations entre eux sur ce qui regarde leurs intérests communs et la conservation et défense de tout le corps. Ces caractères ne se trouvent pas moins dans le gouvernement de l'Allemagne que dans celuy des Provinces-Unies ${ }^{49}$.

En revanche, dans l'imprimé il se montre plus prudent, en omettant la comparaison quand il remarque »que l'Empire doit être mis au nombre de ces Estats composez où confedérez « ${ }^{50}$ et en précisant ensuite:

Il suffira donc, pour prouver que le Corps Germanique doit être raporté dans la Classe des Etats composez, de faire voir qu'il en a les parties essentielles, parce qu'il n'est pas nécéssaire qu'il ressemble entiérement ni à ceux qu'on a vû autrefois en Grèce, ni à celui en particulier dont les Provinces Unies des Pays Bas nous donnent aujourd'hui le meilleur modèle.

46 BL, King's Manuscript 163 fol. 2.

47 Cf. Robert FeEnSTRA, À quelle époque les Provinces-Unies sont-elles devenues indépendantes en droit à l'égard du Saint-Empire?, dans: Revue d'histoire du droit 20 (1952), p. 3063, p. 182-218 et Addendum p. 479-480.

48 L'auteur d'une brochure publiée en 1711 compare également la diète de l'Empire aux États-Généraux des Provinces-Unies des Pays-Bas. Cf. Considérations politiques sur la prochaine élection d'un Empereur [note ms.: "par monsieur de La Chapelle«]. Si l'Empereur peut soûmettre au ban de l'Empire quelqu'un des électeurs ou princes d'Allemagne du consentement du college électoral seul, sans la participation des autres princes, \& états du S. Empire [note ms.: "par monsieur Karg «]. Lettre de monsieur $\mathrm{D}^{* * *}$ à monsieur le docteur $\mathrm{N}^{* * *}$ touchant le royaume de Bohême [note ms.: "par monsieur l'abbé Le Grand«], [s.l.] 1711 (BNF, Collection Clairambault 1024, fol. 185-201), ici p. 7 de la première partie de l'imprimé (pagination particulière).

49 BL, King's Manuscript 163 fol. 2-2'.

50 NECKER, Description, p. 8. Les caractéristiques essentielles formulées par Necker sont cependant restées les mêmes; il précise toutefois que, dans l'assemblée où l'on débat des intérêts communs, chacun doit avoir »une voix décisive« (ibid., p. 9). 
La plus grande différence de l'Allemagne par rapport aux Provinces-Unies, c'est en effet "l'extérieur d'une Monarchie« que l'Empire a gardé51. Certes, quand Necker parle de la diète, il reprend toutefois la même comparaison qu'il avait déjà faite, à cet égard, dans le manuscrit ${ }^{52}$, en disant que son caractère perpétuel suit »la maniere de l'assemblée des Etats Généraux des Provinc[es] Unies des PaysBas dont elle imite, à cette heure la nature « ${ }^{53}$; mais lorsqu'il explique de manière plus détaillée le travail législatif de la diète, c'est-à-dire la façon dont y on délibère et dont on y prend les décisions, la comparaison n'est plus reprise ${ }^{54}$, contrairement à ce qu'on peut lire dans le manuscrit, beaucoup moins nuancé sur ce point, et qui prête à confusion quand Necker souligne le principe d'unanimité des États Généraux ${ }^{55}$. Ce n'est pas que Necker n'a auparavant pas remarqué les différences entre les Constitutions allemande et néerlandaise, soulignant que

comme le gouvernement de la Grande-Bretagne ne laisse pas d'estre aussi bien monarchique que celuy de la France et de la Russie, quoyqu'elle soit gouvernée différemment de ces deux dernières monarchies, l'Allemagne ne sera pas moins du nombre des Estats composez, quoyqu'elle diffère considérablement de la république des Provinces-Unies, ou des ligues des Suisses ${ }^{56}$.

Or, malgré cette restriction concernant la validité de la comparaison entre l'Allemagne et les Provinces-Unies, il y recourt fréquemment dans le manuscrit sans insister sur ses limites. Si on confronte celui-ci à l'imprimé, l'on peut dégager une approche méthodique différente. Dans la deuxième version, l'auteur procède en effet d'une façon plus systématique, et ajoute des parties historiques qui dans le manuscrit font complètement défaut. L'imprimé a un plan plus logique. C'est ainsi que la réflexion sur la souveraineté des États y précède celle qui concerne la nature des États composés, nature qui découle en fait de la souveraineté de ses États membres; dans le manuscrit, c'est l'inverse ${ }^{57}$. C'est une espèce de pamphlet qui défend la liberté des états de l'Empire, tandis que l'imprimé est un ouvrage plus systématique. D'où une organisation différente des matières qui y sont traitées: pour mieux mettre en relief sa conception de l'Empire, Necker commence avec les États, en examinant les membres qui le composent; dans l'imprimé, il suit l'usage des ouvrages systématiques en commençant par le chef de l'Empire, l'empereur, et la dignité impériale. La manière méthodique et historique change encore l'ordre dont les différents aspects d'un sujet sont présentés. Dans le manuscrit, la "grande prérogative de l'Empereur dans le gouvernement d'Allemagne, et de laquelle découlent toutes les autres, c'est qu'il est le chef du Corps germani-

\author{
51 Ibid., p. 11, 355. \\ 52 BL, King's Manuscript 163 fol. 3-3'. \\ 53 NECKER, Description, p. 249-250. \\ 54 Ibid., p. 261-268. \\ 55 BL, King's Manuscript 163 fol. 3-3'. \\ 56 Ibid., fol. 4. Cf. aussi ibid., fol. 45-47' le paragraphe intitulé "Irrégularité du gouverne- \\ ment d'Allemagne qui vient de l'inégalité de la puissance de ses membres«. \\ ${ }^{57}$ Ibid., fol, 2-2' et NECKER, Description, p. 3-9.
}


que «58. Dans l'imprimé, sa qualité originelle d'avocat et de protecteur de l'Église est citée en premier lieu ${ }^{59}$. C'est surtout à l'égard de l'empereur que Necker semble avoir un peu modéré ses idées; il le qualifie en effet dans le manuscrit de simple "représentant «, qui commet quelquefois l'erreur de se croire "réellement revestu de la souveraineté de l'Empire «60; plus tard, il admet que l'Empire a retenu "plusieurs traits de l'ancien gouvernement monarchique « et qu'il y a toujours un certain lien juridique qui soumet les sujets des états de l'Empire à l'empereur et qui fait que ces sujets »se rendent coupables du Crime de Haute Trahison, lorsqu'ils trament quelque chose contre l'empereur et l'Empire, ou lorsqu'ils entrent dans des engagemens qui lui sont contraires « ${ }^{61}$. À part cela, on peut aussi constater, tout au long des deux versions, certaines différences mineures, mais non sans intérêt; signalons, par exemple, que, si dans l'imprimé, en citant les deux premiers alinéas de l'article VIII du traité d'Osnabrück, Necker opte pour la traduction de $\mathrm{Heiss}^{62}$, il en propose sa propre version, moins réussie, dans le manuscrit ${ }^{63}$.

Un trait plus intéressant se manifeste cependant à la fin du manuscrit, où Necker, tout dans l'esprit de Pufendorf, propose des réflexions pour assurer la »bonne harmonie entre l'Empereur et les estats de l'Empire«, considérée comme »la base du bien commun du Corps germanique, et de chacun de ceux en particulier qui le composent ${ }^{6} 64$. Or, ces suggestions sont encore, pour ainsi dire, au stade embryonnaire par rapport à l'imprimé, et, surtout, sa pensée est toute centrée sur une opposition fondamentale qu'il suppose entre l'empereur et les états de l'Empire, tandis que dans l'imprimé Necker considère aussi les différents intérêts que peuvent avoir certains ordres au détriment des autres, et les met en garde contre leurs conséquences néfastes. L'empereur apparaît dans le manuscrit comme un personnage agressif, qui cherche à s'arroger des droits qui ne lui reviennent pas; l'imprimé souligne que l'autorité impériale se trouve dans "l'obligation [...] de maintenir les Constitutions publiques«, et que c'est l'avantage même des états de l'Empire de la respecter et de ne pas chercher à défendre à tout prix leur souveraineté $^{65}$. La confrontation des deux versions du traité de Necker révèle donc, audelà des changements qu'on doit attribuer à la nature différente des deux textes, un homme qui n'a pas fondamentalement modifié ses opinions, mais qui a beaucoup évolué et mûri.

58 BL, King's Manuscript 163 fol. 5'.

59 NeCKER, Description, p. 41.

$60 \mathrm{BL}$, King's Manuscript 163 fol. 6'.

61 NeCKER, Description, p. 45, 222.

62 Ibid., p 35-36. En outre, le renvoi à la capitulation de Charles VI, qui se trouve dans le manuscrit, a été supprimé à cet endroit.

63 BL, King's Manuscript 163 fol. 2'-3'.

64 Ibid., fol. 82.

65 NECKER, Description, p. 355-356. 


\section{Le Coq de Villeray ou la certitude qui s'oppose aux incertitudes de l'époque}

En 1748, Le Coq de Villeray publia, à titre anonyme, un ouvrage sur le droit public allemand qui porte le titre: »Traité historique at politique du droit public de l'Empire d'Allemagne « et qui fut dédié par l'auteur au chancelier de France ${ }^{66}$; ce livre parut à Paris, chez Laurent d'Houry. L'exemplaire conservé par la Bibliothèque nationale de France ${ }^{67}$ porte, sur son frontispice, la mention manuscrite, qui date probablement du XVIII ${ }^{e}$ siècle: »par monsieur Le Coq de Villeray«. L'indentification de l'auteur n'est point douteuse. En effet, la dédicace est signée: »Le très-humble $\&$ très-obéissant serviteur, Le Coq de Villeray «68. Pierre-François Le Coq de Villeray de Rouer était originaire de Rouen, où il était né en 1703 . Il mourut à Caen, en 1778. C'était un pur Normand. Comme historien, il travaillait aussi sur l'histoire de Suède et surtout sur l'histoire ecclésiastique et politique de la ville de Rouen ${ }^{69}$.

Dans la préface de l'ouvrage ${ }^{70}$, l'auteur constate d'abord le maigre état des connaissances des Français en la matière. S'il n'est point surprenant qu' un auteur doive justifier sa propre publication par la nécessité, c'est-à-dire par l'affirmation qu'un tel ouvrage n'existe pas encore ou que la matière dont il traite n'est pas bien connue - de sorte que nous ne devons pas prendre au pied de la lettre de telles affirmations sur la prétendue ignorance des Français à propos de ce sujet - il est en revanche très intéressant de voir que Le Coq note bien les changements que le droit public du Saint-Empire a connus; ce droit n'est donc point conçu comme immuable. Le Coq note ensuite deux autres raisons qui expliquent un certain manque de connaissances des Français en la matière: premièrement, il allègue, tout comme le fera quelques années plus tard Scheid, les maigres connaissances des langues étrangères, et notamment de l'allemand, arguant que "ceux qui auroient eu quelques goût pour approfondir une matiére aussi intéressante, se sont trouvés dans l'impuissance de le satisfaire, la plus saine partie des Auteurs qui en ont écrit, ne l'ayant traitée qu'en Idiome Allemand « ${ }^{71}$.

S'il est bien vrai que la plupart des Français, même les élites, ne savaient très certainement pas lire l'allemand, et que la partie de la Reichspublicistik écrite en allemand devait par conséquent leur échapper - abstraction faite de la connaissance indirecte à travers des médiateurs culturels tels que les Alsaciens - une autre partie de cette Reichspublicistik était écrite en latin par des auteurs allemands,

66 Henri François d'Aguesseau ou Daguesseau (1668-1751).

${ }^{67}$ LE COQ, Traité, cote BNF: F.15030. L'approbation et le privilège ainsi que d'autres documents qui s'y réfèrent et qui sont reproduits dans l'ouvrage, p. [xxiij-xxiv], sont datés respectivement 8 juin, $1^{\text {er }}$ février, 29 mars et $1^{\text {er }}$ juin 1748.

68 Ibid., p. [vj].

69 Cf. CioranEsCu, Bibliographie de la littérature française du dix-huitième siècle, t. II, p. 1070; Archives biographiques françaises I 626, 357-358; 1063, 441-443; II 400, 443.

70 LE CoQ, Traité, p. [vij]-xvij.

71 Ibid., p. [vij]. 
et l'on peut supposer que ces ouvrages, dont la présence est attestée dans des bibliothèques françaises, furent bien lus et compris par les lecteurs français, même si l'évolution générale des langues de publication au XVIIIe siècle, qui est marquée par le déclin du latin, incite, d'une part, à croire qu'il devenait de plus en plus difficile pour les Français de suivre les évolutions du droit public de l'Empire en se référant aux seuls ouvrages latins - parce que les Allemands publiaient de plus en plus de livres de droit dans leur langue maternelle, qui prit le relais du latin comme langue des juristes -, et d'autre part, à penser que le goût littéraire des Français devait les rendre plus enclins aux livres rédigés en français. Ces deux phénomènes - une nécessité croissante de traduction liée à l'usage moins fréquent du latin par les auteurs allemands, et le goût de plus en plus prononcé du public français pour la lecture de livres dans la langue de Corneille - expliquent peut-être l'essor de la littérature française qui traite du droit public germanique au milieu du XVIII' siècle.

Deuxièmement, selon Le Coq, les Français ne voyagèrent pas assez pour bien connaître l'Allemagne ${ }^{72}$. Cette raison alléguée par l'auteur s'accorde bien elle aussi avec les réalités historiques telles qu'elles sont connues par les travaux sur les voyages et la présence des Français en Allemagne vers le milieu du XVIIIe siècle. En effet, si certains voyages d'auteurs français, tels que Voltaire ou Montesquieu, sont bien attestés, il est clair que l'Allemagne ne constituait pas pour les Français une destination privilégiée quand ils se mettaient en route pour visiter et connaître un pays étranger ${ }^{73}$. Les raisons que Le Coq avance pour justifier qu'il publie à son tour un ouvrage sur le droit public allemand semblent donc bien s'accorder, d'un côté, avec les réalités de l'époque, et, de l'autre, avec les mêmes raisons que certains autres auteurs écrivant en français allèguent eux aussi, tel Scheid en ce qui concerne l' argument linguistique.

Or, si Scheid écrit aussi pour un public allemand, Le Coq s'adresse explicitement et exclusivement au public français; c'est ainsi qu'il cherche d'emblée, dans sa préface, à échapper à une éventuelle objection qu'il prévoit: „Un reproche auquel je m'attends, mais qui ne conviendroit tout au plus qu'à la seule Nation Allemande de me faire, sera peut-être que sur une matiére aussi étenduë que celle que je m'hazarde de traiter aujourd'hui, je l'aye fait avec autant de précision « ${ }^{74}$. La justification avancée par Le Coq précise qu'il s'adresse à un public particulier, les Français, et qu'il cherche par conséquent à satisfaire leurs besoins propres, c'est-à-dire qu'il peut se limiter à un aperçu du droit public allemand:

72 Cf. ibid., p. vij-viij.

73 Pour la présence française en Allemagne de 1648 à 1789, cf. Guido Braun, Deutsche Präsenz in Frankreich, französische Präsenz in Deutschland von 1648-1789. Überblick und Probleme der Forschung, dans: Francia 35 (2008), p. 381-430.

${ }^{74}$ LE CoQ, Traité, p. xj. Le mot »précision« ne signifie très certainement pas que Le Coq traite d'une manière détaillée de son sujet, car cela ne pourrait pas justifier des reproches qu'on pourrait lui faire, mais qu'il le traite dans un ouvrage peu volumineux, c'est-à-dire qu'il tente d'offrir un précis d'un sujet aussi vaste qu'est le droit public germanique. 
Ma réponse est toute prête: elle se réduira à dire \& à convenir avec mes critiques, que si j'avois écrit pour l'Allemagne, je n'aurois pour ainsi dire, qu'effleuré un sujet aussi vaste; mais que n'ayant eu d'autre objet que notre France, il suffisoit d'en donner simplement une idée méthodique \& assez suffisamment raisonnée, pour qu'elle puisse mettre à portée les amateurs de l'Histoire \& nos Historiens même, de lire avec plaisir les fastes de l'Empire, \& avec utilité 75 .

Deux autres éléments qui regardent le public visé par Le Coq sont à retenir: premièrement, il vise les historiens et les amateurs d'histoire plutôt que les juristes et les amateurs de droit, son ouvrage revêt donc plutôt un caractère historique que juridique. C'est une précision qui correspond au goût que son siècle avait développé pour l'histoire. Deuxièmement, son public n'est pas forcément un public érudit, spécialiste des questions dont traite Le Coq, mais ce sont les élites en général, qui comprennent les amateurs d'histoire qui n'ont peut-être que des connaissances approximatives de l'histoire et du droit de l'Allemagne. Cette particularité devrait se traduire sur le plan linguistique, car si Le Coq cherche vraiment à ne pas écrire dans un langage uniquement compréhensible par des spécialistes, il devrait s'abstenir de l'emploi de termini technici ou bien les expliquer. Nous essayerons donc de voir comment il traduit les termes les plus difficiles du droit public allemand car les moins bien connus en France. Or, avant d'aborder ce problème et d'examiner la structure du traité, achevons l'analyse de la préface, puisqu'elle est typique des choix opérés par bon nombre des auteurs contemporains de Le Coq.

Parmi ces éléments typiques, on doit tout d'abord retenir les idées de l'auteur à propos de l'origine et des fondements du droit constitutionnel allemand. En effet, il note bien que la Constitution moderne de l'Allemagne commence à se dégager surtout dès l'époque de Charles Quint (nous serions tentés aujourd'hui de citer plutôt celle de Maximilien Ier comme début de la première modernité en Allemagne), et il sait probablement aussi que le XVIe siècle marque le commencement de l'étude scientifique du droit public allemand; en effet, ce fut au XVIe siècle et surtout vers sa fin que naquit la Reichspublicistik en tant qu'objet d'études universitaires et qu'elle donna lieu aux premières grandes publications sur la Constitution du Saint-Empire. Si la difficulté du sujet a bien pu en dissuader quelques auteurs, surtout en France, l'Allemagne a ensuite connu un essor incontestable des publications en ce domaine, au point qu'au XVIIe siècle on a pu affirmer que tout le monde et même des débutants en écrivaient et que les librairies allemandes étaient pleines de traités sur les droits de l'empereur et des états de l'Empire; or, cette extrême richesse semble bien échapper à Le Coq, qui n'évoque que les réticences des auteurs à cause de la complexité et du manque de clarté du sujet. À part cela, il est aussi typique des auteurs contemporains de Le Coq qu'il allègue les lois fondamentales comme principale base de cette Constitution. Le catalogue qu'il en dresse et qui commence par la Bulle d'or de Charles IV n'a rien d'étonnant, bien qu'au moins quatre particularités doivent être notées. Primo, l'on retiendra que Le Coq, tout comme bon nombre de ses contemporains, considère les capitulations

75 Ibid., p. xj-xij. 
impériales comme loi fondamentale la plus importante du Saint-Empire. C'est effectivement l'idée avancée généralement par les auteurs français au milieu du XVIIIe siècle, et les capitulations impériales constituaient effectivement le premier moyen pour développer le droit constitutionnel du Saint-Empire au siècle des Lumières; après le traité de Westphalie, ces capitulations sont au fond les seules véritables lois fondamentales que le Saint-Empire ait connues jusqu'à son éclatement en 1806 si l'on ne retient pas au titre de loi fondamentale les règlements concernant l'organisation de la défense du Saint-Empire (Reichskriegsordnung), qui sont parfois classés loi fondamentale aujourd'hui, mais qui ne le sont pas pour les auteurs français du XVIII' siècle.

Secundo, Charles Quint, en revanche, n'exécuta point tous les articles de sa capitulation impériale. Pourtant, Le Coq insinue le contraire. La différence entre la norme et les réalités fut très importante à l'époque de l'empereur le plus puissant de la première modernité en Allemagne, à côté de Ferdinand II. Le Coq interprète la capitulation comme une prescription que les électeurs font au futur empereur:

[...] toutes les Capitulations que font les Electeurs à chaque nouvel Empereur qui monte sur le Trône, dans l'intervalle de son élection à son couronnement, par lesquelles, les mêrmes Electeurs prescrivent à l'Empereur elû, de certaines conditions arbitraires, suivant les circonstances des tems, \& qu'il est obligé \& s'engage de suivre pendant son administration \& gouvernement de 1'Empire ${ }^{76}$.

L'auteur du traité de 1748 voit bien que l'origine de cette capitulation impériale remonte à la puissance formidable que Charles Quint (Charles Ier d'Espagne) avait acquise. Malgré sa réticence, Charles Quint fut finalement obligé d'accepter la capitulation qui lui avait été présentée. Toutefois, dans un autre chapitre de son livre, Le Coq admet que cet empereur »s'y soumit de bonne grace, mais [qu']il n'y donna pas moins quelques legéres atteintes dans toutes les occasions qu'il trouva favorables \& qui tendoient à augmenter son pouvoir «77. En réalité, Charles Quint ne respecta pas certaines restrictions imposées à l'exercice de son pouvoir.

Tertio, le silence de cet auteur à propos de la paix publique de l'Empire, promulguée en 1495, peut intriguer. Sous-estime-t-il l'importance de cette loi fondamentale? Ce ne serait pas improbable puisque les auteurs français accordent en règle générale assez peu d'importance à celle-ci; il est vrai que si elle avait été très importante pour pacifier l'Empire vers la fin du XVe siècle, ses stipulations ne furent guère contestées ou l'objet d'interprétations divergentes au XVIII' siècle. En revanche, la Bulle d'or, qui réglait l'élection impériale, bien que d'un siècle et demi plus ancienne que la paix publique de 1495, suscita l'intérêt des Français au moment de chaque élection à l'Empire, même dans la seconde moitié du XVIII siècle.

Quarto, la paix de Westphalie continue d'être considérée comme l'un des fondements essentiels du droit public d'Allemagne, mais désormais les capitulations,

76 Ibid., p. 21.

77 Cf. ibid., p. 21 et 22 (citation). 
et notamment le projet d'une capitulation perpétuelle, tendent à la supplanter dans l'esprit des auteurs français ${ }^{78}$.

De l'interprétation de ces lois fondamentales, Le Coq déduit les principes du droit constitutionnel allemand. Contrairement à la diversité des opinions qu'on trouve dans les ouvrages des juristes, ces lois permettent, selon lui, d'avancer avec certitude des affirmations à ce propos. L'on retiendra aussi le fait que cet auteur pense dégager une certaine régularité dans la Constitution du Saint-Empire, idée que l'on pourrait opposer à la qualification de Pufendorf selon laquelle cette constitution serait »monstrueuse « - mais on sait que Pufendorf avait employé cette expression, maintes fois mal comprise, pour dire que le Saint-Empire ne collait pas bien avec les différentes formes d'État telles que les avait enseignées Aristote. Du moins, le point de vue de Le Coq est intéressant dans la mesure où il montre que la constitution finalement assez peu régulière du Saint-Empire n'a pas toujours choqué les esprits dans un pays cartésien comme la France, même en plein siècle des Lumières. Pour ne pas se perdre dans la diversité des ouvrages des juristes qui se contredisent souvent, Le Coq a donc recours aux lois fondamentales qui lui servent de règle, et son objectif est même de démontrer la régularité qui découle de leur interprétation:

On peut donc, appuyé d'actes aussi solemnels ${ }^{79}$ que ceux dont je viens de parler, marcher avec une sorte de certitude, malgré l'opiniatreté de quelques Ecrivains modernes, à soutenir qu'il n'y a encore rien de solide, ni surquoi on puisse s'arrêter sur cette matière. J'ose me flatter de leur démontrer par ce Traité, qu'il est des règles sûres \& suiviës, qui ne seront à l'avenir susceptibles, tout auplus, que de quelques legeres additions, que des évenemens inattendus, qu'il n'a pas été possible de prévoir, pourront occasionner par succession de tems ${ }^{80}$.

Dernière observation sur ce point: c'est une opinion assez singulière que celle dont Le Coq fait part ici, c'est-à-dire que les principes de la Constitution du SaintEmpire sont sur le point d'être fixés définitivement, abstraction faite de certaines modifications qui seront éventuellement causées par l'évolution future. Elle est d'autant plus singulière que les auteurs contemporains notent plutôt les incertitudes à propos de l'avenir constitutionnel du Saint-Empire, à cause des grandes contestations de l'époque et notamment du dualisme austro-prussien, qui commença à marquer de plus en plus les esprits. Finalement, Le Coq n'aurait pas raison, car l'ampleur des »évenemens inattendus, qu'il n'a pas été possible de prévoir «81 devait surpasser son imagination. Les certitudes que l'auteur défend ne le portent pas à renier par ailleurs que certains points du droit public impérial restent litigieux. Il cite notamment les divergences concernant le droit féodal. Mais, là encore, il pense que l'évolution tend vers une clarification successive des problèmes existant encore. L'espoir dont fait preuve Le Coq pour voir les instances de l'Empire résoudre sous peu toutes ces questions indécises est pourtant inébranlable; les

78 Cf. ibid., p. ix.

${ }^{79}$ Les lois fondamentales, surtout les capitulations impériales et la paix de Westphalie.

${ }^{80}$ LE COQ, Traité, p. ix-x.

81 Ibid., p. $x$. 
décisions des tribunaux et de la diète en la matière mèneraient inévitablement à une régularité incontestable et définitive.

Nous avons déjà vu que, en tant qu'auteur imprégné d'esprit méthodique, Le Coq cherche à donner "une idée méthodique $\&$ assez suffisamment raisonnée « de son sujet ${ }^{82}$. Même s'il veut se fonder essentiellement sur l'interprétation des lois dont il vante la pureté - une notion que l'historiographie post-rankenienne a à juste titre ébranlée - il a évidemment consulté les ouvrages des savants spécialistes en la matière, et notamment, il a non seulement consulté l'œuvre du célèbre juriste strasbourgeois Schœpflin ${ }^{83}$, mais encore a soumis son propre »Traité « à la lecture critique de cet oracle des énigmes du droit public allemand, avant sa publication, s'étant »servi utilement des observations qu'il m'a faites, \& que j'ai suiviës exactement $\ll^{84}$.

Tout en ne voulant pas que son ouvrage soit exhaustif, Le Coq cherche à donner une idée complète sur les points essentiels du droit public allemand. Pureté des sources, esprit méthodique, examen critique et présentation systématique - tels sont les principes qui régissent le traité que nous a laissé cet auteur, et ce fut bien son intention de le concevoir de cette manière. Retenons aussi que l'auteur se défend de négliger la profondeur historique de son sujet puisqu'il ajoute que »je fais voir à n'en pas douter, l'Origine Historique du Droit Public tel qu'il existe, ses époques depuis Charles-Magne jusqu'à nos jours « ${ }^{85}$. L'origine de l'empire de Charlemagne coïncide avec celle du droit public allemand. Cette vision traduit une certaine continuité de l'idée impériale, bien que la division en plusieurs époques ne néglige pas les évolutions que l'Empire et son droit ont connues depuis l'avènement des Carolingiens. À noter encore que la paix de Westphalie constitue le dernier des »anciens Traités Publics« que Le Coq se propose de rappeler dans son ouvrage ${ }^{86}$. D'ailleurs, il distingue les droits des électeurs en tant que tels de ceux que seuls les trois électeurs de Mayence, de Trèves et de Cologne peuvent exercer en qualité d'ecclésiastiques ${ }^{87}$. C'est-à-dire que Le Coq a très bien saisi la différence fondamentale qui existe entre les états de l'Empire, en partie séculiers et en partie ecclésiastiques, et la particularité du régime juridique des États territoriaux ecclésiastiques qui en découle. Cette distinction prêtait quelquefois à confusion chez les auteurs français.

Ne se contentant pas d'»étayer « les »autorités « qu'il a consultées et de les citer, Le Coq reproduit un certain nombre de sources en annexe. Parmi ces »Actes authentiques qui servent de règle, $\&$ sur lesquels le Droit Public est singulierement

82 Ibid., p. xj-xij.

${ }^{83}$ En effet, c'est le seul auteur qu'il nomme explicitement dans sa préface, cf. ibid., p. xij n. *: »Mr. Schœpflin Historiographe du Roy, Professeur en Histoire \& Belles Lettres à Strasbourg, \& Membre de l'Academie des Inscriptions \& Belles Lettres «. Autorité de référence s'il en est.

84 Cf. ibid., p. xij-xiij.

85 Ibid., p. xiij-xiv.

86 Ibid., p. xiv.

87 Ibid., p. xv. 
fondé«, il n'en publie cependant qu'un nombre très restreint dans leur teneur intégrale, "par la facilité que l'on a de trouver ces Actes dans presque tous les Corps Diplomatiques « 88 . On peut donc constater qu'il n'était point difficile de trouver en France vers le milieu du XVIII siècle des éditions des lois fondamentales les plus importantes du Saint-Empire, ce qui confirme les résultats que nous avons obtenus. Il ne publie donc que des extraits de la Bulle d'or et des traités de Westphalie. D'autres documents semblent pourtant lui faire défaut, notamment »parce qu'ils ne se trouvent pas communément tel que le Concordat de Leon VIII. avec l'Empereur Othon I. qui est fort rare, \& qui ne se trouve que dans le Spicilegium Germanicum de Lunig «89. Si Le Coq connait donc bien le »Spicilegium Germanicum « de Lünig ${ }^{90}$, il semble bien que celui-ci ne fût pas fort répandu en France, puisque Le Coq décide de ne pas renvoyer à cette édition, mais de publier luimême intégralement ce concordat ${ }^{91}$. La plupart des pièces, surtout celles du Moyen Âge, sont reproduites en latin. Le Coq allègue souvent ${ }^{92}$ l'édition dans laquelle il a retrouvé le document publié ensuite par lui-même: c'est ainsi qu'on peut voir qu'il a puisé dans les collections de Lünig ${ }^{93}$, Leibniz ${ }^{94}$, et surtout Goldast $^{95}$. Le Coq ne cite que rarement les ouvrages ou les collections de documents qu'il a consultés. À titre exceptionnel, on peut constater avec certitude que Le Coq a recours à Leibniz en ce qui concerne le droit d'envoyer des ambassadeurs qui revient aux électeurs mais auquel les autres princes de l'Empire prétendent aussi, puisqu'il renvoie sur cette question au »Traité de Suprematu« 96 du célèbre philosophe allemand ${ }^{97}$.

Si Le Coq s'adresse aussi à un public non spécialiste des questions du droit allemand, on peut toutefois noter qu'il emploie sans hésiter certaines notions techniques, et notamment il a recours au concept de "supériorité territoriale «, que l'on peut par conséquent considérer comme assez bien ancré dans le bon usage du XVIII siècle pour que l'on puisse l'utiliser dans un ouvrage destiné à un public d'honnêtes hommes. C'est ainsi que Le Coq le met même dans certains titres des quarante-deux chapitres de son cuvre ${ }^{98}$. En effet, cet auteur est attentif aux termes techniques propres au droit allemand. C'est ainsi qu'il explique l'origine et le

88 Ibid., p. $x v j$.

89 Ibid., p. xvj-xvij.

${ }^{90}$ Au début du XVIII ${ }^{e}$ siècle, Lünig publia un »Spicilegium ecclesiasticum des Teutschen Reichs-Archivs« (1716-1721) et un »Spicilegium seculare des Teutschen Reichs-Archivs« (1717, 1719).

91 Léon VIII devint pape en 963 et mourut en 965 ; au cours de son pontificat, il fut chassé de Rome et rétabli par Otton Ier, auquel il devait sa dignité pontificale.

92 Mais jamais pour les documents qui sont édités en français.

${ }^{93}$ LE COQ, Traité, p. 289.

94 Ibid., p. 330.

95 Ibid., p. 291, 293, 317, 319, 321, 323.

96 En 1677, Gottfried Wilhelm Leibniz publia sous le pseudonyme de Caesarinus Fuerstenerius sont traité »De jure suprematus ac legationis principum Germaniae«, cf. STOLLEIS, Geschichte des öffentlichen Rechts, t. I, p. 191.

97 LE CoQ, Traité, p. 170, n. (a).

98 Ibid., chapitres XXVII et XXVIII, p. 160, 165. 
sens du mot »recez de l’Empire«, qui signifie que les états qui ont composé la diète ayant arrêté ce recès »se sont retirez: [...] Recesserunt «. Mais ce n'est pas la seule explication que connaît Le Coq puisqu'il ajoute: »On les appelle en Allemand Reichs-Abschied, les congés de l'Empire, parce qu'on les a couchés par écrit dans le moment où les Etats prennent congé les uns des autres «99. Ce n'est pas seulement un auteur allemand, comme Scheid, mais bien un Français, Le Coq, qui est attentif aux origines, à l'étymologie des termes du droit public allemand. En règle générale, sa terminologie est assez précise et montre bien que les expressions latines et allemandes des juristes de l'Empire lui sont familières ${ }^{100}$. Les termes propres au droit allemand sont employés plus fréquemment en matière politique qu'en matière de droit religieux ${ }^{101}$.

Selon Le Coq, l'on peut distinguer trois sortes d'immédiateté: personnelle, réelle et mixte. Aux dires de Le Coq, la dernière s'applique à tous les états de l'Empire, qui sont donc immédiat, à l'égard de l'Empire par rapport à leurs personnes et à leurs biens. Or, Le Coq ne parle pas du tout du prestige lié à ce caractère d'état immédiat, mais insiste sur la sujétion et la soumission qui en découlent. On est ici aux antipodes des opinions d'un Necker, pour lequel tout ce langage féodal ne comptait plus, car il ne faisait que masquer une réalité bien différente. Le Coq ne passe pas non plus sous silence les droits particuliers dont jouissent les états de l'Empire ${ }^{102}$, qu'il décrit par ailleurs de manière précise dans les chapitres suivants de son »Traité«. En particulier, les explications précises que l'auteur fournit au sujet des droits des princes en matière de politique étrangère et de défense montrent qu'il a parfaitement compris le Constitution du Saint-Empire et ses principes à cet égard, sans qu'il se perde toutefois dans les détails. Cette dernière remarque n'est point gratuite puisqu'on peut supposer que Le Coq résume les caractères essentiels des droits des ordres et que son résumé lucide mais plutôt bref fut à la portée de toute l'élite cultivée qui n'était pas spécialiste de la question ${ }^{103}$; il dit ce qu'une personne intelligente peut avoir compris et retenu de ce sujet sans être obligée de dépasser les limites du savoir et des connaissances qui étaient censées être celles d'un honnête homme. Le Coq précise d'emblée que le droit de faire la guerre est soumis à une restriction particulière dans l'Empire. En

99 Ibid., p. 19.

100 Il suffit de lire pour s'en convaincre ses explications à propos de l'origine du mot recès, citée ci-dessus.

101 En ce qui concerne le droit de religion, il consacre curieusement un assez long chapitre aux droits d'»avocatie «, c'est-à-dire aux droits de juridiction séculière que certaines maisons d'Allemagne, et surtout celle d'Autriche exerçaient dans certaines abbayes et certains monastères territoriaux. Cf. LE COQ, Traité, chapitre XLI, p. 272-276.

102 Il en parle, du moins sommairement, ibid., p. 151-152.

103 En examinant le droit de paix des princes de l'Empire, Le Coq dit explicitement qu'il évite d'entrer dans les détails dont il réserve la discussion aux seuls spécialistes qui doivent s'en occuper par profession et qui, comme nous avons déjà vu, ne constituent pas le public qu'il vise uniquement ou principalement: "Ce sont là les principes généraux [du droit de faire la paix] dans lesquels je veux me renfermer simplement sans vouloir entrer plus avant dans une matière trop délicate par elle-même, quoique de mon sujet, pour en laisser discuter tous les points aux illustres négociateurs qui en sont chargés par Etat« (ibid., p. 167). 
effet, il souligne »qu'il ne faut pas perdre de vuë, qu'un Etat d'Empire, ni l'Empereur lui-même, ne doivent pas être attaqués en guerre, par un autre Etat d'Empire ${ }^{104}$. Si certains auteurs ont voulu fonder la quasi-souveraineté des états de l'Empire sur le ius foederis ainsi que sur le ius pacis ac belli de ceux-ci, il n'est pas étonnant que Le Coq ajoute quelques réflexions à la comparaison qu'il vient de faire entre le pouvoir d'alliance des états de l'Empire et celui dont jouit l'empereur, soulignant que »quelques-uns attribuoient à l'Empereur une Puissance Royale, \& aux Etats une liberté bornée par certains temperamens; \& que d'autres qui comparoient l'Allemagne à un gouvernement, dont le pouvoir est moderé, portoient un jugement beaucoup plus solide que ceux qui l'auroirent définie une forme mixte de République «105. On voit que c'est le droit de participer aux congrès internationaux qui fait que les princes de l'Empire ressemblent par certains aspects, même selon l'opinion d'un esprit modéré comme Le Coq, plus ou moins à de véritables souverains; admettons cependant que l'auteur apporte en règle général les restrictions nécessaires pour bien comprendre leur situation juridique.

La structure de son ouvrage révèle deux choix particuliers: premièrement, l'auteur sépare la description du rôle des différents ordres à la diète et de leurs charges et offices au niveau de l'Empire de l'explication de leurs droits dans leur domaine ou dans leurs territoires. L'Empire, et non pas les États territoriaux, se retrouve donc au centre de cet ouvrage. Deuxièmement, l'on reste un peu surpris des quelques remarques sommaires que Le Coq fait à propos des cercles de l'Empire, dont la dimension militaire, c'est-à-dire leur fonction pour organiser la défense de l'Empire, a presque complètement disparu. En revanche, la diète a conservé toute son importance, elle est l'institution impériale qui revient le plus souvent dans les titres mêmes des chapitres ${ }^{106}$. Soulignons aussi l'emploi du mot »Constitution« dans l'acception moderne du terme qui ne s'est développée qu'au XVIII' siècle $^{107}$.

Selon sa périodisation, la neuvième et dernière époque de l'histoire du SaintEmpire commence en 1648 et va jusqu'au moment où Le Coq rédige son ouvrage; cela veut dire que l'année 1740 , avec la perte de la dignité impériale par la maison d'Autriche, n'est point encore perçue comme une rupture dans l'histoire générale ou constitutionnelle du Saint-Empire, contrairement à ce qu'écrira plus tard un auteur aussi important que Koch sur cette matière. L'événement le plus »remarquable« pour Le Coq, durant cette période, est la création du neuvième électorat en faveur du duc de Hanovre, par Léopold I ${ }^{\text {er }}$, en 1692, que Le Coq rapporte assez longuement.

Le Coq distingue plusieurs espèces de droits: droit écrit et droit non écrit. Parmi les collections des constitutions écrites de l'Empire, Le Coq signale celle de Gol-

104 Ibid., p. 165.

105 Ibid., p. 168.

106 Dans dix chapitres sur quarante-deux, le terme »Diéte« ou un autre mot qui s'y réfère, par exemple "Correlation«, est cité dans le titre même du chapitre.

107 LE CoQ, Traité, p. 11. 
dast ${ }^{108}$. Pour ce qui est du droit non écrit (Le Coq utilise ici le terme allemand »Reichs-Her-Kommen«, en caractères italiques), l'auteur renvoie au traité que Kulpisius, professeur à Strasbourg ${ }^{109}$, a rédigé sur ce sujet ${ }^{110}$. Il défend l'existence du Reichsherkommen (c'est-à-dire la coutume ou les usages dans l'Empire) contre certains auteurs qui l'avaient mise en doute. En revanche, il se borne à citer peu d'exemples d'usages qui existent, selon lui, dans l'Empire; peu nombreux, ils ont néanmoins dû retenir l'intérêt de tout lecteur français, car ils évoquent les qualités requises d'un candidat à l'Empire, et notamment sa nationalité: »tel est l'usage reçu, qui exige que l'Empereur soit né Allemand, \& celui qui lui donne le droit de Gouverner l'Empire en pleine liberté, pourvû qu'il ait atteint l'âge de dixhuit ans accomplis «111. Or, une telle assertion à propos de l'origine allemande de tout futur empereur serait bien loin de faire l'unanimité parmi les auteurs non seulement français, mais aussi allemands.

La vision de l'Empire que Le Coq développe dans son traité est celle d'un État et non pas celle d'une confédération d'États indépendants, qui a pourtant trouvé bien des adeptes en France dans la période 1740-1756. Or, pour Le Coq, l'empereur est le seul, dans l'Empire, à jouir du droit »Primarium, ou Principal « tandis que les états de l'Empire n'ont qu'un »Droit propre Secundarium«, qui découle d'une »autorité moins absoluë« et les rend »Co-impérans dans les Diétes« et souverains à l'égard de leurs sujets, mais leur autorité reste »toujours subordonnée à l'Empire «112. Le point le plus intéressant est cependant la distinction du droit, qui se divise en »Principal« et »moins Principal« ou, pour reprendre les termes latins, en »Primarium« et »Secundarium«. Selon lui, le »Droit propre Primarium, est renfermé dans la seule personne de l'Empereur «, alors que ce dernier concept s' applique à celui "qui a une autorité moins abslouë«: ce sont les états de l'Empire qui jouissent de cette seconde catégorie de droit ${ }^{113}$. Le Coq décrit parfaitement la condition juridique des états de l'Empire, qui participent à la fois du pouvoir législatif exercé par la diète de l'Empire, tout en restant eux-mêmes soumis, chacun en particulier, aux autorités impériales (tribunaux, etc.); au niveau territorial, leur Landeshoheit est qualifiée d'»autorité souveraine envers leurs sujets, mais elle

108 Cf. ibid., p. 15.

109 Après ses études à Strasbourg, Johann Georg Kulpis (Kulpisius; 1652-1698), qui était originaire de Hesse, commença sa carrière universitaire à Gießen (1678-1683), où ses travaux lui valurent la réputation d'excellent spécialiste du droit public allemand, avant d'obtenir une chaire à Strasbourg. Mais, trois ans après, il passa au service du duc du Wurtemberg, qu'il représenta aux conférences pour la paix de Ryswick en 1697. En 1685, cet ancien étudiant de Johann Heinrich Boecler et d'Ulric Obrecht avait publié son livre "Dissertatio de observantia imperiali, vulgo Reichs-Herkommen« qui, encore de nos jours, est considéré comme un véritable manuel de base sur cette matière. Kulpis interprétait le Saint-Empire comme un véritable État caractérisé par une continuité juridique remontant au $\mathrm{X}^{\mathrm{e}}$ siècle et par une constitution mixte. Cf. Bernd RoECK, article »Kulpis, Johann Georg«, dans: Neue deutsche Biographie, t. XIII (1982), p. 280-282.

110 Cf. LE CoQ, Traité, p. 20.

111 Ibid.

112 Ibid., p. 26 et 29.

113 Ibid., p. 25-26. 
est limitée car »subordonnée à l'Empire «114. Chez Le Coq, la souveraineté n'est donc point conçue de la même façon que chez Bodin: la souveraineté est divisible, communicable et compatible avec une certaine sujétion. Cependant, il faut se demander si cette définition de la condition des états correspondait encore bien à la situation de la Prusse depuis 1740.

Les droits des états de l'Empire se divisent, d'après Le Coq, en droits communs et droits particuliers. Les droits communs qui reviennent à tous les états en général consistent d'abord dans la séance et le droit de suffrage que les états ont à la diète, »dans celui d'immédiateté, de même que de celui de supériorité territoriale « ${ }^{115}$. Le terme d'»immédiateté«, inventé quelque soixante-quinze ans avant la publication du »Traité« par Le Coq, faisait apparemment bien partie du bon usage vers 1748 , mais aussi celui de "supériorité territoriale«, qui est fréquemment employé par Le Coq, qui vise, comme nous l'avons vu, un public pas forcément spécialiste du droit public allemand, tandis que sur le plan du droit religieux, il semble plus prudent de reprendre des termes particuliers au droit ecclésiastique du Saint-Empire.

Or, il faut noter que Le Coq s'intéresse fort peu à l'organisation militaire du Saint-Empire, où les cercles jouaient aussi un rôle non négligeable, qui évoluait pourtant différemment selon les cercles. Cela traduit une perception différente de ceux-ci: si la diplomatie française avait porté, à l'époque de Louis XIV et après la mort du Roi-Soleil, un très grand intérêt aux cercles, au point d'y envoyer même ses agents diplomatiques, les raisons en avaient été d'ordre militaire; alors qu'ils furent d'abord perçus surtout comme instrument de guerre, ce fut plus leur fonction exécutive qui occupa les esprits au milieu du XVIIIe siècle.

Dans le chapitre quarante-deux de son »Traité du droit public«, Le Coq, un auteur qui vise - rappelons-le - un large public, comprenant, à part les professionnels, les gens cultivés en général, étudie »l'Etat actuel de l'Empire, ses forces \& son gouvernement «116, et y propose les moyens pour réformer l'Empire; en fait, ces moyens-là sont une sévère critique de Chemnitz et des réformes de l'Empire que celui-ci avait proposées à la veille de la paix de Westphalie. L'identité de Chemnitz échappe à Le Coq, qui cite son pseudonyme, »Hippolitus à lapide «117. L'auteur commence son chapitre en réfutant une assertion fausse, selon lui, à propos du status Imperii; cela traduit l'objectif principal du chapitre, qui est une condamnation des pensées de Chemnitz et, par là, de celles de Bodin. Ce dernier, que Le Coq n'évoque pas explicitement, avait qualifié l'Empire d'aristocratie, les états d'Empire rassemblés à la diète étant considérés comme les souverains de cet État. Le Coq s'oppose implicitement à Bodin en refusant d'emblée d'admettre cette vision, sinon historiquement, du moins quant à sa validité à l'époque où il écrit. Il dit en effet: »Lorsque l'on considére l'Etat actuel de l'Empire en général, tel qu'il est aujourd'hui, il pourroit être regardé, comme purement Aristocratique,

114 Voir ci-dessus.

115 LE CoQ, Traité, p. 149.

116 Cf. ibid., chapitre XLII, p. 276-288.

117 Ibid., p. 278 et passim. 
si on n'a précisément en vuë que les assemblées Comitiales ou les Diétes générales, qui sont à la vérité la base de son gouvernement «118. Après avoir brièvement expliqué comment il voit lui-même l'Empire, il reprend la réfutation du prétendu état aristocratique, en définissant le critère essentiel que cette vision demanderait:

L'Aristocratie demande d'abord, que le Domaine suprême ${ }^{19}$ soit confié à l'administration d'un Sénat perpétuel; elle veut qu'il n'y ait que ce Sénat qui, à l'exclusion de tout autre, ait la faculté de délibérer $\&$ de statuer sur toutes les partiës qui le composent, \& sur les affaires qui affectent tout le Corps de la Républiquei20.

C'est très exactement ce que Bodin demande d'un État pour qu'on puisse le qualifier d'aristocratique. Contrairement au fondateur de la théorie moderne de la souveraineté, Le Coq ne concède pas que l'Allemagne remplit ce critère-là: »On ne trouve point en Allemagne aucun Corps, ni Tribunal qui puisse ressembler à un Sénat de cette espéce, ni qui ait un pouvoir aussi étendu «; et de s'attaquer de front, mais toujours sans nommer son auteur, à la thèse selon laquelle la diète d'Empire représenterait ce sénat: »\& quiconque voudroit attribuer aux Diétes la même autorité, \& même les comparer à ce Sénat, tomberoit dans une erreur très absurde«121.

Quelles sont les raisons qui excluent, selon Le Coq, la définition de la diète comme sénat d'une république aristocratique? Cet auteur en avance deux, dont la première peut intéresser le débat actuel entre les historiens, car, ces derniers temps, l'on a discuté, en Allemagne, de la question de savoir si la diète de 1663 , qui est de fait devenue permanente, peut être regardée comme le premier parlement au sens contemporain du terme. Or, pour Le Coq, les diètes d'Empire ne sont pas proprement permanentes:

Premierement, elles [les diètes d'Empire] ne sont point ordinairement permanentes ${ }^{122}$; il n'est point d'usage d'en convoquer, que dans des cas particuliers, ou pour des raisons d'Etat qui intéressent tout le Corps Germanique, sur lesquelles il convient avec justice, qu'il délibere de concert avec le Chef, soit pour prévenir les abus ou pour y remédier, suivant les cas; soit pour faire de nouveaux réglemens, par rapport à de certaines conjonctures qui surviennent, qui n'avoient point encore été prévuës ${ }^{123}$.

Ainsi, l'opinion d'un Français, contemporain de la diète de Ratisbonne, confirme le point de vue selon lequel la diète ne devint permanente qu'à cause de son manque de capacité d'en arriver à un recès, et non pas parce qu'elle avait été conçue comme parlement permanent. En revanche, le catalogue des sujets dont la diète devait débattre, selon les traités de Westphalie, diminua quand même, non seule-

118 Ibid., p. 276.

119 C'est-à-dire la même chose que Bodin avait qualifiée de »souveraineté« ou de »maiestas $\ll$.

120 LE CoQ, Traité, p. 276.

121 lbid., p. 276-277.

122 On peut supposer que c'est donc, pour Le Coq, à titre extraordinaire que la diète convoquée à Ratisbonne, en 1663, s'est perpétuée jusqu'au XVIII' siècle. Il n'évoque pourtant pas de manière explicite ce cas.

123 LE CoQ, Traité, p. 277. 
ment en pratique mais aussi en théorie, le caractère plutôt exceptionnel de la convocation de la diète, qui avait surtout été typique du premier XVIIe siècle; le point de vue de Le Coq, insistant peut-être trop sur la qualité exceptionnelle de la diète, correspond donc moins à la situation qui a existé depuis 1648 qu'à la précédente. Quoi qu'il en soit, il convient de noter que Le Coq se distingue très clairement de Bodin en n'admettant pas la comparaison de la diète de l'Empire avec le sénat de Venise et en niant que la souveraineté réside dans la diète:

Cette seule raison ${ }^{124}$ prouve visiblement que les Diétes ne peuvent représenter ce Sénat, \& que ceux qui voudroient les comparer à celui de Venise, ne porteroient pas un jugement bien sensé, en leur attribuant le pouvoir absolu qu'elles n'ont point, \& que ce sénat exerce sur les biens de chacun de ses Membres, \& même sur leurs personnes ${ }^{125}$.

Si l'Empire n'est donc pas une aristocratie, comment peut-il être défini en recourant aux formes d'État enseignées par Aristote? Chez Le Coq, on retrouve la fameuse solution enseignée par l'une des plus influentes écoles allemandes du XVIIe siècle, qui avait beaucoup marqué les esprits en France et qui voulait que l'Empire ne fût point purement aristocratique ni purement monarchique, mais lui attribuait une forme de gouvernement mixte (status mixtus):

Mais pour peu qu'on examine les choses de plus près [lance-t-il à ceux qui considèrent l'Empire comme une aristocratie pure] on changera bientôt de sentiment, ou du moins, on conviendra qu'il réside dans le caractere Impérial un pouvoir mixte \& limité à la vérité, mais qui ne rend point Aristocratique le gouvernement d'Allemagne, dans toutes ses partiës ${ }^{126}$.

Plutôt qu'au sénat, les diètes d'Empire ressemblent, au regard de Le Coq, aux parlements d'Angleterre. Le comparatisme n'est donc point passé complètement hors d'usage; tout comme les auteurs qui ont écrit aux siècles précédents, Le Coq cherche en fait à trouver des éléments comparables ailleurs pour définir les institutions, en l'espèce la diète, du Saint Empire romain germanique.

Si nous avons dit que les conceptions de Le Coq se distinguent fortement de celles de Bodin, il faut bien préciser qu'il ne cite pas cet auteur; mais il se démarque explicitement et très nettement de Chemnitz, qu'il considère comme »le plus partial des Auteurs qui ont soutenu l'Aristocratie d'Allemagne«, jugeant »que la passion avoit beaucoup plus de part dans ses raisonnemens, que de justice « ${ }^{127}$. Le Coq résume d'ailleurs très bien le principe de Chemnitz, qu'il a lui-même déduit de Bodin, selon lequel »la souveraineté réside dans les Princes \& Etats d'Empire «, estimant que »les Empereurs n'en ont tout au plus que les apparences «128. Par la suite, Le Coq résume en français les moyens proposés par Chemnitz pour »maintenir dans les Etats cette souveraineté « ${ }^{129}$, citant cet auteur en latin dans les

124 Voir la citation ci-dessus.

125 LE CoQ, Traité, p. 277.

126 Ibid., p. 276.

127 Ibid., p. 278.

128 Ibid., p. 279.

129 Ibid., p. 279--281 (citation p. 279). Ces six recommandations sont, primo, de conserver l'unité parmi les états d'Empire; secundo, de ne pas laisser la couronne impériale longtemps dans la même maison; tertio, de convoquer régulièrement l'assemblée des états ou d'insti- 
notes de bas de page ${ }^{130}$. C'est donc dans une édition latine que Le Coq a lu Chemnitz, non pas dans l'une de ses traductions françaises.

Selon Le Coq, les moyens proposés par Chemnitz pour bien gouverner l'Empire »ne tendoient pas moins qu'à abaisser totalement la Maison d'Autriche, qu'il avoit uniquement en vuë« ${ }^{131}$. Le Coq a parfaitement saisi cet objectif de Chemnitz. Il n'admet que le bien-fondé d'une seule des six propositions avancées par ce dernier, son appel à l'union des états ${ }^{132}$.

Or, si Le Coq refuse de souscrire à la vision de l'Empire développée par Chemnitz, il ne se range pas non plus du côté des plus fervents opposants à son livre $»$ De ratione status«. C'est, par ailleurs, l'un des rares passages, dans les livres et les documents français de la période 1648-1756, qui répondent explicitement aux auteurs allemands qui soutiennent que l'Allemagne est une monarchie; en règle générale, il semble bien que ces auteurs ne soient guère connus en France, tant il est rare que les auteurs français les citent ou s'y réfèrent. Par contre, il est évident que Le Coq connaît Sluterus, dont il mentionne la réfutation que ce dernier avait publiée de l'ouvrage de Chemnitz ${ }^{133}$. D'après Le Coq, en suivant Sluterus, »on tomberoit dans un autre inconvénient tout opposé, cet Auteur, s'efforçant de démontrer que le gouvernement de l'Empire est Monarchique, avec au moins autant de partialité, que le précédent ${ }^{134}$ a prétendu en prouver l'Aristocratie avec aigreur « ${ }^{135}$. La critique que Le Coq fait de Sluterus montre bien que la littérature allemande qualifiant le Saint-Empire de monarchie stricto sensu ne trouva pratiquement pas d'adeptes en France ${ }^{136}$. Le Coq estime même que, par rapport à Sluterus, Chemnitz »est mieux fondé \& plus séduisant sans comparaison «137. C'est le jugement généralement porté en France sur ce genre d'auteurs: si les auteurs français les connaissent, ils les tiennent pour des mercenaires de la maison d'Autriche.

tuer un »Tribunal fixe et perpétuel«, comme le »Régiment « établi en 1500 par Maximilien Ier (nommé Reichsregiment en allemand; Le Coq résume l'histoire de cette institution plutôt éphémère, ibid., p. 280-281, citations p. 280, le terme technique est mis en italique dans l'original); quarto, »de ne laisser à l'Empereur, que les marques honoraires de la Majesté Imperiale, \& que la République s'en reserve tous les Droits, \& le pouvoir« (p. 281); quinto, de »ne pas laisser les Empereurs les arbitres de la vie, des biens \& de la réputation des Etats « (ibid.); et, sexto, que les troupes ni les forteresses de l'Empire ne doivent pas être laissées à la seule disposition de l'empereur.

${ }^{130}$ Le Coq reprend aussi les termes allemands utilisés par Chemnitz dans son texte latin, tels que »Reichsdeputationstag « (ibid., p. 280, n. f). Il traduit ce terme par »députations ordinaires des Etats« (ibid., p. 280).

131 Ibid., p. 282.

132 Cf. ibid.

133 J. Slüter (Sluterus), auteur de plusieurs livres contre Chemnitz, publiés entre 1652 et 1674, cf. STOLLEIS, Geschichte des Öffentlichen Rechts, t. I, p. 205, n. 466.

134 C'est-à-dire Chemnitz.

135 LE CoQ, Traité, p. 282.

136 Parmi les auteurs des livres imprimés et des documents manuscrits que nous avons étudiés, nous n'avons pu repérer aucun auteur qui considère l'Empire comme une monarchie pure.

${ }^{137}$ LE CoQ, Traité, p. 282. 
N'admettant point ces deux interprétations extrêmes de la Constitution du Saint-Empire, Le Coq prêche une voie médiane, qui était aussi celle d'une très grande partie des juristes allemands: il conclut en effet de ses observations sur Chemnitz et Sluterus

que sans s'arrêter aux opinions trop marquées de ces deux Auteurs, il faut se fixer à un juste milieu dans ces deux formes de gouvernement, en ne donnant pas aux Empereurs un pouvoir illimité, tel que Sluterius [sic] \& ses Partisans voudroient l'insinuer aux Etats d'Empire, ni celui dont son antagoniste voudroit qu'ils fussent en possession ${ }^{138}$.

Défendant cette voie médiane, Le Coq donne l'exemple de la persistance d'idées plus traditionnelles, en France, après les changements politiques majeurs qui avaient marqué l'histoire de l'Empire depuis 1740. Pourtant, ces idées n'y furent pas unanimement acceptées, ni avant 1740 , ni, surtout, après cette date. Ce qui frappe, c'est que Le Coq discute toujours de la Constitution du Saint-Empire en se fondant sur trois auteurs qui avaient écrit et publié leurs livres bien avant son époque $^{139}$. En principe, son ouvrage aurait pu être écrit au XVIIe siècle, tant il semble ignorer ou négliger les changements postérieurs.

Le fait que Le Coq privilégie toujours la paix de Westphalie par rapport aux capitulations impériales, auxquelles les publicistes allemands et français ajoutèrent de plus en plus d'importance au XVIIIe siècle, pourrait s'expliquer par la consultation des auteurs du XVIIe siècle, qui prévaut chez Le Coq. Cependant, contrairement à un certain nombre d'auteurs français du XVII ${ }^{e}$, ainsi que du XVIII ${ }^{e}$ siècle, Le Coq est loin de souscrire au discours sur la décadence de l'Empire. Au contraire, il souligne les nombreuses forces du Saint-Empire, forces auxquelles il ajoute pourtant ses recommandations pour remédier à certaines faiblesses. En ce qui concerne le péril turc, il faut aussi se demander dans quelle mesure Le Coq a repris les préoccupations du XVIIe siècle, en lisant les auteurs de cette époque-là, au lieu de s'avérer un observateur clairvoyant de son propre temps. En effet, Martin Wrede a bien prouvé, tout récemment, que la diminution du danger que les invasions ottomanes ont représenté pour le Saint-Empire aux Temps modernes contribua, en combinaison avec d'autres évolutions, comme les changements dynastiques de 1742 et de 1745 , à montrer les limites des capacités d'intégration de l'Empire, surtout après $1740^{140}$. En fait, selon Martin Wrede, la disparition de l'ennemi commun de l'empereur et des états d'Empire qu'avait été le Turc fut l'une des causes de la désintégration du Saint-Empire qui suivit à partir des années 1740 .

L'un des plus grands problèmes de l'Allemagne est, d'après Le Coq, son caractère multiconfessionnel, qui remet en cause l'union et l'harmonie dans l'Empire. Les recommandations qu'il fait pour extirper ce problème sans recourir à la force peuvent paraître difficiles à mettre en pratique, et même simplistes, vu la complexité des problèmes religieux existant dans l'Empire et l'infinité de règlements et

138 Ibid., p. 283.

139 Le troisième auteur est Pufendorf.

140 Cf. WREDE, Das Reich und seine Feinde. 
de lois à respecter dans ce domaine-là. Or, à cet égard, c'est encore à Pufendorf que Le Coq se réfère, en arguant qu'il convient "d'avoir les mêmes égards, \& de traiter sans aucune prédilection, les Sujets de l'une \& de l'autre Religion, comme le conseille Puffendorff « ${ }^{141}$. On peut noter que Pütter, dans son compte rendu du traité de Le Coq, cite une partie de ce passage relatif aux différentes religions pour montrer que certaines des remarques que fait ce dernier ne sont pas pertinentes ${ }^{142}$.

Si l'on s'interroge sur l'auteur allemand dont Le Coq partage le plus parfaitement les idées sur la Constitution du Saint-Empire, on doit conclure que c'est très certainement Pufendorf, même si d'autres auteurs sont bien cités positivement par Le Coq, tel Hermann Conring, qu'il défend à la fin de son »Traité« contre la position de Chifflet; il s'agit de la question de savoir si la France a jamais appartenu à l'Allemagne, à laquelle Conring, contrairement à Chifflet, a répondu par la négative $^{143}$. Conring fut donc lu, compris et approuvé en France. Son traité sur les frontières du Saint-Empire compte parmi les meilleurs ouvrages consacrés au droit public de l'Empire au XVII ${ }^{\text {siècle }}{ }^{144}$. En particulier, Le Coq suit l'argumentation de Conring sur deux points qui ont servi à prétendre que la France a dépendu de l'Empire: l'appel lancé par Boniface VIII à l'empereur pour déposer le roi de France et, surtout, le titre d'archichancelier des Gaules qui revenait à l'électeur de Trèves.

Plus que par son accord avec Pufendorf et Conring, c'est par son opposition contre Chemnitz que Le Coq définit cependant sa propre vision de l'Empire. C'est pourquoi, en guise de conclusion, on peut constater, premièrement, un jeu complexe d'échanges réciproques franco-allemands à travers les siècles: le Français Jean Bodin prône l'aristocratie de l'Empire, vers le milieu de la seconde moitié du XVIe siècle; ses idées sont à l'origine de la Reichspublicistik dans l'Empire, dont l'un des protagonistes les plus célèbres, Philipp Bogislaus von Chemnitz, reprend et transforme un certain nombre de pensées bodiniennes, à la fin de la première moitié du XVII e siècle, et en déduit les principes qui peuvent, selon lui, servir à réformer l'Empire; à peu près un siècle plus tard, c'est un Français, Le Coq de Villeray, qui critique cette image de l'Empire de Chemnitz, et à travers cette critique, s'oppose, au siècle des Lumières, implicitement à la vision du Saint-Empire qu'un autre Français avait développée à l'ère des guerres de religion. Le combat des publicistes allemands autour du status Imperii, n'était pas seulement connu en France, et un Français, Jean Bodin, ne fut pas seulement à son origine, mais il échappait à la seule Allemagne; plutôt que d'une discussion purement allemande, il s'agissait d'un débat européen, et, surtout, franco-allemand.

Si l'on s'interroge, deuxièmement, sur les raisons qui ont pu pousser Le Coq à s'attaquer à la vision aristocratique de l'Empire vers le milieu du XVIII'e siècle, la

141 Le CoQ, Traité, p. 287.

142 PÜTTER, Litteratur des Teutschen Staatsrechts, t. II, p. 79-80, n.a.

143 LE COQ, Traité, p. 287.

144 Au sujet de l'ouvrage de Hermann Conring, »De finibus Imperii Germanici« (1654), voir notre chapitre sur les frontières du Saint-Empire. Le Coq se réfère, en particulier, au chapitre 8 du livre premier du traité de Conring, cf. LE COQ, Traité, p. 287, n. n. 
réponse doit tenir compte du fait que ce débat vieux de près de deux siècles avait été relancé en France depuis au moins 1740, et que cette vision aristocratique y avait de nouveau trouvé de nombreux adeptes. C'est cet essor des anciennes idées bodiniennes (transformées par Chemnitz), caractérisant le débat français depuis environ 1740 , qui se reflète dans la structure même du chapitre quarante-deux du »Traité« de Le Coq, lui-même adepte de l'école du status mixtus, dont on trouve donc encore des partisans en France au milieu du siècle des Lumières; cette vision du Saint-Empire est cependant, à cette époque, tellement sur la défensive, dans le royaume, que le souci primordial doit être de s'attaquer d'abord à ses adversaires ${ }^{145}$, avant de pouvoir soutenir sa propre vision divergente, traditionnelle elle aussi, mais en recul.

À travers notre analyse de cet ouvrage, il est apparu que la vision que Le Coq défend du Saint-Empire est aux antipodes de celle de Chemnitz. Le Coq se délimite explicitement des opinions de ce dernier, et nous devrons encore revenir sur ce point.

\section{L'empereur et son élection au centre des discussions: l'exemple de l'abbé Guyon}

Force est de constater que, à partir de 1740 , les éditions françaises de la Bulle d'or et des capitulations impériales connaissent un essor important et qu'en France les commentateurs de ces lois fondamentales les discutent de manière controversée. Ce débat doit être interprété sur l'arrière-fond de la remise en cause de l'appartenance de la dignité impériale à la maison d'Autriche. Dans ce chapitre, nous avons vu également que des auteurs comme Éléazar de Mauvillon mettaient le problème de l'élection impériale au centre de leurs ouvrages sur le droit public allemand.

Or, au même moment, l'abbé Guyon remit en cause le caractère romain même de la dignité impériale, qui était fondé sur la théorie de la translatio Imperii, selon laquelle l'empereur du Saint-Empire était le successeur légitime des empereurs de la Rome antique ${ }^{146}$. Guyon consacre la plus grande partie de son ouvrage à l'histoire de l'Empire d'Occident au temps des Carolingiens. Pour cet auteur, les rois francs sont les »Rois de France «. La première partie de son livre traite des monarques francs, depuis Charles Martel jusqu'à l'extinction de la dynastie carolin-

145 Outre le fait que Le Coq avance les idées des partisans de la théorie de l'aristocratie allemande tout au début du chapitre, il ne développe pas sa propre vision de manière continue, mais en constante opposition avec les pensées de ses adversaires, cf. ibid., chapitre XLII, p. 276-288.

146 M. l'abbé [Claude-Maire] GuYon, Essai critique sur l'établissement et la translation de l'Empire d'Occident, ou d'Allemagne. Les causes singulieres pour lesquelles les François l'ont perdu, Paris 1752; l'ouvrage est dédié au duc de Taillard, pair de France; l'approbation et le privilège du roi datent du premier trimestre de 1746. Selon CIORANESCU, cet auteur naquit à Lons-le-Saulnier, le 13 décembre 1699, et mourut à Paris, en 1771. Il était ex-oratorien. Cf. ID., Bibliographie de la littérature française du dix-huitième siècle, t. II p. 924-925. 
gienne, et de la Francie orientale jusqu'au sacre d'Otton Ier147. La seconde partie examine plus en détail les causes de la chute de l'Empire carolingien ${ }^{148}$. Selon Guyon, cette chute fut provoquée surtout par la faiblesse de certains empereurs et par la puissance temporelle des papes. Enfin, la troisième partie étudie les titres d'»Empereur « et de »Roi des Romains «, avant d'examiner l'origine et les droits des princes électeurs.

Cette attention particulière que Guyon prête aux empereurs francs distingue véritablement son ouvrage de l'»Histoire《 de Maimbourg, que l'auteur attaque sévèrement. En particulier, Guyon lui reproche d'avoir chargé »ses marges d'une longue suite d'Auteurs, qu'il n'a vraisemblablement consultés que très-légerement, puisqu'il leur prête souvent tout le contraire de ce qu'ils disent" et de n' avoir consacré qu' une cinquantaine de pages à l'histoire des empereurs carolingiens et au problème du transfert de l'Empire en Allemagnel49. Dans l'»Avertissement« placé au début du volume, l'abbé résume déjà son opinion défavorable au sujet de la prétention du titre d' "Empereur Romain « par les souverains d'Allemagne. Selon lui, les Allemands n'ont récupéré ce titre qu'à travers »la révolte \& l'usurpation« de princes illégitimes au détriment de leurs véritables seigneurs, profitant de la faiblesse de Charles le Gros ${ }^{150}$. Guyon conclut:

Le terme d'Imperium Romano-Germanicum, dont tous les Ecrivains Allemans se servent depuis deux ou trois siécles, $m$ 'a donné occasion d'examiner sur quel fondement on pouvoit donner le nom d'Empire Romain à l'Empire d'Allemagne. J'ai trouvé que ni Charlemagne, ni ses descendans ne s'étoient nommés Empereurs des Romains; \& que cette qualité de même que celle de Roi des Romains, s'étoit introduite long-tems après eux, sans concession, ni conquête nouvelle, \& malgré les plaintes des Successeurs de Constantin le Grand ${ }^{151}$, qui n'avoient ni perdu, ni quitté ce titre ${ }^{152}$.

L'abbé loue l'attention d'Abel Servien aux conférences de Münster pour éviter que l'empereur ne s'arroge la supériorité sur le roi de Francel53. Selon Guyon, le peu d'autorité qu'ont les empereurs modernes les rend même inférieurs aux rois, en particulier à ceux de France. En évoquant le débat entre les jurisconsultes allemands sur la question »de savoir si l'Etat dans lequel ils vivent, est une Monarchie ou une République«, l'abbé souligne les nombreuses restrictions qui limitent le pouvoir impérial en Allemagne, en particulier à travers les capitulations signées par les empereurs à chaque élection:

Il ne faut qu'ouvrir leurs Traités sur le Droit public, pour voir la difference prodigieuse qu'il y a entre la puissance ou l'autorité des Rois \& celle de l'Empereur, à qui l'Etat a mis des bor-

147 GuYon, Essai critique, p. 1-154.

148 Ibid., p. 155-256.

149 Guyon termine sa critique de Maimbourg par un jugement extrêmement sévère: "Je m'étonnerai toûjours des témoignages avantageux que quelques Savans ont donné au dernier Ouvrage de cet Ecrivain fécond; \& je penserois bien mal des autres, si j'en jugeois par celuici«; GuYON, Essai critique, p. xvj.

150 lbid., p. ix-x.

151 C'est-à-dire les empereurs d'Orient à Byzance.

152 GuYON, Essai critique, p. $x$.

153 Cf. ibid., p. 255-256. 
nes très-étroites, \& qui sont encore resserrées par les capitulations particulieres que l'on fait à chaque élection, \& auxquelles l'Élu promet par serment de se soumettre ${ }^{154}$.

Dans l'essai de l'abbé Guyon sur les titres d'»Empereur« et de »Roi des Romains «, on peut constater une grande influence de Pufendorf sur ses idées par rapport aux inconvénients de l'élection du successeur au trône vivente Imperatore. Guyon a lu son »Etat de l'Empire et le cite à plusieurs reprises en français 155 . L'abbé prétend que cette forme d'élection porte préjudice au pouvoir des vicaires de l'Empire, qu'elle restreint la liberté d'élection des princes électeurs et qu'elle rend l'Empire quasiment héréditaire.

Dans sa dissertation sur l'origine des électorats, placée à la fin du volume ${ }^{156}$, Guyon aborde l'un des problèmes les plus épineux dans l'histoire des empereurs médiévaux. Au milieu du XVIII siècle, Guyon part encore de la digression du cardinal Baronius sur les événements historiques de l'année 996 quand il examine le problème de l'origine des électeurs, quoique l'exposé du cardinal ait été réfuté depuis le XVIe siècle. Toutefois, l'abbé Guyon ne peut pas accepter la thèse de Baronius selon laquelle les papes auraient transféré la dignité impériale aux Germains, puisqu'elle contredit son refus de la théorie de la translatio Imperii. Guyon reproche à »Heiss, qui a si long-tems passé pour le meilleur Historien d'Allemagne, parce qu'il n'y en avoit point d'autres « d'avoir »suivi aveuglément Baronius « ${ }^{157}$. Nous verrons que, au moins à l'égard de l'origine du collège électoral, cette critique n'est pas fondée, puisque Heiss s'exprime en faveur de l'institution des sept électeurs au XIII' siècle. Sa critique de l'exposé de Maimbourg sur ce problème est également infondée, parce que Maimbourg n'adhère pas non plus à la thèse de Baronius. Comme Guyon, il cherche l'origine du collège électoral durant le règne de Frédéric II et le grand interrègne du XIIIe siècle. Guyon observe que le nombre, l'autorité, les prérogatives, les droits et les fonctions des princes électeurs furent fixés définitivement par Charles IV dans la Bulle d'or de $1356^{158}$. Ainsi, l'usurpation du droit d'élection par certains princes aurait été transformée en coutume. En expliquant la Bulle d'or de cette façon, à l'égard de la fondation du collège électoral, l'abbé se fonde encore explicitement sur l'»Etat de l'Empire « de Pufendorf ${ }^{159}$.

Enfin, il examine les changements survenus dans la composition du collège depuis 1623, quand Ferdinand II transféra la dignité électorale palatine au duc de Bavière. En interprétant les clauses de la paix de Westphalie qui entérinaient cette translation et créaient une nouvelle dignité électorale pour le palatin, c'est encore à Pufendorf que Guyon s'en remet. En revanche, pour la création du neuvième électorat en faveur du duc de Hanovre, c'est à la continuation de l'»Histoire de

154 Ibid., p. 252.

155 Cf. ibid., p. 257-286, en particulier p. 282-286.

156 Cf. ibid., p. 287-318.

157 Ibid., p. 290.

158 Cf. ibid., p. 291-294 et 299. Par la suite, Guyon fait un résumé de la Bulle d'or avec une traduction partielle de certains articles (p. 300-305).

159 Cf. ibid., p. 305. 
l'Empire « de Heiss que Guyon renvoie son lecteur ${ }^{160}$. Il est évident que l'étude du droit public est inséparable de celle de l'histoire.

\section{Les historiens (I): l'exemple de Massuet}

Parmi les historiens, il faut distinguer ceux qui ont écrit sur l'histoire du SaintEmpire en particulier des écrivains qui ont traité de ce sujet dans leurs ouvrages sur l'histoire de France ou sur l'histoire de l'Europe. Nous nous intéresserons surtout à la première catégorie, puisqu'on peut supposer qu'un lecteur français qui cherchait à se renseigner sur le Saint-Empire a puisé ses informations dans ces ouvrages. En particulier, les années 1741-1756 furent fécondes en publications sur l'histoire du Saint-Empire. Dans ce chapitre, nous analysons les ouvrages historiographiques de trois auteurs: Massuet, qui écrivit au début de cette période; Barre, l'auteur de l'histoire d'Allemagne la plus volumineuse publiée en France sous l'Ancien Régime; Voltaire, philosophe, ami de Frédéric II de Prusse et en même temps historien de l'Allemagne.

En 1742, Pierre Massuet s'inspira de la mort de Charles VI en publiant l'histoire du monarque défunt et des empereurs de la maison d'Autriche qui avaient régné sur l'Empire depuis Rodolphe Ier en 1274. Massuet était originaire de Mouzon, où il était né en 1698. Entré dans l'abbaye de Saint-Vincent de Metz à l'âge de dix-huit ans, il s'enfuit en Hollande. Après ses études de médecine à Leyde, il s'établit à Amsterdam. Il fut à la fois spécialiste des sciences naturelles et historiques. Comme historien, il se consacra surtout à l'histoire politique et militaire. En particulier, il était l'auteur d'une biographie du prince Eugène de Savoie.

Selon Massuet, le décès du dernier empereur, Charles VI, risquait de provoquer une »révolution « importante dans l'Empire et en Europe ${ }^{161}$. Dans la première partie de son ouvrage, Massuet expose l'histoire des empereurs de la maison de Habsbourg avant Charles VI. L'histoire du règne de celui-ci constitue la deuxième partie. Les conséquences que sa mort a entraînées jusqu'au 9 septembre 1741, date à laquelle l'auteur termina la rédaction de son livre ${ }^{162}$, sont étudiées dans la troisième partie ${ }^{163}$. Massuet se consacre essentiellement à l'histoire des empereurs habsbourgeois depuis Charles Quint. L'auteur estime que cet empereur devait son élection, en 1519, au fait que les princes électeurs craignaient que son compétiteur, François $\mathrm{I}^{\mathrm{er}}$, »étant né dans une Monarchie absolue, [...] ne réduisît les Electeurs et les Princes de l'Empire au pied des Ducs \& Pairs de France ${ }^{164}$.

160 Cf. ibid., p. 311 , n. e et p. 312 , n. f. Le neuvième électorat fut créé après la rédaction du livre de Pufendorf.

161 Massuet, Histoire de l'Empereur Charles VI, t. I, »Préface«, p. j-vij, ici p. j-ij.

162 Cf. ibid., t. II, p. 354; cf. aussi ibid., p. 310, n. *.

163 Ce plan est exposé dans la préface. Pourtant, l'ouvrage est constitué d'un récit strictement chronologique divisé seulement par années; il n'est subdivisé ni en chapitres ni en parties.

164 Massuet, Histoire de l'Empereur Charles VI, t. I, p. 31. 
Cependant, dans son ouvrage, Massuet ne parle que très rarement des problèmes du droit d'État. Il privilégie l'histoire diplomatique et l'histoire militaire. Le pro-

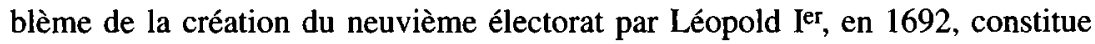
l'une des rares exceptions ${ }^{165}$. Son récit témoigne d'une certaine vénération de l'auteur à l'égard de la puissance de la maison d'Autriche. Selon lui, cette puissance n'a pas diminué sous les derniers empereurs de cette maison ${ }^{166}$; bien au contraire, Léopold Ier sut encore l'augmenter ${ }^{167}$. À la différence de certains auteurs du temps de Louis XIV, comme Maimbourg, Massuet ne conclut point à un déclin du Saint Empire romain germanique. D'ailleurs, le fait que Massuet cite de temps à autre l'»Histoire« de Heiss prouve que cet ouvrage était toujours lu au cours des années $1740^{168}$.

\section{Les historiens (II): l'exemple de l'»Histoire générale d'Allemagne« de Joseph Barre}

En 1748, le père Joseph Barre, chanoine régulier de Sainte-Geneviève, à Paris, publia une volumineuse $»$ Histoire générale d'Allemagne «, en dix volumes ${ }^{169}$. Cette »Histoire « fut même traduite en allemand; le premier volume de cette traduction parut dès 1749, à Leipzig, chez Arkstee \& Merkus, sous le titre de »Allgemeine Geschichte von Deutschland, vor und nach Errichtung des Kaiserthums bis auf itzige Zeiten ${ }^{170}$.

L'auteur de cette "Histoire « est un savant bien connu du XVIIIe siècle171. Joseph Barre, que certains auteurs écrivent "Barré«, né en 1692 et mort en 1764, fut un théologien et un érudit universel, très bien connu au-delà des frontières $\mathrm{du}$ royaume, et surtout en Allemagne. Barre enseigna longtemps la théologie à l'abbaye de Sainte-Geneviève. En outre, il fut recteur de l'université de Paris à partir de 1744.

C'est notamment son Histoire d'Allemagne qui lui donna une grande notoriété, malgré les critiques parfois acerbes: selon la »Correspondance littéraire «, l'auteur manquait d'esprit. Ce périodique et Jöcher lui reprochèrent aussi quelques erreurs. En 1751, Barre se justifia dans une »Dissertatio apologetica«. Voltaire alla

165 Cf. ibid., p. 119 et p. 134-136.

166 Cf. ibid., p. [1].

167 Selon Massuet, le neuvième électorat atteste la puissance de cet empereur et montre son "pouvoir immense«, ibid., p. 134.

168 Cf., par exemple, ibid., t. II, p. 2 , n. $†$ et p. 134, n. *.

169 BARRE, Histoire générale d'Allemagne.

170 ID., Allgemeine Geschichte von Deutschland; ouvrage incomplet.

171 Pour sa biographie et son œuvre, cf. P. FéreT, L'Abbaye de Sainte-Geneviève et la Congrégation de France, précédées de la vie de la patronne de Paris (d'après des documents inédits), t. II, Paris 1883, p. 299-312. Selon le »Dictionnaire des lettres françaises «, le père Barre est connu surtout pour sa »grande Histoire d'Allemagne«; cf. Georges GRENTE et al. (dir.), Dictionnaire des lettres françaises. Le dix-septième siècle, Paris 1954; Le dix-huitième siècle, 2 vol., ibid. 1960, ici le premier volume concernant le XVIIIe siècle, p. 135. 
jusqu'à accuser Barre de plagiat, puisque ce dernier aurait recopié deux cents pages de son »Histoire de Charles XII«. Bien qu'il soit incontestable que Barre ait fait de larges emprunts aux travaux antérieurs, son »Histoire « connut un grand succès non seulement en France, mais aussi en Allemagne ${ }^{172}$. Par ailleurs, Barre assura, en 1766, la réimpression à Paris, chez Hérissant fils, de la nouvelle édition de l'»Abrégé chronologique « de Chrétien-Frédéric Pfeffel ${ }^{173}$.

Notons que la bibliothèque Sainte-Geneviève, à Paris, conserve les papiers du père Barre qui éclairent l'origine de son projet et ses relations épistolaires avec les savants allemands. En effet, le manuscrit 2537 de cette bibliothèque renferme la correspondance entre le père Barre et certains historiens et juristes d'Allemagne (par exemple, Senckenberg 174); il leur demande souvent des renseignements précis sur un certain sujet en vue de la rédaction de sa volumineuse "Histoire générale d'Allemagne«. On peut donc déterminer l'origine précise de certaines informations, et cette correspondance témoigne surtout de la diffusion de connaissances sur l'histoire et le droit public de l'Allemagne à travers les relations personnelles entre savants; rappelons aussi, à ce propos, que le couvent du père Barre reçut certaines de ces personnalités échangeant des correspondances avec ce dernier. Mais nous reviendrons plus tard sur ce point.

La fameuse »Histoire générale d'Allemagne « du père Joseph Barre, fut une entreprise d'une grande envergure non seulement intellectuelle mais aussi financière. D'après le projet de souscription, dont plusieurs exemplaires sont conservés à la bibliothèque Mazarine ainsi qu'à la bibliothèque Sainte-Geneviève, le prix de souscription variait de cent vingt à cent soixante-dix livres en fonction du papier choisi ${ }^{175}$. Alors que l'ouvrage était d'abord conçu en dix volumes, Barre donna finalement au public onze volumes au lieu de dix, dépassant ainsi légèrement le cadre initialement fixé $\mathrm{e}^{176}$. L'approbation date du 20 octobre 1747 . Le privilège royal, en date du 12 octobre de la même année, attribua le droit exclusif d'imprimer et de vendre cet ouvrage pendant vingt ans à Charles Jean-Baptiste Delespine, qui prit comme associé Jean-Thomas Hérissant, auquel il céda pour moitié ce privilège, le 17 octobre; le privilège et cette cession furent enregistrés le même jour ${ }^{177}$. L'ouvrage de Barre est dédié au roi de Pologne, Frédéric Auguste III, qui

172 Cf. M. Prevost, article "Barré (Le P. Joseph)«, dans: Dictionnaire de biographie française, t. V (1951), p. 570-571.

173 Pfefrel, Abrégé chronologique, ici l'édition en 2 t. (1 vol.) de Paris 1766 (Nouvelle edition, revue, corrigée $\&$ augmentée par l'auteur). Cette édition est due au père Barre d'après le Catalogue général des livres imprimés de la Bibliothèque nationale, t. 7 (1901), col. 10721073, ici col. 1073, et t. 135 (1936), col. 668-669, ici col. 669. Voir aussi, à ce sujet, PREvosT, Barré.

174 Heinrich Christian Senckenberg (1704-1768), auteur d'un grand ouvrage sur le Conseil aulique de l'Empire, cf. STOLLEIs, Geschichte des Öffentlichen Rechts, t. I, p. 263 et p. 311. $175 \mathrm{Cf}$. ce projet de souscription (voir ci-dessus). Sur la dernière page du volume VIII/1 de l'exemplaire de l'Institut historique allemand de Paris (cote: S-40 Trautz 86,3), on a noté la somme de »130 livres«, qui pourrait correspondre au prix de cet exemplaire.

176 Cf. BARRE, Histoire générale d'Allemagne, t. Ier, »Préface«, p. [I]-XXXIII, ici p. [I].

$177 \mathrm{Cf}$. ibid., pièces non paginées, insérées après la préface (qui se termine à la p. XXXIII). 
était en même temps électeur de Saxe; le premier tome comprend une gravure de cet électeur ${ }^{178}$. La dédicace, signée "Joseph Barre, Chanoine Régulier \& Chancelier de l'Université de Paris «179, annonce que l'»Histoire générale d'Allemagne « est publiée, avec la permission expresse du roi de Prusse, sous les auspices de Frédéric Auguste III. Barre voit en lui un grand protecteur des sciences et des arts, qui sont cultivés à sa cour et à l'université de Leipzig.

En ce qui concerne le sujet de l'ouvrage, Barre le juge, dans cette épître, »noble, intéressant, \& d'une étendue presqu'infinie «. Il ajoute une révérence au peuple allemand qu'il considère comme »illustre par l'antiquité de son origine, \& par la reputation constante d'une valeur héroïque, à laquelle tous les Historiens anciens \& modernes rendent à l'envi le tribut d'éloges qui lui est dû«. Même les Romains, pourtant fiers maîtres de l'univers, n'ont pas su dominer cette nation, d'après le jugement de Barre, de sorte que les Germains purent fonder de nouveaux royaumes sur les débris de leur empire, et enfin fonder »l'Empire RomanoGermanique, si célébre dans nos Histoires par les maximes de sa politique \& par la sagesse de son gouvernement ${ }^{180}$.

Cette vision positive de l'histoire d'Allemagne est certainement conditionnée par le genre littéraire de l'épître dédicatoire et par la volonté de l'auteur d'attirer l'attention du public sur son sujet; mais le choix même de Barre de publier une histoire de l'Allemagne en onze tomes, c'est-à-dire de consacrer de longues années de sa vie à ce sujet, et le fait que des éditeurs parisiens prirent le risque de cette aventure éditoriale qu'ils jugeaient donc rentable, témoignent d'un intérêt certain des Français à l'égard de leurs voisins. Par ailleurs, le mariage d'une princesse de Saxe en France ${ }^{181}$, qui »fait aujourd'hui les délices \& les espérances des François «182, a bien évidemment joué un rôle très positif dans les relations entre les deux peuples, à en juger par le sentiment du père Barre.

La préface que Barre a publiée au début du premier tome de son »Histoire générale d'Allemagne« est particulièrement intéressante, à plusieurs égards, car l'auteur évite de répéter les lieux communs qui font souvent le seul objet de ce genre de texte. D'une part, cette préface est un véritable abrégé de l'exposé détaillé que Barre fournit de l'histoire d'Allemagne dans le corps de son ouvrage; il résume quelques idées essentielles de l'auteur sur les Allemands, leur histoire et leur État; de plus, Barre y fait un examen bref, mais critique des sources et des

178 Ibid., page non numérotée après le frontispice, avec deux explications en-dessous de la gravure: »Peint à Dresde par De Silvestre« et »Gravé par J. Daullé Graveur du Roy«.

179 Ibid., six pages non numérotées, entre la gravure du roi de Pologne et la p. [I].

180 Ibid., deuxième page.

181 Il s'agit très certainement du mariage du dauphin, Louis (1729-1765), avec Marie-Josèphe de Saxe (1731-1767), mère de trois rois de France (Louis XVI, Louis XVIII et Charles X). Le mariage eut lieu par procuration à Dresde, le 10 janvier 1747, et en présence des époux à Versailles, le 9 février de la même année. Pour les relations entre la France et la Saxe au XVIII'e siècle, voir Guido BRAUN, La France et les princes allemands de 1763 à 1789, dans: Jean-Luc LiEz (dir.), D'Allemagne en Champagne. Xavier de Saxe, seigneur de Pontsur-Seine (1730-1806). Actes du colloque, 6 et 7 octobre 2006, [Troyes] 2008, p. 43-51.

182 BARRE, Histoire générale d'Allemagne, t. Ier, dédicace, quatrième page. 
auteurs où il a puisé. D'autre part, l'auteur fournit aussi, dans cette préface, des renseignements personnels sur son intérêt pour l'histoire d'Allemagne et sur les raisons qui l'ont poussé à y consacrer plusieurs décennies de sa vie.

Commençons par le dernier aspect, car il éclaire l'origine de l'»Histoire générale d'Allemagne«, avec les correspondances conservées à la bibliothèque SainteGeneviève. Quelles sont les raisons pour lesquelles Barre a entrepris ce vaste projet d'écrire une histoire d'Allemagne? D'abord, c'est un passionné d'histoire. Étant donné que les conditions dans lesquelles il vivait lui ont procuré dès sa jeunesse la possibilité de se consacrer aux études, il choisit l'histoire, qui, au lieu d'un simple plaisir, fut sa vocation. Ces remarques que Barre fait sur sa passion pour l'histoire ne se limitent pas aux conventions, parfois même s'y opposent et rendent ainsi crédibles ses propos; tout religieux qu'il soit, il estime, pour sa part, que l'histoire, en permettant de bien connaître l'humanité, est plus instructive que tout traité de morale ${ }^{183}$. Pour autant, les passionnés d'histoire n'étant pas si rares en France, aux XVII ${ }^{e}$ et XVIII ${ }^{e}$ siècles, rares furent ceux qui se passionnèrent pour l'Allemagne, du moins en ce qui concerne les écrivains ${ }^{184}$. Pourquoi ce chanoine se pencha-t-il sur ce pays, dont la langue était inconnue à la majorité des érudits français? Ses explications à ce sujet réservent une surprise: en effet, Barre a des origines allemandes, peut-être pas récentes, mais qui font qu'il considère encore l'Allemagne en quelque sorte comme sa patrie ${ }^{185}$.

Cependant, Barre ne cherche pas à se donner les couleurs d'un auteur quasi allemand. Il affiche même sa différence par rapport aux auteurs de cette nation. Admettant que sa propre nationalité pourrait occasionner des préjugés contre son histoire ${ }^{186}$, il estime personnellement que le fait qu'il soit Français ne l'empêche en aucune manière d'écrire l'histoire d'Allemagne, alléguant une citation de Charles II d'Angleterre au sujet de l'histoire de ce pays écrite par l'Italien Gregorio Leti ${ }^{187}$; remplaçant la »prérogative « que procure la naissance par »le travail \& l'application «, Barre juge qu'un étranger peut plus librement parler de l'histoire d'une autre nation, car il le tient pour moins enclin à la partialité que l'amour de la

183 Cf. ibid., préface, p. [I]-XXXIII, ici p. [I]-II.

184 Le nombre de livres d'histoire qui traitaient de l'Allemagne permet de supposer un lectorat assez large; mais leurs auteurs ne furent pas toujours français.

185 Cf. BarRe, Histoire générale d'Allemagne, t. Jer, préface, p. [III]: »En entrant dans une carrière aussi vaste que celle de l'Histoire, mes premières vues se portérent vers l'Allemagne. Ce n'étoit pas sans raison; je pouvois regarder ce paiis comme étant ma patrie en quelque sorte, puisque mes ancêtres en tirent leur origine «. Étant donné que Barre a signé son livre et qu'il était connu dans Paris et en Europe, il n'y a pas lieu de douter de la véracité de cette remarque, même si de fausses indications sur les origines d'un auteur sont bien attestées dans de nombreuses publications de l'époque.

186 Cf. ibid., p. XXXI.

187 Cf ibid., p. XXXI-XXXII. En 1684, l'historien Gregorio Leti (1630-1701) avait publié son histoire d'Angleterre intitulée »Il Teatro britannico, o vero Historia della Grande Brettagna« en cinq volumes. Il était aussi l'auteur d'ouvrages sur Élisabeth Ire et sur Cromwell, traduits en français. 
patrie, les craintes et les espérances ainsi que les passions ne permettraient de l'être aux auteurs nationaux ${ }^{188}$.

Ainsi, ses ancêtres étant originaires d'Allemagne, Barre a commencé à étudier l'histoire de ce pays dès sa jeunesse; cet ouvrage qu'il rend public en 1748 est donc le fruit des lectures de presque toute une vie: il dit explicitement que l'»Histoire générale d'Allemagne « est le résultat de vingt-deux ans de recherches. Cette remarque coïncide avec les conclusions que nous avons pu tirer de la correspondance du père Barre avec les savants allemands ${ }^{189}$. Pourtant, vers 1729 , il n'avait pas encore conçu son projet d'histoire d'Allemagne lorsqu'un jésuite ${ }^{190}$ annonça une histoire latine de ce pays, mais celui-ci mourut avant de pouvoir la terminer ${ }^{191}$; ce ne fut que suite à la mort de Vasner que, au dire de Barre, un Allemand le convainquit d'écrire une histoire d'Allemagne ${ }^{192}$.

Il est important de noter que, au mois de novembre 1743, le »Journal des Savants« publia une lettre de Barre sur son projet d'une histoire d'Allemagne destinée à un certain $\gg \mathbf{M}$. Scheid, Medecin Allemand «193. Dans sa lettre publiée en 1743, Barre rappelle qu'il travaille depuis quinze ans à son histoire. Selon lui, Ludewig ${ }^{194}$, Gundling 195 et Vasner »n'ont fait que les premiers pas« en ayant an-

188 Barre, Histoire générale d'Allemagne, p. XXXII. Les exemples que nous avons vus dans les chapitres précédents montrent cependant que le regard qu'on porta de l'étranger sur l'Allemagne ne fut point plus impartial que les écrits des auteurs allemands eux-mêmes; il y avait seulement d'autres raisons pour ces auteurs d'être partiaux.

189 Outre nos remarques dans ce livre, cf. BRAUN, Scheid, Necker et Dupal, p. 230-232.

190 Il s'appelait Vasner, selon les explications de Barre. Or, nous n'avons pas pu identifier cet auteur ni son ouvrage, qui ne sont pas répertoriés par Carlos SOMMERVoGEL (S.J.), Bibliothèque de la Compagnie de Jésus. Bibliographie et histoire. Nouvelle édition publiée par la Province de Belgique, 12 vol., Bruxelles, Paris, Toulouse ${ }^{3} 1890-1932$ (reproduction en fac-similé, Louvain, 1960), ici bibliographie, t. VIII-X.

191 Cf. BARRe, Histoire générale d'Allemagne, t. Ier, préface, ici p. IV.

192 En revanche, cette remarque paraît un peu énigmatique: Barre parle d'»un Seigneur Allemand, aussi respectable par ses lumières que par sa haute naissance«, qui l'aurait incité à vaincre sa timidité et à faire part au public de ses travaux, cf. ibid., p. V. Bien que cette remarque ressemble à une convention littéraire, il est pourtant vrai, à en juger par la correspondance de Barre, que son travail a été encouragé par ses connaissances allemandes.

193 Cf. Le Journal des Sçavans (novembre 1743), p. 317-324, ici p. 317. Pour les articles du journal sur le droit public d'Allemagne, voir le dernier chapitre. Au sujet de la famille Scheid, voir ci-dessous.

194 Johann Peter (von) Ludewig (1668-1743, professeur à Halle à partir de 1705) publia en 1707 son ouvrage principal »Entwurf der Reichs-Historie«. Il est également l'auteur d'un commentaire de la Bulle d'or, publié en deux volumes, entre 1716 et 1719 , à Francfort et à Leipzig (Gießen 21753) sous le titre de »Vollständige Erläuterung der Güldenen Bulle«; cf. STOLLEIS, Geschichte des Öffentlichen Rechts, t. I, p. 298, 302-306, en particulier p. 303 et passim (voir l'index, p. 415). Cet auteur et son commentaire sont aussi évoqués dans une »Dissertation par raport à une méthode sur le droit public d'Allemagne«; copie: AE, MD All. 67 fol. 10-35, ici fol. 34 (voir le chapitre précédent).

195 Après ses études de théologie, Nicolaus Hieronymus Gundling (1671-1729) avait étudié le droit, à l'instigation de Christian Thomasius, et entamé une carrière universitaire. Promu docteur en droit en 1703, il devint professeur de philosophie en 1705 et, en 1706, obtint la chaire de rhétorique et de droit naturel à Altdorf. En 1708, il publia son »Abriß einer rechten 
noncé seize ou dix-sept ans avant de donner au public une histoire d'Allemagne »une Histoire«, qui, d'après Barre, est »si intéressante« et pourtant "nous est si peu connue «196. Barre rend ensuite hommage à Bünau, auteur d'une »Histoire de la nation germanique jusqu' au siècle de Charlemagne «, rédigée en allemand, dont Barre n'attendait pas la suite, estimant que cet auteur était mort ${ }^{197}$. En réalité, Heinrich Graf von Bünau, en même temps homme d'État et historien, né en 1697 à Weißenfels, ne décéda qu'en 1762 à $O B$ mannstedt, près de Weimar. Cet écrivain est considéré comme l'un des pères fondateurs de l'historiographie allemande moderne ${ }^{198}$. Pour sa part, Barre admet que l'ouvrage de Bünau »n'est pas sans mérite«, tout en prétendant que lui, Barre, a consulté »les mêmes sources où [Bünau] a puisé, \& plusieurs autres qu'il a sans doute ignorées «199.

Si Barre parle d'une façon aussi peu emphatique des premiers historiens d'Allemagne, on ne sera pas étonné du jugement beaucoup plus sévère qu'il porte sur l'»Histoire de l'Empire« de Jean Heiss. Barre prétend qu'il n'en a pas tiré un grand profit, "quoique ce soit presque la seule que l'on connoisse \& qu'on lise en France « ${ }^{200}$. Selon lui, même la nouvelle édition n'a pas remédié aux faiblesses de l'édition originale: "Cet Ouvrage, estime-t-il, même avec la revision de feu M. Bourgeois de Chastenet ${ }^{201}$, n'est qu'un abregé très-superficiel; les faits y sont plutôt insinués que racontés; il ne commence d'ailleurs qu'au 9me siècle, \& souvent il manque d'exactitude. Pour n'instruire pas à demi un Lecteur, \& souvent l'égarer, étoit-ce la peine d'écrire? ${ }^{202}$. Si l'on peut s'interroger sur la pertinence de la sévérité du jugement que Barre porte sur Heiss, le père jésuite a raison de souligner le fait que beaucoup d'auteurs ont négligé l'histoire des siècles précédant celui de Charlemagne, voire celle de la Germanie à l'époque des empereurs francs, des Othons et des autres dynasties allemandes avant la maison d'Autriche, alors que le règne des empereurs autrichiens était souvent traité par les auteurs écrivant en latin ou en français.

À la différence de nombreux compatriotes, Barre savait lire l'allemand. Il prétendait même avoir lu les livres portant sur l'histoire d'Allemagne non seulement en latin et en allemand, mais aussi en italien, en grec, voire en arabe. Dans sa let-

Reichshistorie $(21724)$, cf. Rolf LIEBERWIRTH, article »Gundling, Nicolaus Hieronymus«, dans: Neue deutsche Biographie, t. VII (1966), p. 218-219.

196 Le Journal des Sçavans (novembre 1743), p. 318.

197 Cf. ibid. Le journal corrige l'erreur de Barre, puisque Bünau n'était pas mort (ibid., n. *).

198 Après ses études de droit, il se mit au service de l'électorat de Saxe et, en 1727, devint président du consistoire à Dresde. Charles VII nomma ce protestant conseiller aulique de l'Empire. Malgré ses fonctions officielles, Bünau préférait se consacrer à l'étude de l'histoire, des sciences politiques et des mathématiques. Ce fut à Leipzig, entre 1728 et 1743 , que Bünau fit publier son histoire des empereurs sous le titre "Genaue und umständliche Teutsche Kayser- und Reichshistorie« (4 vol.), cf. Herbert Helbig, article »Bünau, Heinrich Graf v.«, dans: Neue deutsche Biographie, t. II (1955), p. 739-740.

199 Le Joumal des Sçavans (novembre 1743), p. 318-319.

200 Ibid., p. 319.

201 Cf. les différentes éditions de HeIss, Histoire de l'Empire, publiées au XVIII' siècle.

202 Le Journal des Sçavans (novembre 1743), p. 319-320. 
tre, Barre évoquait également sa correspondance avec les érudits allemands qui lui avait fait connaître de nombreuses sources de l'histoire d'Allemagne203.

À la fin de sa lettre, qui en réalité est une forme de publicité, Barre expose le plan de son ouvrage. Cette histoire d'Allemagne se veut à la fois une histoire ecclésiastique, 》Civile « (c'est-à-dire politique) et militaire ${ }^{204}$; les observations d'ordre économique et culturel ne sont pas complètement absentes de son ouvrage, mais le récit des événements ecclésiastiques, politiques et militaires en constitue la partie essentielle. Si Barre parle aussi, à l'occasion, du droit public d'Allemagne, c'est que le droit public est, d'après son jugement, indispensable à la compréhension de l'histoire générale. Cependant, il ne lui concède pas la même place dans sa narration historique que ne le font Heiss et Pfeffel. Malgré ses origines allemandes, Barre est un véritable auteur français et il ne cherche pas à imiter le style des auteurs allemands. Il observe une différence de méthode entre les écrivains allemands et français: d'après lui, les premiers insèrent, par un souci de précision, des digressions sur des problèmes particuliers dans le corps de leur exposé, au détriment de la clarté. Par contre, Barre se propose de suivre le modèle français, qui privilégie la clarté; ainsi, il se restreint à discuter des particularités dans les notes de bas de page et dans les digressions qu'il a classées à la fin des différents tomes de son ouvrage ${ }^{205}$.

Profitant, comme ces correspondances nous l'ont montré, d'un vaste réseau de correspondants en Allemagne, avec lesquels il pouvait échanger des informations au sujet de l'histoire allemande, le chanoine de Sainte-Geneviève pouvait aussi se servir de l'une des premières bibliothèques d'Europe, qui était à son entière disposition, aux dires de l'auteur même, quand il rédigeait son propre ouvrage ${ }^{206}$.

$\mathrm{Au}$ début, il y avait Heiss. Malgré la critique que Barre a réservée à cet auteur dans sa préface et dans le corps de son exposé, il faut noter que Barre lui aussi a bien commencé son étude de l'histoire allemande en lisant Heiss; car il n'y avait rien d'autre. Barre consulta l'édition de Heiss établie par Bourgeois du Chastenet $^{207}$. Or, Barre s'intéresse beaucoup à l'histoire avant Charlemagne. Heiss n'y prête guère attention; initiant son "Histoire de l'Empire « avec ce premier empereur médiéval, son véritable objet est l'histoire récente, l'époque de la paix de Westphalie. L'embarras de Barre, à la recherche d'auteurs qui puissent le renseigner sur le haut Moyen Âge, est compréhensible ${ }^{208}$. Évidemment, Heiss ne pou-

203 Cf. ibid., p. 320-322.

204 Cf. BARRE, Histoire générale d'Allemagne, t. Ier, p. XXV.

205 Cf. ibid., p. XXVI et p. XXIX.

206 Cf. ibid., p. XXVII-XXVIII.

207 Cf. ibid., p. III: »Je crus d'abord trouver dequoi me satisfaire dans l'ouvrage de M. Heiss. Mais, après l'avoir lu, je m'apperçus qu'il ne présentoit qu'une idée trop imparfaite de l'Allemagne. Ce qu'il en dit est peu éxact, \& en général, son Histoire n'est qu'un abrégé assés informe qui ne commence qu'à Charlemagne, $\&$ auquel les notes de $M$. Bourgeois du Châtenet n'ajoutent pas grand mérite«.

208 Cf. ibid., p. III, où il accuse Heiss d'être responsable du dédain avec lequel on traite cette période pré-carolingienne, tout en témoignant un certain respect envers cet auteur, consacré par l'usage qu'on a fait de son ouvrage longtemps irremplaçable: »Sans avoir dessein de rui- 
vait remplacer toute une bibliothèque. Car c'est seulement dans une bibliothèque, non pas dans un ouvrage singulier, que Barre trouve les réponses à ses questions, et il est obligé de remonter aux sources pour se faire une image de la Germanie et de l'Allemagne ancienne ${ }^{209}$. La critique faite à Heiss (que Barre a aussi critiqué dans sa correspondance) ne se limite d'ailleurs pas au seul fait que celui-ci ne commence son Histoire d'Allemagne qu'à l'époque de Charlemagne. L'autorité de Heiss étant sévèrement ébranlée en France, depuis environ 1740, Barre n'est pourtant pas l'un de ses critiques les plus âpres.

En ce qui concerne la vision du Saint-Empire de Barre, il est d'abord à noter qu'il le considère comme un État composé ou confédéré; il estime que c'est déjà depuis les $\mathrm{X}^{\mathrm{e}}$ et $\mathrm{XI}^{\mathrm{e}}$ siècles que l'Empire a pris cette forme, qu'il a en principe conservée jusqu'au XVIII siècle. Pour Barre, les princes jouissent d'une véritable souveraineté dans leurs territoires, les affaires qui sont d'un intérêt commun se décidant dans une assemblée des états.

En parlant des difficultés de son sujet, Barre définit la Constitution de l'Empire d'une manière qui montre qu'il adhérait probablement à la théorie du status mixtus, puisqu'il refusait de définir le Saint-Empire comme une monarchie ou comme une aristocratie républicaine. Au contraire, Barre parlait d'un véritable partage de la souveraineté entre l'empereur et les ordres ${ }^{210}$. Contrairement à Bodin, il ne considérait donc pas la souveraineté comme indivisible ${ }^{211}$.

ner l'autorité de M. Heiss, on pourroit dire qu'il semble avoir voulu faire croire au Public, que l'Histoire de l'ancienne Germanie ne pouvoit mériter son attention. Cependant, en gardant le silence sur tout ce qui s'est passé avant Charlemagne, combien cet Auteur n'a-t'il pas laissé d'événemens dans l'oubli. Je me rappellois ce que j[']avois lu dans les anciens Auteurs, \& je cherchois avec empressement quelqu'Historien qui en eût fait usage. Mes recherches furent inutiles $\ll$.

${ }^{209}$ Cf ibid., p. IV: „Pour connoître l’Allemagne, soit ancienne soit moderne, il a donc fallu que je me sois mis à l'étudier dans les compilations, les recueils, les dissertations \& autres piéces de cette nature, qui sont en effet très-abondantes, $\&$ d'autant plus utiles que la plupart des Compilateurs ou Abbréviateurs, ont eu l'attention d'indiquer les sources qu'il falloit consulter

210 Cf. Le Journal des Sçavans (novembre 1743), p. 322: „L'Empire Germanique n'est ni une véritable Monarchie, ni une simple République. Si on y voit un Empereur qui en est le chef, on y voit aussi des Electeurs, des Princes \& des Villes partager avec lui la Souveraineté «.

211 Cf. aussi BARRE, Histoire générale d'Allemagne, t. VII, p. 419-421: "Jusqu'ici on n'avoit pu bien définir l'Empire, on commença sous Albert [II, depuis 1440] à avoir quelque connoissance de son administration \& des différens ordres dont il étoit composé. Son gouvernement dans les villes libres Impériales étoit démocratique, [...] dans les autres Etats, il étoit aristocratique [...]; enfin par rapport à tous les Ordres, il étoit monarchique, parceque l'Empereur, revêtu des ornemens de la Royauté, y présidoit comme il y préside encore ajourd'hui en qualité de Souverain, \& que s'il ne peut rien faire sans les Etats, les Etats ne peuvent rien faire sans lui. Ce n'est pas une Monarchie absolue ou illimitée. Quoique l'Empereur soit élu, \& couronné Roi de tout l'Empire pour le gouverner [...], \& que selon une ordonnance des Princes, publiée en 1337. il ne reléve que de Dieu \& de son épée; cependant il ordonne inutilement s'il n'a pas le consentement des Etats. [...] II n'est pas le véritable Seigneur des fiefs de l'Empire, [...] il ne dispose pas souverainement des contributions publiques, ni des armées Impériales: il n'a pas l'autorité de déclarer la guerre pour tout l'Empire: 
Barre définit le status Imperii au début du premier volume de son »Histoire générale d'Allemagne « mais il en parle aussi, de temps à autre, dans le corps de son exposé. À en juger par ses explications, la Constitution de l'Empire, et en particulier la distribution des pouvoirs entre l'empereur et les États territoriaux, n'aurait guère été modifiée depuis les $\mathrm{X}^{e}$ et $\mathrm{XI}^{e}$ siècles, et surtout depuis le $\mathrm{XV}$. Après une brusque décadence du pouvoir impérial à la fin de la dynastie carolingienne, les compétences respectives de l'empereur et des ordres apparaissent presque comme statiques dans la description que Barre fait du Saint-Empire à plusieurs moments de son histoire; s'il y a bien une évolution, que Barre constate, c'est plutôt une clarification successive de la Constitution de l'Empire qu'une modification profonde en faveur de l'empereur ou des princes. D'ailleurs, les idées que Barre professe ne sont pas toujours cohérentes.

Au début de l'histoire du règne de l'empereur Frédéric III, l'auteur a inséré une brève »Notice de l'Empire Germanique«, qui fait le point sur sa forme de gouvernement en $1440^{212}$. À l'issue de la période d'Albert II, que Barre estime beaucoup, car cet empereur était, selon lui, soucieux d'»établir une bonne harmonie entre les membres \& le chef« du Saint-Empire, on avait acquis, toujours d'après Barre, une meilleure connaissance de l'Empire, »de son administration et des différens ordres dont il étoit composé «213, tandis que la situation antérieure avait été moins claire ${ }^{214}$. Pourtant, la question du status Imperii fut en réalité un problème que l'on discuta surtout à partir de la fin du XVIe siècle. En 1440, Barre perçoit dans la Constitution du Saint-Empire et de ses États territoriaux à la fois des éléments démocratiques, aristocratiques et monarchiques. Mais il ne s'agit pas véritablement d'un mélange de tous ces éléments tel que l'enseignait l'école du status mixtus. En effet, au dire de Barre, l'aspect démocratique était représenté par le gouvernement particulier des villes libres de l'Empire parce que la population urbaine y participait. Dans les autres États territoriaux, le gouvernement était aristocratique, puisque les électeurs et les princes y avaient la plus grande autorité. Enfin, face aux ordres en général, l'empereur disposait d'un pouvoir monarchique. Bien que Barre le qualifie bien de souverain, il dresse un bilan plutôt médiocre de son autorité.

Or, cet auteur ne distingue pas toujours clairement le gouvernement de l'Empire du gouvernement des États territoriaux ${ }^{215}$. De plus, il ne définit pas, dans les

il est bien sur le trône, mais les Etats y donnent la loi, comme Ferdinand [ [er] l'a reconnu depuis dans la Diète de Ratisbonne en 1559. A l'égard des Etats particuliers de l'Allemagne, ils sont obligés de reconnoître l'Empereur pour leur Souverain [...]. Du reste, ils sont maîtres dans leur district « (passage mis en italique selon l'original).

212 Cf. ibid., p. 419-421 et les passages cités ci-dessus.

213 Ibid., p. [419]-420.

214 Barre observe que, avant le règne d'Albert II, »on n'avoit pu bien définir l'Empire« (voir di-cessus).

215 Par exemple, au lieu de dire que le gouvernement des villes était démocratique, il dit que le gouvernement de l'Empire »dans les villes libres Impériales étoit démocratique«; de la même manière, il dit que »dans les autres Etats, il étoit aristocratique « (voir ci-dessus). De cette façon, Barre donne l'impression de parler d'un mélange de plusieurs formes de gouver- 
catégories aristotéliciennes, la participation des états au gouvernement de l'État fédéral. Pour lui, l'Empire est en partie aristocratique parce que les princes exercent »la principale autorité « dans leurs territoires ${ }^{216}$ (on pourrait lui objecter que, dans les territoires, la participation des ordres provinciaux plutôt que l'autorité du seigneur serait une preuve d'aristocratie); au moins dans ce contexte précis, il ne qualifie pas l'Empire d'aristocratique, puisque les ordres participent, avec l'empereur, au gouvernement de l'État fédéral.

Qu'en est-il du pouvoir de l'empereur? Barre a certainement lu beaucoup d'auteurs sur cette question, mais parfois il semble bien qu'il en fasse une compilation plutôt que d'en tirer des conclusions. Pour résumer ses idées, on peut dire que Barre définit l'Empire, en 1440, comme une monarchie limitée, mais où l'empereur ressemble au doge de Venise et où les états donnent la loi. Est-ce une image cohérente? Si l'on peut bien s'interroger sur cette question, il est indubitable que Barre dispose d'une connaissance détaillée d'un grand nombre de particularités de l'histoire et du droit public du Saint-Empire. Cependant, certaines de ses conclusions sont discutables. À titre d'exemple, Barre suppose que depuis les $\mathrm{X}^{\mathrm{e}}$ et $\mathrm{XI}^{\mathrm{e}}$ siècles, le Saint-Empire a pris »la forme d'un Etat confédéré«, malgré les irrégularités de sa Constitution. Il attribue deux caractéristiques à cette définition: premièrement, que »les Princes qui composent entr'eux un même corps, conservent chacun sa souveraineté \& son gouvernement particulier «; deuxièmement, que »les affaires qui regardent la sûreté \& le bien de tout le Corps, doivent être traitées dans une assemblée générale où chacun ait une voix délibérative «217. Or, il est légitime de se demander si l'Empire remplit véritablement ces deux critères dès le haut Moyen Âge. Selon Barre, l'Empire est devenu une confédération à cause du déclin de l'autorité monarchique ou impériale, sans perdre complètement son unité; mais son ancien souverain est rétrogradé à la condition de chef de cette confédération ${ }^{218}$.

Selon Barre, les papes poursuivaient au Moyen Âge l'objectif d'affaiblir l'autorité des empereurs. Après le règne de Frédéric II, l'Empire serait devenu une véritable anarchie ${ }^{219}$. Barre explique que, au moment de l'élection de Rodolphe Ier, les princes d'Allemagne évitèrent d'élire plusieurs empereurs de la même maison,

nement, mais au fond, il confond ou du moins ne distingue pas assez clairement les différents niveaux auxquels les pouvoirs étatiques se manifestaient.

216 BARRE, Histoire générale d'Allemagne, t. VII, p. 420. En parlant de "la principale autorité«, Barre évite le terme de »souveraine autorité«.

217 Ibid., t. Ier, p. XJ.

218 »Ces sortes d'Etats se forment, ou par une convention expresse [...]; ou par une convention tacite, lorsqu'un Empire composé de plusieurs Provinces qui dépendoient toutes d'un seul Monarque, arrive par des révolutions, à ce point que ceux qui n'étoient auparavant que de simples Gouverneurs, en deviennent insensiblement les Souverains. Dans ce demier cas, si la liaison qui se trouvoit dans ces Provinces n'est pas rompue, si au contraire elle continue sous une autre forme, alors les successeurs de celui qui étoit le Souverain de ces Provinces, ne sont plus que les Chefs de la confédération. C'est sous cette face qu'on verra paroître l'Empire Romano-Germanique«; ibid., p. XJ-XIJ.

219 Cf. ibid., p. XIIJ, XVIJ. 
afin de conserver leur indépendance et leur souveraineté220. Barre prétend que, même dans les dernières années du règne de Charles Quint, les princes allemands tirèrent profit de la faiblesse de l'autorité impériale au bénéfice de leur souveraineté221. L'histoire de l'Empire lui apparaît donc comme une voie à sens unique menant irrémédiablement au déclin de l'autorité de l'empereur et de l'Empire, d'un côté, et à l'essor de la souveraineté des princes, de l'autre.

À la fin du règne de Charles Quint, ce processus était déjà pratiquement achevé, si l'on en croit Barre. Il prétend même que les princes jouissaient incontestablement du droit d'alliance et que leurs prérogatives et leurs libertés avaient été définitivement entérinées ${ }^{222}$. Selon Barre, il ne manquait alors aux ordres que la reconnaissance formelle de leur souveraineté par l'empereur. Enfin, ils obtinrent cet avantage par la paix de Westphalie ${ }^{223}$, alors que, toujours selon Barre, Ferdinand III perdit, par le même traité, »la plus grande partie de son autorité \& de son pouvoir dans l'Empire «224. Cette vision de la condition juridique des états de l'Empire n'empêche pas Barre de qualifier parfois leur autorité de "supériorité territoriale« au lieu de souveraineté225; de toute évidence, ce sont pour lui deux expressions qui désignent la même chose. Pour certains auteurs, la »supériorité territoriale « correspond exactement à la souveraineté. Pourtant, la définition de la forme du gouvernement de l'Empire que Barre donne dans la préface du premier volume de son ouvrage montre le caractère parfois très hétérogène de ses idées concernant l'interprétation de la Constitution du Saint-Empire. En effet, selon cette définition, l'empereur et les ordres se partagent la souveraineté, et l'Empire n'est considéré ni comme une monarchie ni comme une république 226 .

220 „Le soin de conserver parmi eux une Souveraineté compatible avec la nature d'un Corps confédéré, leur fit alors prendre garde à ne pas continuer, sans nécessité, la dignité Impériale dans la même maison«; ibid., p. XVIJ.

221 Cf. ibid., p. XX.

222 En effet, il écrit à ce sujet: „On éxamina alors avec plus d'attention en quoi consistoit précisément l'autorité de l'Empereur sur le Corps Germanique, \& la dépendance de celui-ci à l'égard de son Chef. Le résultat fut, qu'il étoit libre aux Etats d'Allemagne de contracter des alliances entr' eux \& avec les Puissances étrangères, pour la défense de leurs intérêts particuliers \& de ceux du Corps Germanique, \& qu'on ne pouvoit regarder les Princes \& les Villes comme de vrais sujets de l'Empereur. En conséquence de cette maxime, fondée sur le gouvernement de l'Empire, les Etats d'Allemagne n'hésitérent plus à négocier avec les Cours étrangères, des traités qui fussent convenables au maintien de leur liberté «, ibid., p. XX.

$223 \gg I 1$ ne manquoit à ce droit de souveraineté, d'être reconnu publiquement par les Empereurs. La paix de Westphalie procura cet avantage aux Princes \& aux Villes Impériales«; ibid.

224 Ibid., p. XXIIJ. Cf. aussi ibid., pour la prétendue consécration de la souveraineté des États territoriaux.

$225 \mathrm{Cf}$., par exemple, ibid., p. XXV.

$226 »$ L'Empire Germanique n'est ni une véritable Monarchie, ni une simple République. Si l'Empereur en est le Chef, il y a aussi des Electeurs, des Princes \& des Villes qui partagent avec lui la Souveraineté«, ibid., p. XXIX. Cette définition correspond très exactement à celle de la lettre publiée par Barre en novembre 1743 (voir ci-dessus). 
En ce qui concerne les sources, il est normal que Tacite ne soit pas négligé dans l'introduction qui traite des anciens Germains avant l'arrivée des Romains ${ }^{227}$. Mais ce n'est pas le seul auteur sur lequel Barre se fonde; d'autres écrivains, antiques (tel Strabon, César et Diodore de Sicile228) et modernes (Leibniz, Spener, Hachenberg) ${ }^{229}$, ne sont pas absents ${ }^{230}$. Tacite ne conditionne donc pas de manière exclusive l'image que Barre se fait de la vie et des mœurs des Germains. Au lieu de suivre un seul auteur, il oppose leurs contributions respectives aux différents problèmes de l'histoire de la Germanie 231 . En ce qui concerne l'Antiquité tardive, Ammien Marcellin et Zosime (un historien du temps de Constantin le Grand) sont les auteurs le plus souvent cités ${ }^{232}$. À partir du Ve siècle, les auteurs chrétiens, tel Grégoire de Tours, prennent successivement le relais ${ }^{233}$. À la fin du premier tome, Barre a ajouté deux dissertations, dont la première traite de certains peuples ayant habité la Germanie ${ }^{234}$. Dans cette dissertation, il cite, à propos de l'origine des Francs, une »Histoire en Allemand de l'ancienne Germanie« de Mascov, dans une traduction française ${ }^{235}$. On peut supposer qu'il a utilisé la version manuscrite de Mascov que conserve encore aujourd'hui la bibliothèque Sainte-Geneviève ${ }^{236}$. Pour le même sujet, il cite aussi les noms de Bodin et d'Obrecht, dont il a consulté le »Prodromus rerum Alsaticarum «237.

227 Ibid., p. [1]-32; Tacite est par exemple cité p. 6 et, dans une citation très longue sur les mours des Germains, p. 9-14.

228 Par exemple, ibid., p. 18 (Strabon), p. 19 (Diodore) et p. 30 (César).

229 Par exemple, ibid., p. 2 (Spener), p. 3 (Leibniz) et p. 15 (Hachenberg).

230 Ces auteurs sont évidemment aussi cités dans les deux premiers livres (respectivement p. [1]-149 et p. 150-220), qui traitent de l'Antiquité romaine et de la domination de Rome sur une partie de la Germanie jusqu'à la mort de Tibère; par exemple, pour ce qui est des auteurs antiques, de longs extraits de la »Germania « de Tacite (dont Barre a bien évidemment aussi utilisé les »Annales«, par exemple ibid., p. 185-188) sont recopiés ibid., p. 94-96 et p. 151-152, tandis que Barre - pour ce qui est des auteurs modernes - renvoie à Spener ibid., p. 96 et 135. Il a consulté de nombreux auteurs sur ces questions. La troisième partie (ibid., p. 221-327), qui commence en 38 après J.-C. et finit en l'année 270, se fonde en partie sur ces mêmes auteurs, mais surtout sur Suétone, les »Annales« et les »Histoires« de Tacite, ainsi que sur Dion Cassius (ibid., passim), et, à la fin, sur des auteurs de l'Antiquité tardive ou bien du haut Moyen Âge, tel Grégoire de Tours (ibid., p. 325) au sujet des mœurs des Francs.

231 Cf. son avant-propos à cette introduction, où il justifie explicitement ce procédé, ibid., p. 2.

232 Cf. ibid., livre quatrième (période 270-399), p. 328-480.

233 Cf. ibid., livre cinquième (période 402-516), p. 481-612.

234 Ibid., dissertation [I] à la fin du premier tome, pagination particulière, p. [1]-11.

235 Ibid., p. 7.

236 BSG, ms. 2111: »Traduction des six premiers livres de l'histoire allemande de monsieur Mascow par l'abbé de Préci. Cette histoire est celle des premiers siècles de la Germanie, et cette traduction finie $[\mathrm{sic}]$ au commencement du $4^{e}$ siècle, c'est-à-dire l'an 305 de l'ère chrétienne« (titre, fol. 2). Note (éventuellement du XIX ${ }^{e}$ s.), fol. 1: »papiers du Père Barre «. En France, on lisait Mascov également en latin; cf. Bibliothèque Mazarine, ms. 1879, "Annotations « de Frédéric Melchior Grimm »in librum J. Mascovii intitulatum: Principia juris publici imperii rom. germ. 1745 , qui était le principal ouvrage de Johann Jakob Mascov (1689-1761).

237 C'est en 1681 qu'Obrecht publia à Strasbourg son ouvrage fondamental »Alsaticarum 
À part les nombreuses et longues citations de Tacite que l'on peut trouver chez Barre, force est de constater que deux idées essentielles de cet auteur romain ont imprégné la vision non seulement de la Germanie mais du peuple allemand dans l'»Histoire générale d'Allemagne«: ce sont la liberté comme idéal des Germains et des Allemands ${ }^{238}$, et la simplicité pour leur principal trait de caractère ${ }^{239}$. Par contre, il semble bien que la bellicité soit pour Barre plutôt une particularité des anciens Germains que de leurs descendants les Allemands.

Barre fait preuve d'un certain esprit critique à l'égard des ouvrages et des sources qu'il a consultés; il formule certains principes, comme, par exemple, la préférence qu'il donne aux auteurs contemporains pour la relation des événements par rapport aux écrivains postérieurs. Mais sa méthodologie n'est pas très développée: il n'est pas souvent facile de juger pourquoi il fait confiance à tel auteur et pourquoi il se méfie de tel autre. En particulier, bien que sa critique ne soit pas infondée, son acharnement contre le père Bougeant peut frapper; s'expliquerait-il par des motifs personnels? À d'autres égards, Barre s'avère pourtant moins partial; soucieux de la recherche de la »vérité« historique, qui constitue pour lui l'idéal historiographique, il a notamment voulu observer une impartialité confessionnelle, à l'instar de l'abbé de Vertot ${ }^{240}$.

Parmi les sources et les auteurs utilisés par Barre, dans le corps de son exposé de l'histoire allemande depuis le XVIe siecle, on peut noter Struvius ${ }^{241}$. Il connaît aussi Londorp, Lünig, Goldast et d'autres auteurs, ainsi que des éditions d'acta publica et des ouvrages fondamentaux ${ }^{242}$. En ce qui concerne la paix de religion de 1555, l'histoire de la discussion sur l'autonomia et l'histoire du protestantisme allemand en général, aux XVI et XVII e siècles, il cite Lehmann ${ }^{243}$; à l'égard des

rerum prodromus«. Cf. aussi BARRE, Histoire générale d'Allemagne, t. Ier, dissertation [I], p. 6 et 8 (Bodin), p. 9, n. c (Obrecht).

238 À propos de l'échec des tentatives des Romains pour subjuguer les Germains à leur domination, Barre évoque, par exemple, leur caractère belliqueux et leur amour de la liberté; cf. ibid., "Préface«, p. IX.

239 Si la simplicitas que Tacite atteste aux Germains est ambiguë, Barre l'utilise dans un contexte positif en justifiant la simplicité de son style par son sujet, arguant qu'il a "tâché de l'exposer avec le plus d'ordre \& de clarté qu'il m'a été possible, sans affecter les ornemens, qui ne conviennent jamais à l'Histoire, \& qui seroient encore plus déplacés dans celle d'un peuple dont la simplicité a toujours été le principal caractère«, cf. ibid., p. XXXIII.

240 Cf. ibid., p. XXX-XXXI.

241 Cf., par exemple, ibid., t. VII, passim (par exemple, p. 69), où l'auteur se réfère à la neuvième période de l'histoire de Struvius. Cf. aussi t. VIII/1, passim (par exemple, p. 785), et t. IX, passim (par exemple, p. 4 et 7), où l'auteur se reporte à la dixième période de Struvius. Burkhard Gotthelf Struve (Struvius; 1671-1738), qui était professeur à Iéna, publia en 1716 son ouvrage »Syntagma historiae germanicae «, en 1730 son »Corpus historiae Germanicae et en 1732 son livre "Vollständige teutsche Reichshistorie«, cf. Lotte HILLER, Die Geschichtswissenschaft, p. XX-XXI (œuvres de Struve) et p. 94-135 (biographie de Struve). 242 Cf., par exemple, BARRE, Histoire générale d'Allemagne, t. IX, p. 36-37 (Londorp et Lïnig), p. 49 (Londorp), p. $62-63$ et 369 (Goldast). Bien sûr, ces auteurs sont aussi fréquemment cités dans d'autres parties de l'ouvrage.

243 Cf., par exemple, ibid., p. 36, 164, 207 et 367. Barre définit ainsi l'autonomia: „on appelloit ainsi le libre éxercice de la Religion, ou la liberté de conscience dans les Provinces de 
diètes de l'Empire et de divers événements du XVIe siècle, il renvoie à Chytraeus et à Schard ${ }^{244}$. Il connaît de même les "Annales Ferdinandei« de Khevenhül$\operatorname{ler}^{245}$, Adelzreiter (c'est-à-dire Vervaux) ${ }^{246}$, ainsi que le »Theatrum Europaeum $\ll^{247}$.

Parmi les éditions de sources auxquelles Barre se reporte, signalons également les $\gg$ Negociations secretes ${ }^{248}$. En ce qui concerne l'histoire de la paix de Westphalie, il a aussi lu Adami, qu'il qualifie d'»Historien Allemand, très-attaché à la maison d'Autriche «249. Bien évidemment, Barre utilise aussi les recueils de traités internationaux ${ }^{250}$, qui renferment des documents divers sur

l'Empire «, ibid., p. 164; pourtant, ce ne fut pas la seule signification de ce terme fondamental du droit de religion allemand du XVIe siècle, REPGEN, Die Römische Kurie und der Westfälische Friede, vol. $\mathrm{V} 1$, p. $111, \mathrm{n} .124$, résume de manière précise les cinq significations différentes de ce concept.

244 Cf., par exemple, BARRE, Histoire générale d'Allemagne, t. IX p. 137-139. David Chytraeus (1530-1600), théologien protestant et historien qui enseignait à Wittenberg, puis à Rostock; il se chargea de la première collection d'actes concernant l'histoire de la confession d'Augsbourg au XVIe siècle et est l'auteur d'un livre latin ainsi que d'un ouvrage allemand sur le même sujet. Simon Schard était juriste, assesseur auprès de la Chambre impériale et auteur de publications sur le droit public allemand.

245 Cf., par exemple, ibid., p. 204-205, à propos du règne de Rodolphe II; il va sans dire que cet auteur est fréquemment cité pour la période postérieure. Franz Christoph Graf von Khevenhüller (1588-1650), était un diplomate et historien autrichien. À plusieurs reprises, il était chargé de missions diplomatiques en France. Entre 1640 et 1646, il publia les »Annales Ferdinandei«, son seul livre imprimé. La première édition comprend neuf volumes, la deuxième (qui date de 1721-1726) quatorze volumes. Il s'agit d'un des principaux ouvrages historiques du baroque autrichien. Ce livre traite la période qui va de 1588 à 1637 . Bien que l'auteur veuille contribuer à la glorification de la maison d'Autriche, son ouvrage est toujours estimé par les historiens, puisque Khevenhüller utilisa de nombreuses sources perdues depuis le XVII ${ }^{\mathrm{e}}$ siècle (journaux intimes, brochures, correspondances privées, etc.); cf. Kurt PEBALL, article »Khevenhüller, Franz Christoph Graf v. K.-Frankenburg«, dans: Neue deutsche Biographie, t. XI (1977), p. 569-570.

246 Cet historien de la Bavière, dont l'identité échappe à BARRE, est fréquemment cité dans ID., Histoire générale d'Allemagne, t. IX, par exemple p. 709 et 729.

${ }^{247} \mathrm{Cf}$., par exemple, ibid., p. 701, 704 et 725. Le »Theatrum Europaeum « était une publication consacrée à l'histoire récente; vingt-et-un volumes parurent à Francfort/M., chez Matthaeus Merian, entre 1635 et 1738 . Ils portent sur l'histoire européenne de la période qui va de 1618 à 1718; cf. Hermann BINGEL, Das Theatrum Europaeum, ein Beitrag zur Publizistik des 17. und 18. Jahrhunderts, Berlin 1909; Gerd DetHlEFs, Schauplatz Europa. Das Theatrum Europaeum des Matthaeus Merian als Medium kritischer Öffentlichkeit, dans: Klaus Bussmann, Elke Anna Werner (dir.), Europa im 17. Jahrhundert. Ein politischer Mythos und seine Bilder, Stuttgart 2003, p. 149-179.

248 Cf., par exemple, BARRE, Histoire générale d'Allemagne, t. IX, p. 790.

249 Ibid., p. 826.

250 Cf. ibid., p. 667; en ce qui concerne le traité de cession de Philippsbourg de la Suède à la France, Barre renvoie au »Recueil des Traités. t. 3. p. 359«. Il s'agit de la collection de traités de [Frédéric LÉONARD], Recueil des traitez de paix [...], 6 vol., Paris 1693, que BarRE cite aussi à propos du traité entre Louis XIII et le duc Bernard de Saxe-Weimar; cf. ID., Histoire générale d'Allemagne, t. IX, p. 681. 
l'histoire d'Allemagne, tels les testaments de princes ${ }^{251}$. Il utilise également les auteurs qui ont écrit l'histoire d'autres pays que l'Allemagne ${ }^{252}$ et les étrangers qui ont écrit sur l'Allemagne ${ }^{253}$, ainsi que les auteurs qui ont écrit sur l'histoire et sur le droit des différentes régions de l'Empire ${ }^{254}$. En règle générale, Barre donne en marge du texte, en italique, les références des auteurs auxquels il recourt dans le passage respectif de son »Histoire«. Outre les ouvrages historiographiques, il puise aussi dans les grands juristes allemands, tels Pufendorf, qui était à la fois historien ${ }^{255}$ et juriste ${ }^{256}$, Ziegler ${ }^{257}$, Limnaeus ${ }^{258}$, Moser $^{259}$. Si le

251 Cf., par exemple, ibid., p. 87, où Barre cite le supplément au »Corps diplomatique« de Dumont, à l'an 1554, au sujet du testament de Ferdinand Ier.

252 À la fois les auteurs étrangers et allemands; cf., par exemple, pour ce qui est de la seconde catégorie, ibid., p. 390 et 434, où il cite »Puffendorf. rerum Suecicarum«. Pufendorf avait publié son Histoire de Suède sous le titre de "Commentariorum de rebus suecicis libri XXVI« en 1686; pour un aperçu de sa vie et de sa pensée de juriste, cf. Klaus LuIG, article „Pufendorf, Samuel«, dans: Neue deutsche Biographie, t. XXI (2003), p. 3-5. Cf. également, pour ce qui est de la première catégorie d'auteurs, BARRE, Histoire générale d'Allemagne, t. IX, p. 562 et p. 581 où Barre cite, respectivement au sujet des Grisons et au sujet de la mort de Vincent II, duc de Mantoue et de Montferrat, le »Memorie recondite « de Siri. L'historien italien Vittorio Siri (1608-1685), qui avait passé de nombreuses années de sa vie en France, avait publié à Ronco, Paris et Lyon, entre 1676 et 1679, ses »Memorie recondite dall'anno 1601 sino al 1640«; il est également l'auteur du »Mercurio, ovvero Historia de' correnti tempi «, paru en quinze volumes à Casale, Venise et Florence de 1644 à 1682 . Sur cet auteur, cf., entre autres, Guido BraUn, article »Siri, Vittorio«, dans: CROXTON, Tischer, The Peace of Westphalia, p. 276-277. On pourrait aussi alléguer l'histoire de Venise par Nani, citée chez BARRE, Histoire générale d'Allemagne, vol. IX, par exemple p. 571, 573 et 740 . L'Histoire de Venise écrite par Giovan Battista Nani (1616-1702) avait été publiée à plusieurs reprises en français, entre 1679 et 1682, et traduite par l'abbé François Tallemant (1620-1693) et Paulin de Masclari.

253 Cf., par exemple, ibid., p. 366, où il renvoie à la »Germania sacra «e Carlo Carafa, au sujet de la diète de Ratisbonne de 1608; ibid., p. 404, il cite le même auteur à propos de la diète électorale de Nuremberg, en 1611; de même, au sujet de la diète générale de Ratisbonne, en 1613 (ibid., p. 425), et à d'autres occasions (par exemple, p. 486 et 489). Cf. Carlo CARAFA, Commentaria de Germania sacra restavrata [...], Aversa 1630; Francfort/M. ${ }^{2} 1641$. Au sujet de Carafa et de son image du Saint Empire romain germanique, cf. Guido Braun, Kaiserhof, Kaiser und in der »Relazione « des Nuntius Carlo Carafa (1628), dans: Richard Bösel, Grete KLINGENSTEIN, Alexander Koller (dir.), Kaiserhof - Papsthof (16.-18. Jahrhundert), Vienne (Autriche) 2006 (Publikationen des Historischen Instituts beim Österreichischen Kulturforum in Rom im Verlag der Österreichischen Akademie der Wissenschaften, Abhandlungen, 12), p. 77-104.

254 Cf., par exemple, BARRE, Histoire générale d'Allemagne, t. IX, p. 308, où il renvoie à »Sagittarius. hist. Elect. Brandeb. ad an. 1598«. Caspar Sagittarius était connu comme historien de plusieurs villes et États territoriaux d'Allemagne. En 1684, il publia l'»Historia marchionum ac electorum Brandenburgicorum«, qui est en réalité le travail de Samuel Ulrici rédigé sous sa direction. Son ouvrage principal, »Nucleus historiae germanicae«, publié en latin en 1675 (et réimprimé en 1682), fut traduit en français par J. B. de Rocoles. Cf. HILLER, Die Geschichtswissenschaft an der Universität Jena, p. XVI-XIX et p. 15-77; MENK, Sagittarius. Cf. aussi Caspar SAGITTARIUS, Q. D. B. V. Historiam marchionvm ac electorvm Brandenburgensivm [...], Iéna 1684, p. 67-70 et p. 72, sur l'année 1598 .

255 Cf., par exemple, BARRE, Histoire générale d'Allemagne, t. IX p. 467, p. 482 et p. 491.

256 Barre ignore que Pufendorf est l'auteur du »Status Imperii «; il cite en effet son pseudonyme, par exemple ibid., p. 580. La première édition du livre »De statu Imperii Germanici« 
vrai nom de l'auteur du "Status Imperii« lui échappe, Barre sait bien en revanche quel personnage se cache derrière le nom de "Hippolythus a Lapide«, à savoir Chemnitz ${ }^{260}$.

Dans le volume IX (1558-1658), l'auteur le plus fréquemment cité est Pufendorf $^{261}$. Parmi les ouvrages que Barre indique, on trouve aussi, mais rarement, des titres en allemand ${ }^{262}$. En ce qui concerne les auteurs français, il a très certainement consulté de Thou. Il utilise de même le »Mercure françois« et la »Gazette de France ${ }^{263}$. En outre, il se reporte à Bougeant et ses histoires de la guerre de Trente Ans et de la paix de Westphalie, où il relève pourtant plusieurs erreurs ${ }^{264}$ :

de Pufendorf avait été publiée en 1667, cf. LuIG, Pufendorf. Comme nous l'avons vu, ce livre fut aussi traduit en français.

257 Cf., par exemple, BARRE, Histoire générale d'Allemagne, t. IX, p. 479, à propos de la capitulation de Ferdinand II, où l'auteur renvoie à l'ouvrage de Ziegler sur les capitulations impériales. Cf. Christoph ZIEGLER, Wahl=Capitulationes, Welche mit denen Rómischen Kấ âsern und Kơnigen/ Dann des H. Ro̊m. Reichs Churfứrsten [...] auffgerichtet/ vereiniget und verglichen [...], Francfort/M. 1711.

258 Cf., par exemple, BARRE, Histoire générale d'Allemagne, t. IX, p. 479, à propos de la même capitulation impériale, où Barre cite à la fois le »lus publicum« de Limnaeus et l'édition des capitulations impériales de ce même auteur, qui connut plusieurs rééditions. Entre 1629 et 1634, Limnaeus avait publié son ouvrage fondamental »Iuris publici Imperii Romano-Germanici libri IX «; en 1651, il avait publié son livre »Capitulationes imperatorum et regum Romanogermanorum «, dont la cour impériale de Vienne avait envisagé l'interdiction, puisque Limnaeus y critiquait ouvertement la politique de Ferdinand II. À propos des ouvrages de Limnaeus (1592-1663) et notamment de sa publication des capitulations des empereurs jusqu'à Ferdinand III, cf. Bernd ROECK, article "Limnaeus, Johannes«, dans: Neue deutsche Biographie, t. XIV (1985), p. 567-569; PüTTER, Litteratur des Teutschen Staatsrechts, t. I. p. 194-199.

259 Cf., par exemple, BARRE, Histoire générale d'Allemagne, t. IX, p. 843, n. a, où cet auteur définit le droit des premières prières en se fondant sur une dissertation publiée dans un volume de mélanges d'œuvres mineures de Moser. Pour Johann Jacob (Jakob) Moser (17011785), qui était peut-être le juriste le plus important du Saint Empire romain germanique, cf. Karl Otmar Freiherr vON ARETIN, article »Moser v. Filseck, Johann Jakob«, dans: Neue deutsche Biographie, t. XVIII (1997), p. 175-178 (bibliographie); Guido BRAUN, article $\gg$ Moser, Johann Jacob«, dans: CroxtoN, TISCHER, The Peace of Westphalia, p. 196-197 (bibliographie).

260 Cf., par exemple, BARRE, Histoire générale d'Allemagne, t. IX, p. 604, 611, 632, 658, 660 , etc., où il le nomme correctement.

${ }^{261}$ BARRE utilise plusieurs ouvrages de cet auteur; outre ceux qui ont déjà été signalés, il a aussi consulté son Histoire de Frédéric-Guillaume de Brandebourg, cf. ID., Histoire générale d'Allemagne, t. IX, p. 768. En 1695, Pufendorf avait publié son livre sur l'électeur de Brandebourg, intitulé »De rebus gestis Friderici Wilhelmi Magni Electoris Brandenburgici«, cf. Luig, Pufendorf.

262 Cf., par exemple, BARRE, Histoire générale d'Allemagne, t. IX, p. 675.

263 Cf., par exemple, ibid., p. 203, n. a, ibid., p. 208, p. 211 (pour de Thou), p. 437-438 et 441-443, où il cite le »Mercure«, en particulier à l'an 1614, et p. 758, où il puise dans la "Gazette « de 1642, ainsi que p. 850, avec des informations tirées de la »Gazette « des années 1650,1651 et 1652 .

264 Cf., par exemple, ibid., p. 492 , n. a et b, p. 493 , n. a, p. 495 , n. a,p. 496 , n. a et p. 562 , n. a. Barre fait une lecture critique de Bougeant, l'opposant à ce que rapportent le »Mercure françois«, Khevenhüller, Struvius et d'autres historiens de la guerre de Trente Ans. 
parmi celles-ci, notons seulement l'une des plus flagrantes, mais qui n'était pas aussi rare à l'époque que l'on aurait tendance à le croire de nos jours; il s'agit de la confusion entre le traité de Passau de 1552 et la paix de religion d'Augsbourg de 1555 , une confusion qu'on peut aussi trouver chez d'autres auteurs, en particulier chez les écrivains italiens. Mais Barre a bien confronté la datation de 1555 que Bougeant avance en parlant du traité de Passau à celle qu'il a trouvée chez les auteurs allemands, et en tire la bonne conclusion ${ }^{265}$. On peut constater que Barre est particulièrement critique à l'égard de l'ouvrage de Bougeant ${ }^{266}$, non seulement sur ce point certainement très important, mais aussi sur d'autres aspects d'importance secondaire. Alors qu'il se borne, en général, à noter les noms d'auteurs et les références en marge du texte, il relève les fautes de Bougeant dans des notes de bas de page, qui montrent bien que Barre a fait une lecture assez précise de cet auteur 267 .

En ce qui concerne l'influence que l'»Histoire générale d'Allemagne « de Barre a exercé sur la vision française du Saint-Empire, il est à noter qu'un auteur de la seconde moitié du XVIII esiècle, Élie-Catherine Fréron, publia une sorte d'abrégé, pourtant assez maladroit, de cet ouvrage sous le titre d'»Histoire de l'Empire d'Allemagne, et principalement de ses révolutions, depuis son établissement par Charlemagne jusqu'à nos jours «; pourtant, le huitième et dernier tome de cet ouvrage est un traité systématique du droit public allemand, de sorte que Fréron offre à la fois une histoire d'Allemagne et un aperçu du droit public de l'Empire268.

\section{Entre histoire et philosophie: Voltaire et l'»Encyclopédie«}

L'image du Saint Empire romain germanique dans le »Siècle de Louis XIV $«^{269}$ et dans les »Annales de l'Empire«, de Voltaire ${ }^{270}$, a déjà fait l'objet de plusieurs

265 BARre, Histoire générale d'Allemagne, t. IX, p. 587-588, n. a.

$266 \mathrm{Cf}$. [Guillaume-Hyacinthe] BougEANT (S.J.), Histoire des guerres et des negociations qui precederent le traité de Vestphalie [...], Paris 1727; ID., Histoire du traité de Westphalie, ou des negociations qui se firent à Munster \& à Osnabrug [...], 2 vol., Paris 1744; autres éditions des deux ouvrages en 1744,1751 et 1767 . Pour la critique de cet ouvrage, cf. également L'Année littéraire. Année M.DCC.LXVI, t. VII, Paris 1766, p. 73-94.

$267 \mathrm{Cf}$., par exemple, BARRE, Histoire générale d'Allemagne, t. IX, p. 600, n. a.

268 [Élie-Catherine FrÉRON, Histoire de l'Empire d'Allemagne, et principalement de ses révolutions, depuis son établissement par Charlemagne jusqu'à nos jours [...], 8 vol., Paris 1771 ; c'est Barbier qui qualifie l'ouvrage entier d'abrégé de celui du père Barre, et y constate des »fautes en assez grand nombre «. Selon lui, la rédaction du livre avait été commencée dès l'année 1742. Malgré les faiblesses de l'ouvrage, l'auteur note que les »Göttingische Gelehrte Anzeigen« faisaient cas du travail de cet abréviateur et en parlèrent dans plusieurs numéros, cf. Ant[oine]-Alex[andre] BARBIER, Dictionnaire des ouvrages anonymes, troisième édition, revue et augmentée par Olivier Barbier, René et Paul BILlaRd, 4 vol., Paris $1872-$ 1879, ici t. II, col. 682.

269 Nous avons utilisé cette édition: VolTaIRE, Le Siècle de Louis XIV, Paris 1994 (reproduction anastatique à partir des »Euvres complètes« de Voltaire, édition établie par Louis 
études 271 , tout comme l'image de l'Allemagne dans l'»Encyclopédie méthodique «272. Comme Klaus Malettke le rappelle au début de son article sur la perception de l'Allemagne et des Allemands dans le »Siècle de Louis XIV«, on sait au moins depuis 1966 que des parties importantes du manuscrit furent écrites par Voltaire entre son arrivée à Berlin, à l'été 1750, et l'édition de Leipzig, qui parut

MoRand, 1878). Pour le "Siècle de Louis XIV « comme pour les ouvrages historiques de Voltaire en général, nous nous sommes également reporté à: VOLTAIRE, Euvres historiques. Texte établi, annoté et présenté par R[ené] POMEAU, Paris 1957 (Bibliothèque de la Pléiade, 128).

270 Nous avons utilisé surtout l'édition suivante: VolTaIRE, Annales de l'Empire, depuis le temps de Charlemagne, 2 vol., Deux-Ponts 1792 (GEuvres complètes, 30-31). Pour ses écrits concernant le droit et les sciences politiques, nous avons aussi consulté: VolTAIRE, Recht und Politik, édité par Günther MEschING, Francfort/M. 1986 (Taschenbücher Syndikat, EVA, 75) [extraits des œuvres de Voltaire sur la philosophie du droit et la théorie de l'État, traduits en allemand].

271 Cf. Klaus MaletTKe, Deutschland und die Deutschen im Siècle de Louis XIV, dans: Peter BROCKMEIER, Roland DESNÉ, Jürgen Voss (dir.), Voltaire und Deutschland. Quellen und Untersuchungen zur Rezeption der Französischen Aufklärung. Internationales Kolloquium der Universität Mannheim zum 200. Todestag Voltaires [Mannheim, 1978], Stuttgart 1979, p. 139-152; Dieter GEMBICKI, Voltaire historien de l'Empire germanique et l'érudition allemande, dans: BROCKMEIER, DESNÉ, Voss (dir.), Voltaire und Deutschland, p. 191-199; Sven Stelling-Michaud, Janine Buenzod, Pourquoi et comment Voltaire a-t-il écrit les Annales de l'Empire?, dans: BROCKMEIER, DESNÉ, Voss (dir.), Voltaire und Deutschland, p. 201-222; Notker HAMMERSTEIN, Voltaire und die Reichspublicistik, dans: BrockMEIER, DesnÉ, Voss (dir.), Voltaire und Deutschland, p. 327-342; Nikolaus GöTZ, Das Deutschlandbild Voltaires in seinen historiographischen Werken, Sarrebruck 1989, en particulier p. 165-189 pour la perception par Voltaire des structures politiques du Saint-Empire. Pour Voltaire comme historien, cf. également: Robert MANDrou, La méthode historique de Voltaire, une lecture du "Siècle de Louis XIV «, dans: Karl HAMMER, Jürgen Voss (dir.), Historische Forschung im 18. Jahrhundert. Organisation, Zielsetzung, Ergebnisse. 12. Deutsch-Französisches Historikerkolloquium des Deutschen Historischen Instituts Paris, Bonn 1976 (Pariser Historische Studien, 13), p. 364-373.

272 Cf. Eberhard WEIS, Geschichtsschreibung und Staatsauffassung in der französischen Enzyklopädie, Wiesbaden 1956 (Veröffentlichungen des Instituts für Europäische Geschichte Mainz, Abteilung Universalgeschichte, 14); Klaus MALETTKE, Altes Reich und Reichsverfassung in der französischen Enzyklopädie, dans: Zeitschrift für Neuere Rechtsgeschichte 9 (1987), p. 129-151; ID., Die Perzeption des Alten Reiches in der "Encyclopédie«, dans: Olaf Asbach, Klaus MalettKe, Sven Externbrink (dir.), Altes Reich, Frankreich und Europa. Politische, philosophische und historische Aspekte des französischen Deutschlandbildes im 17. und 18. Jahrhundert, Berlin 2001 (Historische Forschungen, 70), p. 279-298. Pour l'»Encyclopédie méthodique« (1784-1788), postérieure à l'époque qui nous intéresse, cf. Roger DuFRAISSE, Das Reich aus der Sicht der Encyclopédie méthodique 1784-1788, dans: Rainer A. MÜLLER (dir.), Bilder des Reiches. Tagung in Kooperation mit der schwäbischen Forschungsgemeinschaft und der Professur für Geschichte der Frühen Neuzeit der Katholischen Universität Eichstätt im Schwäbischen Bildungszentrum Kloster Irsee vom 20. März bis 23. März 1994, Sigmaringen 1997 (Irseer Schriften, 4), p. 123-153. Pour l'influence des philosophes allemands sur l'»Encyclopédie«, cf. aussi Marcel THOMANN, Influence du philosophe allemand Christian Wolff (1679-1754) sur l'»Encyclopédie« et la pensée politique et juridique du XVIII e siècle français, dans: Archives de philosophie du droit 13 (1968), p. 233-248. 
au printemps de $1752^{273}$. Comme Necker, Voltaire avait probablement commencé la rédaction de son ouvrage au début des années 1730 , reprenant ce travail après une pause de plus de dix ans, en 1750. Voltaire disait explicitement que les lois, les arts et les mœurs étaient l'objet principal de son travail d'historiographe ${ }^{274}$. Il n'est donc pas surprenant que Voltaire ait consacré une partie importante des passages de son »Siècle de Louis XIV « concernant l'Allemagne à l'histoire des institutions et des lois du Saint-Empire au XVIIe siècle et au début du XVIII

Selon Voltaire, à la veille du règne de Louis XIV, le gouvernement de l'Allemagne ressemblait approximativement à celui de la France au temps des premiers Capétiens ${ }^{275}$ et se distinguait nettement de la monarchie française du XVII ${ }^{e}$ siècle. L'empereur est considéré comme le chef de presque cent soixante-dix potentats, qui formaient le corps germanique (villes d'Empire, princes ecclésiastiques et séculiers, électeurs). Selon Voltaire, il n'était ni plus puissant ni plus riche que le doge de Venise, ne disposant pas de domaines impériaux. Pourtant, à la différence de la confusion qui avait régné en France au temps des Capétiens, d'après Voltaire, le gouvernement de l'Empire était marqué par le respect de l'ordre. La Constitution germanique n'est donc pas dépeinte d'une manière négative. Tout comme Montesquieu, qui regardait l'Allemagne comme une république éternelle, au même titre que la Suisse et la Hollande, Voltaire admirait la longévité de cette Constitution. Le respect du droit, qui privilégiait la voie judiciaire dans les litiges opposant les états de l'Empire à d'autres états, et son caractère corporatif étaient les éléments positifs de cette Constitution. Voltaire souligne que la paix de Westphalie assurait le respect des privilèges des princes et des villes d'Empire, voire de la simple noblesse impériale. Or, le fait qu'il prétende que ce fut la France qui, à Münster, posa les fondements de cette liberté germanique ${ }^{276}$ pose un problème, puisque nous avons vu que le gouvernement et les diplomates français n'ont pas imaginé et mis en œuvre une véritable politique constitutionnelle en faveur des princes d'Empire, abstraction faite de leur convocation au congrès et de leur droit d'alliance. En revanche, il faut bien voir que cette interprétation correspondait parfaitement à l'image que les Français se faisaient de leur propre rôle historique aux XVII et XVIII e siècles ${ }^{277}$.

Selon Voltaire, malgré les faiblesses de sa condition constitutionnelle, l'empereur jouissait d'un grand nombre de prérogatives. Il concède même que, jusqu'au temps de Ferdinand II, certains empereurs habsbourgeois avaient fait de leur dignité impériale un puissant instrument politique, au point de transformer le corps germanique en véritable monarchie ou de convertir l'»aristocratie allemande « et cette »république des princes« en »monarchie absolue«, pour reprendre ses pro-

273 Cf. MaleTtKe, Siècle, p. 139. Voltaire resta à Berlin et à Potsdam jusqu'au mois de mars 1753.

274 Cf. MANDRou, La méthode historique, p. 366.

275 VOLTAIRE, Euvres historiques, p. 621.

276 Cf. ibid., p. 881.

277 Cf. MaletTKe, Siècle, p. 141. 
pres termes ${ }^{278}$. Cependant, comme nous l'avons vu, Voltaire compare l'empereur au doge de Venise, comme l'avait déjà fait Jean Bodin presque deux siècles auparavant. Or, cette comparaison ne reflétait pas les pouvoirs constitutionnels de l'empereur, qui étaient plus importants que ceux du doge. Mais, à cet égard, comme au sujet du rôle de la France en Westphalie, on peut constater que l'interprétation de Voltaire était conforme à une certaine tradition française remontant jusqu'à Jean Bodin, même si celle-ci n'avait pas toujours été prédominante au cours des deux siècles qui séparaient ces deux auteurs. En règle générale, force est de constater que Voltaire disposait de connaissances très précises sur la Constitution allemande. Il voyait clairement que, à la différence de la monarchie française, la Constitution de l'Empire ne permettait guère à celui-ci de mener des guerres offensives à l'étranger. Grâce aux travaux de Malettke, on sait qu'il évoquait des problèmes du droit public allemand dans sa correspondance avec Frédéric II. Par exemple, Voltaire abordait le problème de la souveraineté du duché de Lorraine et de son indépendance du Saint-Empire dans une lettre envoyée au futur roi de Prusse le 5 août 1738 , se référant aux »Considérations sur l'état présent du corps de l'Europe« que Frédéric avaient rédigées la même année ${ }^{279}$.

Malgré le soin avec lequel Voltaire avait étudié au moins une partie des sources, ses »Annales de l'Empire « furent assez fraîchement accueillies par des savants allemands, comme Schœpflin, qui considéraient Voltaire comme un amateur ${ }^{280}$. En effet, l'esprit de ses ouvrages historiques différait trop de l'érudition de la Reichspublicistik allemande pour que ses représentants pussent accepter Voltaire comme leur confrère281. Les "Göttingische Gelehrte Anzeigen « le qualifiaient d'»historiographe superficiel« (»der flüchtige Historiograph «); leurs comptes rendus énuméraient ses erreurs »avec une précision pédantesque «282. Néanmoins, aujourd'hui, l'historien peut constater que »les Annales valent beaucoup mieux que leur réputation, et qu'elles méritent une attention d'autant plus vive qu'il s'agit de la seule histoire d'Allemagne écrite pour le grand public au $18^{\mathrm{e}}$ siècle par un Français - et quel Français! «283

Parmi les livres qui, très certainement, ont connu une diffusion plus large que les ouvrages des spécialistes, il faut évoquer l'»Encyclopédie« de Diderot et d'Alembert. Tout comme Necker, les auteurs de l'»Encyclopédie« considéraient l'Allemagne comme une confédération d'États souverains et libres, quoique placés sous un chef commun. C'est ainsi que, du moins, le premier volume définis-

278 Voltaire, Euvres historiques, p. 622-623. Cf. MaLETTKE, Siècle, p. 142.

279 Cf. ibid., p. 143-144.

280 Cf. Stelling-Michaud, Buenzod, Les Annales de l'Empire, p. 213-214. Le bien-fondé de cette assertion dépend de ce qu'on entend par »grand public «, car nous avons vu qu'il y avait bien d'autres historiens français qui ont écrit sur l'Allemagne au XVIII' siècle.

281 Cf. HaMmersteIn, Voltaire und die Reichspublicistik, p. 339.

282 Cf. Peter-Eckhard KNABE, L'accueil fait à Voltaire par les Göttingischen Gelehrten Anzeigen (1739-1779), dans: BrockMEIER, DESNÉ, Voss (dir.), Voltaire und Deutschland, p. $343-355$, ici p. 349 .

283 Stelling-Michaud, Buenzod, Les Annales de l'Empire, p. 201. 
sait l'Allemagne en $1751^{284}$. La suite de l'article présente les solutions que les Allemands, en l'occurrence l'empereur, ont imaginées pour résoudre les problèmes que cette fragmentation de leur pays, qui découlait de sa constitution politique et géographique, posait au commerce ${ }^{285}$. Klaus Malettke a observé que cette définition de l'Allemagne était en réalité incompatible avec le concept de »souveraineté« défini par Bodin, puisque, selon ce dernier, des États souverains et libres ne pouvaient pas avoir un même souverain ${ }^{286}$.

Mais ce premier article sur l'Allemagne, publié en 1751, n'est pas le seul qui doit retenir l'intérêt de l'historien qui étudie la perception des structures politiques du Saint-Empire dans l'»Encyclopédie «. En tenant compte de l'article sur l'Empire (1755) et du deuxième article sur l'Allemagne (dans le supplément de 1776) ${ }^{287}$, on s'aperçoit du fait que, d'un article à l'autre, la perception des différents auteurs n'est pas homogène. En effet, dans l'article »Empire «288, l'auteur, peut-être Diderot ${ }^{289}$, estimait que l'Empire était une »république mixte«, dans laquelle il détectait des éléments monarchiques, aristocratiques et démocratiques.

284 Cf. [Denis] DIDERot, [Jean Le Rond] D'ALEMBERT, Encyclopédie ou dictionnaire raisonné des sciences, des arts et des métiers. Nouvelle impression en facsimilé de la première édition de 1751-1780 [Par une société de gens de lettres. Mis en ordre \& publié par M. Diderot $[\ldots]$ \& quant à la partie mathématique, par M. d'Alembert], 35 vol., Stuttgart, Bad Cannstatt 1966-1967, ici t. I (édition originale: 1751), article »Allemagne«, p. 281-282: "C'est un composé d'un grand nombre d'Etats souverains \& libres, quoique sous un chef commun « (citation p. 281).

285 Après avoir constaté que l'on "conçoit que cette constitution de gouvernement établissant dans un même empire une infinité de frontieres différentes, supposant d'un lieu à un autre des lois différentes, des monnoies d'une autre espece, des denrées appartenantes à des maîtres différens, \&c. on conçoit, dis-je, que toutes ces circonstances doivent mettre beaucoup de variété dans le commerce«, ibid.

286 Cf. MaletTKe, Die Perzeption des Alten Reiches in der »Encyclopédie«, p. 281-282. Pour l'origine du concept de »souveraineté«, cf. Jürgen DENNERT, Ursprung und Begriff; Helmut QUARITSCH, Staat und Souveränität, vol. 1: Die Grundlagen, Francfort/M. 1970. Pour l'importance du concept de »souveraineté « forgé par Bodin, cf. également Robert DERATHÉ, La place de Jean Bodin dans l'histoire des théories de la souveraineté, dans: DENZER (dir.), Bodin, p. 245-260; Max IMBODEN, Johannes Bodinus und die Souveränitätslehre, Bâle 1963; Hans-Ulrich ScuPIN, Der Begriff der Souveränität bei Johannes Althusius und bei Jean Bodin, dans: Der Staat 4 (1965), p. 1-26 (traduction partielle française dans: Annales de la faculté de droit et des sciences économiques de Lille 1963, p. 7-27); et, parmi les travaux anciens, Max LANDMANN, Der Souveränetätsbegriff bei den französischen Theoretikern, von Jean Bodin bis auf Jean Jacques Rousseau. Ein Beitrag zur Entwickelungsgeschichte des Souveränetätsbegriffes, Leipzig 1896 (Ausgewählte Doktordissertationen der Leipziger Juristenfakultät); Adolf Dock, Der Souveränetätsbegriff von Bodin bis zu Friedrich dem Grossen, Strasbourg 1897.

${ }^{287}$ En outre, l'»Encyclopédie« publiait aussi des articles sur un certain nombre d'institutions du Saint-Empire, telles que les cercles, la diète, l'empereur, les états, etc. Parmi ces articles, le plus important nous semble être celui sur la »Constitution« de l'Allemagne, qui contient des informations très précises sur les membres de l'Empire, sur les lois et sur le système judiciaire de ce dernier; cf. [DIDEROT, D'ALEMBERT], Encyclopédie ou dictionnaire raisonné des sciences, t. IV (édition originale: 1754), p. 63-72.

288 Ibid., t. V (édition originale: 1755), p. 582-583.

289 Cf. WeIS, Geschichtsschreibung und Staatsauffassung, p. 264, n. 5. 
Les éléments aristocratiques lui semblaient particulièrement importants, alors que l'empereur ne pouvait guère prétendre à un pouvoir monarchique, puisqu'il n'était pas le seul législateur dans l'Empire et que certains attributs d'un véritable suzerain lui manquaient ${ }^{290}$. Il est vrai que cette explication de la Constitution de l'Empire - qui se situait dans la tradition de la théorie du status mixtus, très répandue en France et en Allemagne aux siècles précédents ${ }^{291}$ - ne tenait pas compte des progrès que les auteurs français avaient faits depuis la deuxième moitié du XVII siècle, en admettant que cette Constitution ne pouvait pas être comparée aux différentes formes de gouvernement enseignées par Aristote ${ }^{292}$.

L'article »Empire « évoque trois ouvrages relatifs à l'histoire et au droit de l'Allemagne: l'»Histoire « du président de Thou; les »Annales de l'Empire« de Voltaire; les »Institutiones iuris publici«, de Vitriarius ${ }^{293}$. À la différence du président

290 Cf. [Diderot, D'AlEmBERT], Encyclopédie ou dictionnaire raisonné, t. V, p. 583: »Il y a des auteurs qui ont trouvé très-difficile à déterminer le nom qu'il falloit donner au gouvernement de l'Empire. En effet, si on le considere comme ayant à sa tête un prince à qui les états de l'Empire sont obligés de rendre hommage, de jurer fidélité \& obéissance, en recevant de lui l'investiture de leurs fiefs, on sera tenté de regarder l'Empire comme un état monarchique. Mais d'un autre côté l'empereur ne peut être regardé que comme le représentant de l'Empire, puisqu'il n'y a point de droit d'y faire seul les lois: il n'a point non plus le domaine direct des fiefs, puisqu'il n'a que le droit d'en donner l'investiture, sans avoir celui d'en priver, sous aucun prétexte, ceux qui les possedent, sans le consentement de l'Empire; d'ailleurs, en parlant des états, l'empereur les appelle toûjours nos vassaux \& de l'Empire. Si on considere la puissance \& les prérogatives des états de l'Empire, la part qu'ils ont à la législation, les droits que chacun d'eux exerce dans les territoires qui leur sont soûmis, \& que l'on nomme la supériorité territoriale, on aura raison de regarder l'Empire comme un état aristocratique. Enfin, on trouvera la démocratie dans les villes libres qui ont voix $\&$ séance aux dietes de l'Empire. D'où il faut conclure que le gouvernement de l'Empire est celui d'une république mixte«. Toutefois, au début de cet article, l'auteur répète, en principe, la définition du premier tome de l'»Encyclopédie« en définissant le corps germanique comme »une république composée de tous les princes \& états qui forment les trois colléges de l'Allemagne, \& soumise à un chef qui est l'empereur«, ibid., p. 582.

291 Pour la France, cf. Christian NADEAU, Les constitutionnalistes français face au problème de la constitution mixte: Claude de Seyssel et Jean Bodin, dans: Marie GaILLE-NIKOdimov (dir.), Le Gouvernement mixte. De l'idéal politique au monstre constitutionnel en Europe (XIIIe-XVIIe siècle), Saint-Étienne 2005, p. 95-115; Isabelle BouviGNIES, Monarchie mixte et souveraineté des états chez les monarchomaques huguenots, dans: GAILLE-NIKODIMOV (dir.), Le Gouvernement mixte, p. 117-138. Pour l'Allemagne, cf. Michael SToLlEIS, La respublica mixta au XVII ${ }^{e}$ siècle. Réception de l'idéal de la constitution mixte en Allemagne, dans: GaIlle-NiKodimov (dir.), Le Gouvernement mixte, p. 139-151; Giuseppe Duso, La constitution mixte et le principe du gouvernement: le cas Althusius, dans: GaILLE-NIKODIMOV (dir.), Le Gouvernement mixte, p. 153-173. Pour l'opposition à ce concept en France, cf. R. J. SCHOECK, Bodin's Opposition to the Mixed State and to Thomas More, dans: DENZER (dir.), Bodin, p. 399-412. Pour la pensée politique française au XVIe siècle, cf. en général William Farr CHuRCH, Constitutional Thought in Sixteenth-Century France. A Study in the Evolution of Ideas, Cambridge (Mass.), Londres 1941 (Harvard Historical Studies, XLVII).

292 Cf. MAletTKe, Die Perzeption des Alten Reiches in der »Encyclopédie«, p. 283-284. 293 [DIDEROT, D'AlEMBERT], Encyclopédie ou dictionnaire raisonné, t. V, p. 583. Pour cet auteur et son ouvrage, cf. le chapitre précédent; STOLLEIS, Geschichte des Öffentlichen Rechts, t. I, p. 251. 
de Thou, l'auteur de cet article estimait que les états de l'Empire ne s'étaient pas réunis pour constituer un État, "mais que des sujets puissans d'un même état se sont rendus souverains, sans pour cela se séparer de l'état actuel auquel ils appartenoient; \& c'est l'intérêt, le plus puissant mobile, qui les y a tenus attachés les uns aux autres; union qui leur a donné les moyens de se maintenir «294. Selon cet auteur, l'intégrité du Saint-Empire n'était donc pas menacée, bien qu'il constatât un grand nombre de défauts dans sa Constitution, notamment le fait que »l'autorité du chef n'[étai]t pas assez grande pour se faire écouter«, et, peut-être le plus important, l'inconvénient que représentait la lenteur des délibérations de la diète de l'Empire 295 . En outre, il notait le nombre insuffisant de juges dans les tribunaux de l'Empire ainsi que d'autres défauts, sans toutefois proposer de solutions à ces problèmes constitutionnels.

Le deuxième article sur l'Allemagne, publié dans le supplément de $1776^{296}$, n'entre pas dans notre cadre chronologique. Toutefois, pour conclure ces remarques sur l'image de l'Empire dans l'»Encyclopédie«, signalons le fait que son auteur, Charles-Claude de Montigny (1744-1818), qui publia également une »Histoire générale d'Allemagne « en six volumes ${ }^{297}$, avait une image du Saint-Empire qui était très proche de celle de Pufendorf. Cette influence pufendorfienne ne se manifestait pas seulement dans la définition du Saint-Empire comme »un corps monstrueux « sans que cette notion eût une connotation négative, si ce n'était quant à l'incapacité de l'Empire de subir des réformes ${ }^{298}$. Cependant, en interprétant l'Empire comme une »confédération de peuples libres «299, Montigny allait plus loin que Pufendorf, qui avait seulement envisagé l'éventualité de la transformation du Saint-Empire en une confédération ${ }^{300}$. Toutefois, on peut relever une contradiction dans l'article même de Montigny, quand celui-ci prétend qu'en Allemagne l'empereur et les électeurs sont »les seuls princes qui soient véritablement souverains, parce qu'ils sont assez puissans, pour faire respecter leur privilege \& la foi des traités ${ }^{301}$.

En étudiant les sources auxquelles les auteurs des articles sur l'Allemagne recouraient, on peut constater une certaine continuité. Parmi les ouvrages cités, on

294 [DIDEROT, D’ALEMBERT], Encyclopédie ou dictionnaire raisonné, t. V, p. 583.

295 Ibid.

296 Ibid., t. XVIII (= supplément t. I; édition originale: 1776), p. 308-313.

297 [Charles-Claude] MONTIGNY, Histoire générale d'Allemagne, depuis l'an de Rome 640 jusqu'à nos jours, 6 vol., Paris 1772-1779.

298 [DIDEROT, D'AlEMBERT], Encyclopédie ou dictionnaire raisonné, t. XVIII, p. 312. Avant cette définition, Montigny rappelle les différentes tentatives des juristes allemands de définir leur forme de gouvernement comme monarchique, aristocratique ou démocratique (ibid.). 299 Ibid

300 Cette différence entre Montigny et Pufendorf est soulignée par MaLetTKe, Die Perzeption des Alten Reiches in der »Encyclopédie«, p. 285-286.

301 [DIDEROT, D'AlEMBERT], Encyclopédie ou dictionnaire raisonné, t. XVIII, p. 309. Cette remarque est problématique, puisque d'autres princes de l'Empire jouissaient presque des mêmes droits que les électeurs et étaient parfois plus puissants que les électeurs les plus faibles, en particulier les électeurs ecclésiastiques. 
retrouve par exemple l'édition de l'»Histoire de l'Empire« de Heiss de 1731 (2 volumes) et l'»Abrégé chronologique « de Pfeffel (édition de 1754) ${ }^{302}$.

En général, force est de constater que, dans les articles sur la Constitution de l'Allemagne, l'»Encyclopédie« brosse une image somme toute positive de ses structures politiques, bien que, très certainement, cette Constitution ne correspondît pas aux idéaux rationalistes des philosophes des Lumières ${ }^{303}$. De toute façon, Schubert avait tort quand il prétendait que l'»Encyclopédie « avait sévèrement critiqué la Constitution de l'Empire ${ }^{304}$.

D'autres philosophes tels que Montesquieu, Rousseau et l'abbé de Saint-Pierre abordaient des problèmes de la Constitution germanique dans le contexte de leurs travaux qui n'étaient pas uniquement consacrés à ce sujet: par exemple, Montesquieu dans son "Esprit des lois«, publié en 1748, l'abbé de Saint-Pierre et Rousseau dans leurs études sur le problème de la paix perpétuelle en Europe, respectivement en $1713^{305}$ et en $1761^{306}$. Mais nous n'étudierons pas de manière détaillée leurs visions de l'Empire ${ }^{307}$. Pour l'abbé de Saint-Pierre et pour Rousseau, l'Empire avait une fonction essentielle dans le maintien de la paix en Europe. Rousseau estimait que, malgré ses défauts, la Constitution du Saint-Empire rendait celui-ci incapable de faire des conquêtes en Europe, tout en protégeant ses membres aussi bien que ses voisins. Rousseau en concluait que tant que l'Empire subsiste-

302 Cf. MALETTKE, Altes Reich und Reichsverfassung in der französischen Enzyklopädie, p. $150-151$.

${ }^{303}$ Cf. WeIS, Geschichtsschreibung und Staatsauffassung, p. 145; MALETTKE, Die Perzeption des Alten Reiches in der "Encyclopédie«, p. 295-296.

304 Cf. Friedrich Hermann Schubert, Französische Staatstheorie und deutsche Reichsverfassung im 16. und 17. Jahrhundert, dans: LUTZ, SCHUBERT, WEBER (dir.), Frankreich und das Reich, p. 20-35, 55-59 (notes), ici p. 32 et 58-59 (n. 21).

305 Cf. Charles-Irénée Castel DE SAINT-PIERRE, Projet pour rendre la paix perpétuelle en Europe, [Paris] 1986. L'édition originale du livre de Saint-Pierre (1658-1743) parut en 2 vol., à Utrecht, en 1713.

306 C'est en 1756 que Rousseau avait entamé la rédaction de son »Extrait du projet de paix perpétuelle de Monsieur l'Abbé de Saint-Pierre «. Pour cette œuvre, cf. Jean-Jacques RousSEAU, Extrait du Projet de paix de M. l'abbé de Saint-Pierre, dans: ID., Euvres complètes, vol. III: Du Contrat social. Écrits politiques, édition publiée sous la direction de Bernard GaGnebin et Marcel Raymond, Paris 1964 (Bibliothèque de la Pléiade, 169), p. 563-589. 307 Comme nous l'avons dit au début de ce chapitre, nous privilégions l'étude des auteurs qui - comme Voltaire - ont écrit des livres consacrés intégralement à l'histoire ou au droit du Saint-Empire. Par ailleurs, les positions des grands philosophes sont déjà assez bien connues; pour l'abbé de Saint-Pierre et Rousseau, cf., par exemple, Olaf AsBach, Die Reichsverfassung als föderativer Staatenbund. Das Alte Reich in der politischen Philosophie des Abbé de Saint-Pierre und Jean-Jacques Rousseaus, dans: ID., MaleTTKE, ExTERnBRinK (dir.), Altes Reich, p. 171-218; Olaf AsBACH, Die Zähmung der Leviathane. Die Idee einer Rechtsordnung zwischen Staaten bei Abbé de Saint-Pierre und Jean-Jacques Rousseau, Berlin 2002 (Politische Ideen, 15); ID., Staat und Politik zwischen Absolutismus und Aufklärung. Der Abbé de Saint-Pierre und die Herausbildung der französischen Aufklärung bis zur Mitte des 18. Jahrhunderts, Hildesheim et al. 2005 (Europaea Memoria. Studien und Texte zur Geschichte der europäischen Ideen, série I: Studien, 37). Dans ces deux livres, Asbach a également étudié la position de Montesquieu. Pour les philosophes en général, cf. Fred E. SCHRADER, L'Allemagne avant l'État-nation. Le corps germanique 1648-1806, Paris 1998. 
rait, jamais l'équilibre entre les puissances européennes ne serait rompu; la paix de Westphalie constituerait peut-être pour toujours la base du système politique européen. Rendant hommage à l'assiduité avec laquelle les Allemands étudiaient leur droit public, Rousseau pensait que celui-ci était encore plus important que les Allemands ne le croyaient eux-mêmes, puisque, outre le droit public germanique, il était également en quelque sorte celui de l'Europe tout entière. Pour sa part, Montesquieu comparait, comme Necker, le Saint-Empire à la Hollande et à la Suisse. De la même façon que Rousseau, il soulignait le caractère corporatif du Saint-Empire ${ }^{308}$. Enfin, comme Voltaire et Rousseau, ce théoricien de l'État estimait que les éléments monarchiques de la Constitution germanique étaient plutôt faibles. Pourtant, à la même époque, il y avait encore des auteurs qui soulignaient l'importance de ces éléments monarchiques, tel l'excellent connaisseur de la Constitution allemande qu'était Scheid.

\section{L'apogée de la littérature française sur l'Empire: Scheid}

Malgré les différents centres d'intérêt que nous avons esquissés dans ce livre, ce n'est qu'en 1754 que deux véritables chefs-d'œuvre sur le droit d'État du SaintEmpire apparaissent en langue française: l'un ${ }^{309}$, dû à »l'oracle ambulant des relations extérieures « ${ }^{310}$, Chrétien-Frédéric Pfeffel, en propose un abrégé chronologique, qui devient un »ouvrage classique «311; l'autre, rédigé par Jean-Frédéric Scheid ${ }^{312}$, choisit une approche systématique. Salué par la critique comme meilleur ouvrage jamais publié en français sur le droit constitutionnel allemand, au moment de sa parution, son influence resta, par la suite, plus limitée que celle de l'ouvrage de Pfeffel, peut-être à cause de sa taille et de son style moins attrayants; il souffrait très certainement de la concurrence et du très grand succès de Pfeffel. Ce n'est pourtant pas à juste titre que Scheid, qui chercha à garder l'anonymat de

308 Cf. Winfried BECKER, Der Kurfürstenrat. Grundzüge seiner Entwicklung in der Reichsverfassung und seine Stellung auf dem Westfälischen Friedenskongreß, Münster 1973 (Schriftenreihe der Vereinigung zur Erforschung der Neueren Geschichte e.V., 5), p. 351.

309 Celui-ci a connu de nombreuses rééditions. Cf. PFEFFEL, Abrégé chronologique, première édition 1754 , deuxième édition 1758 ; la $2^{2}$ édition a été réimprimée en 1766 . Cette édition est due au père Barre. Cf. aussi ID., Nouvel Abrégé chronologique [...], 2 vol., Paris 1776; autre édition: 2 vol., ibid. 1777.

310 D'après un jugement qui date de 1806, cf. Anne SALOmon, Les Alsaciens employés au ministère des Affaires étrangères à Versailles au XVII et au XVIII e siècles, dans: Revue d'histoire diplomatique 45 (1931), p. 448-472, ici p. 459.

311 D'après l'éloge de Pfeffel prononcé par Gérando, qui qualifie son livre d'»ouvrage classique dans une matière très difficile de sa nature et qui ne lui offrait presque ni modèle, ni guide«; et de souligner que Pfeffel »eut le mérite de réunir, dans un tableau exact et rapide, une suite d'événements, ou plutôt une réunion d'histoires particulières, laissées jusqu'alors dans une assez grande confusion, et de débrouiller, dans un sommaire plein de clarté, le chaos d'une législation extrêmement compliquée«; éloge cité par SALOMON, Les Alsaciens, p. 460 .

312 SCHEID, Traité sistématique. 
son vivant ${ }^{313}$, est devenu un auteur dont l'historiographie a oublié jusqu'au nom. Au sujet de la plupart des juristes qui ont écrit en français sur la Constitution allemande, on sait peu de choses; sur Scheid, on ne sait presque rien. C'est pourquoi nous nous sommes proposés de ressusciter la figure de ce spécialiste du droit public allemand, bien que son œuvre n'ait connu, d'après nos recherches, qu'une seule édition.

Or, Scheid est un Allemand qui écrit en français, pour être lu non seulement par les Français, mais aussi par les jeunes nobles allemands et tous ceux qui lisent la langue de Molière ${ }^{314}$, devenue la première langue culturelle et véhiculaire du savoir en Europe. Ainsi, la France comme entité linguistique et communauté culturelle de tous ceux qui maîtrisent sa langue et qui pensent en français ne se limite pas à la France géographique, administrative et politique. Le choix linguistique de Scheid ${ }^{315}$ correspond non seulement aux préférences des Allemands de son époque, mais aussi à celles de l'Europe quasi entière. Scheid s'insère délibérément dans la tradition des auteurs français, c'est-à-dire ceux qui écrivent en français. Sa critique de Heiss, formulée en 1751 et que nous avons déjà évoquée, est des plus âpres. Le reproche qu'il fait à l'»Histoire de l'Empire« d'être »déféctueuse «, »superficielle« et »remplie d'abus \& de choses contraires aux Loix fondamentales \& à ce qui se pratique « ${ }^{316}$ est certainement justifié en ce sens où l'»Histoire de l'Empire« ne pouvait plus, au milieu du XVIII ${ }^{e}$ siècle, tenir lieu de traité systématique

313 Cf. ibid., préface, t. I, p. [*8]-[*8'], ici p. [*8].

314 C'est ce que Scheid explique lui-même dans l'»Avis« au lecteur, t. l, p. *4-[*7'], ici p. ${ }^{*} 4-\left[{ }^{*} 4^{\prime}\right]$ : il s'adresse en premier lieu à »ceux qui n'entendent point la Langue Allemande«, mais il estime que l'ouvrage est »utile aussi en Allemagne«, et généralement »par tout ailleurs, à ceux qui savent ou apprennent la Langue Françoise«. Scheid vise »la Jeunesse de Qualité « aussi bien que »les Gens destinés aux Affaires Publiques« (ibid.).

315 Signalons que ce personnage, qui naquit en Allemagne et y passa la plus grande partie de sa vie, ne connaissant la France que par ses voyages, est néanmoins classé, dans un compte rendu de son "Traité sistématique«, parmi les auteurs français, puisqu'il écrivit en français; et ceci bien que les traits essentiels de sa biographie, et notamment sa »nationalité « (pour employer un mot attesté seulement depuis 1808), soient connus à l'auteur de ce compte rendu, paru dans les »Göttingische Gelehrte Anzeigen«, en 1751 (voir ci-dessous). Comme nous avons déjà pu le constater, le qualificatif d'auteur »français«, dans son sens historique, désigne en effet l'auteur qui écrit en français, même s'il n'est pas français d'origine. Si l'on ne prenait pas en considération ce groupe d'auteurs étrangers écrivant en français, on perdrait de vue un phénomène d'un intérêt non négligeable: la France fit en effet le plus souvent appel à des auteurs alsaciens ou étrangers, surtout aux résidents des princes allemands à la cour, pour rédiger des ouvrages et des mémoires sur l'Allemagne en langue française (Jean Heiss, Abraham de Wicquefort), ou à ceux qui entretenaient des relations particulières avec ce pays (Louis Du May); certains des plus grands auteurs allemands furent par ailleurs traduits en français (Chemnitz, Pufendorf). Une partie essentielle de la production de livres imprimés en français sur ce sujet est due à ce type d'auteurs qui ont exercé une très grande influence sur le public français. La France, contrairement à l'Allemagne, ne vit cependant pas la naissance d'une littérature latine sur le droit public allemand, abstraction faite de quelques publications antérieures à 1648 . À cet égard, la production de livres français au cours de la période qui va de 1740 à 1756 est conforme à celles des périodes précédentes (1648-1683 et 1684-1739).

316 SCHEID, Traité sistématique, t. I, p. *5. 
du droit public allemand en France, étant donné les progrès que celui-ci avait connus depuis soixante-quinze ans; mais Scheid néglige les conditions dans lesquelles Heiss avait dû travailler au siècle précédent. Sa critique s'avère ainsi lacunaire dans ses fondements et partiellement injustifiée dans ses conclusions. Il faut aussi prendre en considération la richesse de la littérature française sur le droit public allemand avant $1740^{317}$ pour comprendre quelles omissions Scheid a commises en ne citant de cette période que l'»Histoire de l'Empire« de Heiss. Ce n'a point »été pendant long tems presque le seul essai, qui pût en [sc. du droit public allemand] donner, dans ladite langue [le français], quelque idée«, comme le prétend Scheid ${ }^{318}$. Outre les travaux de Heiss, il signale, au début de son ouvrage, ceux de Necker, de Spon et de Mauvillon ${ }^{319}$, pour la période qui commence en 1740 . Or, là encore, les ouvrages français étaient beaucoup plus nombreux.

Or, Scheid ne connaissait pas encore l'ouvrage de Pfeffel en composant le sien. En effet, ce fut déjà au début des années 1730, que Scheid, encore jeune homme, commença à rédiger son »Traité sistématique«, vingt ans avant la publication du premier tome ${ }^{320}$. C'est à titre volontaire que l'auteur garda l'anonymat, priant le lecteur de »faire réflexion aux raisons, qui peuvent porter un jeune homme à suprimer son nom, quand il donne un Essai au public, \& même sur une matiere aussi délicate, que la présente [sc. le droit public allemand], vû la différence des intérêts de chaque ordre des membres de l'Empire «321. Scheid dit cependant avoir »passé plus de vingt ans dans des affaires, qui [lui] ont fourni l'occasion « d'améliorer son ouvrage ${ }^{322}$; il a donc travaillé au service d'un prince. C'est Jean-Jacques Moser, en annonçant la publication du premier tome de Scheid, dans son "Teutsches Staats=Archiv « 323 , qui révèle, dès 1751 , l'identité de celui-ci: il s'agit du conseiller de justice et de gouvernement du duc de Holstein-Plön, charge effectivement occupée par Jean-Frédéric Scheid. Cette information est implicitement confirmée, en 1753, par les »Göttingische Gelehrte Anzeigen «324, qui renvoient à l'identité

317 Ce fut d'ailleurs déjà vers 1730 que Scheid commença à écrire son ouvrage, tout comme Necker; voir ci-dessous.

318 Cf. SCHEID, Traité sistématique, t. I p. *5.

319 Cf. ibid., p. *5-[*6'].

320 Cf. ibid., p. $* 2-* 4$.

321 Ibid., préface p. [*8-*8'], ici p. [*8].

322 Ibid., avis, ici p. *4-[*4'].

323 Cf. Johann Jacob Moser, Teutsches Staats=Archiv, oder Sammlung derer neuest= und wichtigsten Reichs $=$ Crays $=$ und anderer Handlungen, Deductionen, Urtheile derer hóchsten Reichs $=$ Gerichte, Vertrăge, und anderer Staats=Schrifften und Urkunden [...] Mit Anmerckungen und gelehrten Neuigkeiten von Teutschen Staats=Sachen begleitet, neuvième partie, Hanau 1751, p. 178.

$324 \gg$ Herzoglich=Holstein=Plönische Justiz= und Regierungs=Rath Scheid «; Göttingische Zeitungen von gelehrten Sachen; à partir de 1754: Göttingische Anzeigen von gelehrten Sachen [...], Göttingen, année 1753, t. I, p. 131-135, ici p. 131-132. C'est la troisième partie (portant sur le t. III du »Traité sistématique«) d'un compte rendu publié en quatre livraisons; les autres livraisons se trouvent ibid., année 1751, p. 387-393 (sur le t. I); année 1752, t. I, p. 302-308 (sur le t. II); année 1754, no 41, p. 345-346 (sur le quatrième et dernier tome de 
révélée par Moser, tout en soulignant que l'auteur persiste néanmoins à interdire au journal de reproduire son nom. En effet, déjà en envoyant le premier tome du "Traité sistématique « à ce journal pour le prier d'en publier un compte rendu, il lui avait en même temps adressé une lettre lui interdisant de mentionner le nom de l'auteur ${ }^{325}$. Celui-ci ne figure d'ailleurs toujours pas sur les frontispices des volumes suivants du »Traité sistématique«, parus entre 1752 et 1754, mais l'identité de l'auteur est encore confirmée par Pütter ${ }^{326}$.

Si l'identité de l'auteur, incorrectement identifié dans les catalogues des plus prestigieuses bibliothèques, est donc désormais bien établie, les informations dont nous disposons sur sa vie demeurent toujours lacunaires. Moser n'en dit pas plus, et les »Göttingische Gelehrte Anzeigen« ne font que répéter ce que Scheid dit sur lui-même dans son ouvrage, c'est-à-dire qu'il a commencé à l'écrire quand il était jeune, vingt ans auparavant, et qu'il a passé les deux dernières décennies de sa vie dans l'administration, ce qui lui a permis d'acquérir des connaissances pratiques; connaissances qui, au dire même de l'auteur, lui ont permis de revoir, de corriger et d'augmenter son œuvre, et d'en faire non seulement un essai théorique d'universitaire, mais aussi un traité pratique et systématique nourri d'expérience. Pütter sait seulement que Scheid est mort au Wurtemberg, où il avait donné des cours privés dans les derniers temps de sa vie ${ }^{327}$.

Pourtant, la famille de Scheid est bien connue; elle est de souche alsacienne, plus précisément de Haguenau, où elle est attestée depuis 1311328; de nombreux juristes et autres savants en sont issus. C'est une famille évangélique depuis le $\mathrm{XVI}$ siècle, qui occupa de nombreuses charges dans l'administration locale, jusqu'à ce que la plupart des éminentes familles alsaciennes protestantes soient contraintes à l'exil. Au XVII e siècle, on trouve les juristes de cette maison aussi bien à la Chambre impériale de Spire qu'au congrès de la paix de Nimègue, et un peu partout dans l'administration de diverses principautés de l'Empire.

Si sa famille est illustre, Jean-Frédéric est éclipsé par la renommée éclatante de son frère, Chrétien-Louis ${ }^{329}$, le célèbre professeur de droit public. Ce qu'on sait de Jean-Frédéric, outre les faits que nous venons de signaler, se cache encore dans des ouvrages épars ${ }^{330}$ et se résume ainsi: Jean-Frédéric Scheid naît à Francfort-

l'œuvre de Scheid). Pour la critique de l'ouvrage de Scheid dans les »Göttingische Gelehrte Anzeigen«, voir également le dernier chapitre.

325 Ibid., année 1751, p. 387-394, ici p. 387-388.

326 Cf. PÜTTER, Litteratur des Teutschen Staatsrechts, t. II, p. 81. Le commentaire de Pütter montre qu'il n'estime pas beaucoup les auteurs qui écrivent en français (à noter qu'il range Scheid parmi les "écrivains français«!) et qui, selon son opinion, n'ont pas de connaissances précises de l'Allemagne, mais qu'il tient pour plus correctes les informations qu'on peut trouver chez Scheid.

327 Cf. ibid.

328 ZEDLER, Grosses vollständiges Universal-Lexikon, t. 34, col. 1126-1133.

329 Sur ce dernier, voir ci-dessous et BRaUN, Traductions, p. 140 et n. 6.

330 Cf. Ernst Ludwig Gerber, Historisch=Biographisches Lexicon der Tonkünstler [...], Zweyter Theil [...], Leipzig 1792, p. 417; reproduit sur microfiche dans: Deutsches Biographisches Archiv I 1093, 204. Cf. aussi Archives biographiques françaises I 945, 150-151 (d'après Édouard SrTzmanN, Dictionnaire de biographie des hommes célèbres de l'Alsace 
sur-le-Main, tout au début du XVIII⿸ siècle ${ }^{331}$. Son père est Jean Scheid, qui devient conseiller et secrétaire de la seigneurie de Waldenburg 332 et qui est luimême fils du célèbre philologue strasbourgeois Balthasar Scheid, mort en $1670^{333}$. Jean-Frédéric arrive à Strasbourg en 1718 et y fait ses études de droit; en 1719 , il soutient une thèse de doctorat en droit sur la constitution et les droits de la corporation des ménétriers en Allemagne, d'abord publiée chez Jean Pasteur à Strasbourg, et rééditée, en 1738, à léna; elle porte le titre »Dissertatio de iure in musicos singulari [...], Rappolsteinensi comitatui annexo«. Il est aussi l'auteur d'un écrit sur la juridiction des sires de Ribeaupierre en leur qualité de »roi des musiciens« (Pfeifferkönig), avant de se consacrer à l'étude plus approfondie du droit public allemand. Au début des années 1730 , il commence à travailler dans les »affaires «, comme il le dit lui-même. En 1751, on l'a vu, il est au service du Holstein. Il finira ses jours au Wurtemberg.

C'est dans une bibliothèque parisienne que nous apprenons plus de choses sur la situation de la famille Scheid au début des années 1730, et par conséquent de ce qui fut le cadre familial de Jean-Frédéric. En effet, le manuscrit 2537 de la bibliothèque Sainte-Geneviève renferme la correspondance entre le père Barre et d'autres savants, dont un certain Scheid, que le »Catalogue général « identifie avec Chrétien-Louis Scheid ${ }^{334}$; l'inventaire ne justifie pas ce choix, mais une indication autobiographique, dans l'une des lettres, permet de le vérifier. L'auteur, qui signe toujours ses lettres adressées au père Barre "Scheid « (sans prénom ni autre précision), y évoque en effet l'éloge qu'il a fait d'un de ses oncles mort récemment; cet éloge latin est assurément de Chrétien-Louis Scheid, qui a apparemment déjà acquis une certaine notoriété. Chrétien-Louis Scheid (1709-1761) 335, historien et juriste, qui obtint une chaire de droit public à Copenhague et finit ses jours à Hanovre, où il se trouvait depuis 1748 en tant qu'historiographe et bibliothécaire royal, ne devait pas avoir la vie facile: un de ses élèves s'étant suicidé et sa femme vivant ouvertement en adultère avec un domestique, il se consolait de ses

[...], 2 vol., Rixheim, 1909-1910). Cf. de même les rares indications autobiographiques de Scheid dans le premier tome de son traité et les comptes rendus que nous venons de signaler. Les papiers de Chrétien-Louis Scheid, par contre, ne foumissent pas de renseignements complémentaires sur la vie de son frère, du moins si l'on en croit l'inventaire, cf. Eduard BoDEMANN, Die Handschriften der Königlichen Bibliothek zu Hannover [...], Hanovre 1867, notamment p. 652 et p. $615 \mathrm{n}^{\circ} 1257$.

${ }^{331}$ La date de la soutenance de sa thèse de doctorat nous incite personnellement à dater sa naissance vers la fin du XVII' siècle, mais la littérature n'apporte, autant que nous sachions, aucun élément pour vérifier cette hypothèse.

332 »Rath und Amtmann der Oberherrschafft Waldenburg «, cf. ZEDLER, Grosses vollständiges Universal-Lexikon, t. 34, col. 1132.

333 Ibid., col. 1128-1130 et col. 1132.

$334 \mathrm{Cf}$. Ch. KoHLER, Catalogue général des manuscrits des bibliothèques publiques de France. Paris, bibliothèque Sainte-Geneviève, publié sous les auspices du ministère de l'Instruction publique et des Beaux-Arts, t. II, Paris 1896, p. 389.

335 En général, on écrit le nom de famille de Chrétien-Louis »Scheidt «; mais, dans ce chapitre, nous respectons l'orthographe de sa signature personnelle, qui est »Scheid«. 
chagrins personnels par un travail assidu; les éloges que la postérité lui a faits à propos de son œuvre lui rendent pourtant justice ${ }^{336}$.

Chrétien-Louis Scheid voyage au début des années 1730 en France, et entretient donc une correspondance avec le savant père Barre. Ainsi, dans une desdites lettres, datée de Paris, le 16 avril $1733^{337}$, Scheid s'excuse pour n'avoir pas répondu, depuis six mois, à une demande de renseignement que le père Barre lui avait adressée au sujet de l'empereur Henri IV. Scheid est donc estimé en France pour ses connaissances historico-juridiques. Il dispose aussi de manuscrits sur ce sujet, dont il se trouve cependant »éloigné « pendant qu'il voyage; mais il n'a pas encore atteint »l'âge un peu plus mure [sic]«, dont il promet à Barre de réserver les »grâces [...] volontièrement à [se]s ordres «, le priant pour l'instant d'excuser les »foiblesses « liées à sa jeunesse ${ }^{338}$. Rappelons que Chrétien-Louis Scheid naquit le 26 septembre 1709. Ces lettres de Scheid sont de la plus grande importance pour notre sujet parce que, outre le fait qu'elles fournissent des renseignements sur la famille Scheid en général, elles sont riches en informations sur les relations entre les savants français et allemands au milieu du XVIII' siècle.

La première lettre adressée par Chrétien-Louis Scheid au père Barre, conservée dans ledit manuscrit, date du 12 décembre $1732^{339}$. Scheid est alors depuis deux mois à Tours; il voyage en groupe à travers la France ${ }^{340}$. Ce voyage est aussi mentionné par Zedler, qui précise que Scheid, accompagné de trois frères à lui, est allé, via Genève, Lyon, Orléans et Blois, à Tours, où il resta quatre mois, avant de passer six mois à Paris ${ }^{341}$. On peut supposer que Jean-Frédéric était aussi du groupe, et il n'est même pas exclu qu'il ait lui aussi tenu une correspondance avec le père Barre, puisqu'il est attesté que ce dernier ne correspondait pas uniquement - en ce qui concerne la famille Scheid - avec Chrétien-Louis. Il est en effet à noter que dans le même manuscrit ${ }^{342}$ se trouve la minute d'une lettre ${ }^{343}$ adressée par le père Barre à »Monsieur Scheid médecin allemand «. Il pourrait s'agir de Jean-Godefroy Scheid, frère de Chrétien-Louis et de Jean-Frédéric, qui avait soutenu sa thèse de doctorat en médecine, à l'université de Strasbourg, en 1728; il naquit en 1703 à Strasbourg et y mourut en 1734 quand il y était médecin à l'hôpital alle-

336 Cf. le jugement dans: Biographie universelle, t. XLI, p. 97-99, en particulier p. 98; Nouvelle Biographie générale, t. 43, col. 498-499.

337 Original autographe: BSG, ms. 2537 fol. 5-6'.

338 Ibid., fol. 6.

339 Original autographe: ibid., fol. 2-3. Ce n'est très certainement pas la toute première lettre que Scheid adresse à Barre, dont il vient d'apprendre la maladie; il résulte en effet de sa teneur que les deux personnages se connaissent déjà.

340 Cf. ibid., ici PS fol. 3.

341 ZEDLER, Grosses vollständiges Universal-Lexikon, t. 34, col. 1132. Pütter mentionne de même le voyage de Christian Ludwig Scheidt en Suisse et en France, en 1732 (PưTTER, Litteratur des Teutschen Staatsrechts, t. II, p. 31).

342 BSG, ms. 2537 fol. 33-34'.

343 S.l.n.d. Cette pièce est probablement antérieure à une deuxième lettre adressée au même

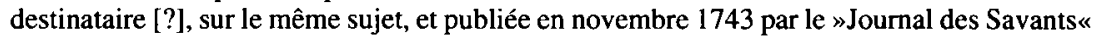
(voir ci-dessus). 
mand ${ }^{344}$. On peut exclure comme destinataire de la lettre son professeur et oncle, Jean Valentin Scheid, fils de Balthasar, né en 1651, puisqu'il était déjà mort en 1731; celui-ci avait occupé pendant cinquante-cinq ans une chaire de médecine à Strasbourg, il avait eu, en outre, une solide connaissance des belles-lettres, puisqu'il avait étudié et voyagé à l'étranger, notamment en France, où il avait fait la connaissance de nombreux savants et avait joui, en particulier, de l'amitié du cardinal de Rohan ${ }^{345}$.

Quel qu'en soit le destinataire, c'est une lettre très intéressante, où Barre expose le projet »de l'histoire générale d'Allemagne avant et depuis l'établissement de l'Empire germanique, que j'ay dessein de donner au public «, sujet qu'il juge »neuf et intéressant«. Il y expose ensuite sa critique des auteurs qui ont traité du même sujet en français, en particulier Heiss, et fait allusion aux lectures qu'il a déjà faites en vue de cette publication. En novembre 1743, le "Journal des Savants« publia une autre lettre de Barre sur son projet d'une Histoire d'Allemagne, qui, elle, était destinée également »à M. Scheid, Medecin Allemand «346. Or, cette lettre diffère de celle qui avait été expédiée en 1732. Selon l'expéditeur, la lettre fut écrite sur la demande du destinataire, qui désirait être renseigné sur le projet de Barre; mais, dans ce cas-là, il s'agissait peut-être d'une convention littéraire.

Dans sa première lettre à Barre ${ }^{347}$, alors malade, Chrétien-Louis Scheid, quant à lui, évoque »la différence qu'il y a entre nous [le père Barre et lui-même] dans le sentiment de la religion «, mais qui "ne peut diminuer le respect et la profonde vénération « qu'il éprouve pour le père. La correspondance entre les deux savants, les fréquents témoignages de respect mis à part, tourne autour de la discussion de problèmes d'histoire. C'est ainsi que Scheid, alors qu'il est à Paris, répond le 11 mai $1733^{348}$ à une lettre que lui avait écrite le père Barre, au sujet des aïeux et du destin de l'empereur Henri IV »qui, comme dit Scheid, fera aujourd'hui l'objet de notre entretien « ${ }^{349}$. La question se pose de savoir s'il s'agit d'un vrai entretien, donc d'une rencontre personnelle, ou si Scheid emploie ce mot simplement pour désigner le sujet de la correspondance que les deux savants entretiennent. La deuxième solution est plus vraisemblable, car Scheid, qui envisage, ce 11 mai 1733, de quitter Paris dans l'espace de deux jours, et de s'en retourner dans son pays en passant par Bruxelles et »les meilleurs endroits de la Hollande«, assure au père Barre qu'il aura »seurement de [s]es nouvelles avant [s]on arrivé en Allemagne« 350 . Un rendez-vous n'est apparemment pas prévu d'ici là. Pourtant, le 16 avril 1733, alors que Scheid se trouvait déjà depuis plusieurs semaines à Paris,

$344 »$ Deutscher Hospital=Arzt«, cf. ZEDLER, Grosses vollständiges Universal-Lexikon, t. 34, col. 1132.

345 Ibid., col. 1132 et 1133 .

346 Voir ci-dessus.

347 Celle du 12 décembre 1732.

348 Original autographe: BSG, ms. 2537 fol. 4-4', 7-9.

349 Ibid., fol. 4'.

350 Ibid., fol. 8 '. 
il avait signalé son adresse au père Barre: l'hôtel Vendôme, rue Christine ${ }^{351}$. Et de confesser: "Je suis très mortifié que mon séjour à Paris ne me procure pas le plaisir de vous y entretenir quelquefois. J'y perde $[s i c]$ infiniment « 352 . Or, Scheid et Barre se sont probablement rencontrés auparavant, puisqu'il lui déclare à ce propos que »[la] première heure que j'ai passé[e] dans votre conversation « lui a révélé un homme "chez qui l'érudition a rassemblé tout ce qu'il y a de plus précieux parmi les gens d'esprit «353. Scheid a aussi fréquenté la bibliothèque de l'abbaye Sainte-Geneviève et y a noué d'autres contacts. Nous ne savons pas si, par la suite, il y a de nouveau rencontré le père Barre. La lettre suivante, du 11 mai, reste, on l'a vu, ambiguë sur ce point.

Dans celle-ci, Scheid évoque pourtant, peu avant son départ, son destin personnel et les difficultés que connaît sa famille:

Ma famille [y avoue-t-il] qui a considérablement perdu dans les dernières guerres et qui a quitté ses biens par amour de la religion dont je fais profession, n'est pas assez puissante pour se soutenir toute entière dans la province où mon père fut reçu comme étranger 354 . Ainsi je vois bien que je suis obligé de chercher mon établissement partout ${ }^{355}$. Quoi qu'il en soit, la peine ne m'épouvantera point. Je suis d'un naturel qui est content même dans son malheur. [...] J'ai perdu il y a trois mois le dernier de mes oncles, qui après la mort de celui dont $\mathrm{j}$ 'ai fait l'éloge ${ }^{356}, \mathrm{~m}$ 'a comblé de ses bienfaits. Son décès ruine presque entièrement mes espérances ${ }^{357}$.

Ces informations servent à mieux cerner la triste situation familiale de ChrétienLouis ainsi que de Jean-Frédéric Scheid au moment où ce dernier entreprit la rédaction des premières lignes de son ouvrage sur le droit public allemand. Revenons au contexte intellectuel qui a accompagné la rédaction finale, pendant les années 1740 et 1750 . À en juger par les seuls titres des ouvrages juridiques ou historiques consacrés à l'Allemagne, évoqués dans les paragraphes précédents, $s$ 'impose une conclusion qui a été confirmée par l'étude plus approfondie de ces écrits: leurs centres d'intérêt sont le statut et la fonction de l'empereur, son élection, le rôle des états de l'Empire, et plus particulièrement des électeurs, ainsi que le caractère étatique de l'Empire ${ }^{358}$, franchement remis en cause, notamment par Necker.

C'est autour des mêmes sujets que Scheid construit sa description générale de l'Empire, dans le premier tome de son traité, mais son ouvrage est sensiblement

351 Cf. le [PS] de sa lettre du 16 avril, ibid., fol. 6'.

352 Ibid., fol. 5'.

353 Ibid.

354 Le pays de Hohenlohe.

355 Veut-il dire »ailleurs $«$ ?

356 Jean-Valentin Scheid; l'éloge que lui fit Chrétien-Louis fut ensuite imprimé, cf. ZEDLER, Grosses vollständiges Universal-Lexikon, t. 34, col. 1130 et 1133.

357 Cf. sa lettre du 11 mai; BSG, ms. 2537, ici fol. 8'-9.

358 Pour le débat en Allemagne, cf. Bernd ROECK, Reichssystem und Reichsherkommen. Die Diskussion über die Staatlichkeit des Reiches in der politischen Publizistik des 17. und 18. Jahrhunderts, Stuttgart 1984 (Veröffentlichungen des Instituts für Europäische Geschichte Mainz. Abteilung Universalgeschichte, 112; Beiträge zur Sozial- und Verfassungsgeschichte des Alten Reiches, 4). 
différent, puisqu'il veut décrire le système du droit public allemand, c'est-à-dire en donner une vision complète. C'est ainsi qu'il ne commence pas par des professions de foi dogmatiques, comme tant de ses collègues, mais en introduisant son lecteur dans la »Matiere de l'Ouvrage en général«, les difficultés et les moyens d'acquérir des connaissances sur l'Empire, la géographie, les citoyens et les cercles qui composent celui-ci. Ce n'est que dans les deux derniers livres (livres quatrième et cinquième) du tome I ${ }^{\mathrm{er}}$ que Scheid en vient à la condition de l'empereur et des états de l'Empire. Ensuite (dans ses tomes deuxième et troisième), il se penche sur des thèmes que les auteurs avant lui n'ont que rarement traités, et jamais d'une manière aussi détaillée, tel le droit universitaire allemand. La partie la plus intéressante, parmi ces thèmes nouveaux, est certainement celle qui traite du droit public ecclésiastique de l'Empire, que les auteurs précédents avaient plutôt traité en orphelin. Dans le tome quatrième, il offre, suivant la tradition de Heiss, les traductions des plus importantes lois fondamentales de l'Empire: la capitulation de l'empereur alors régnant, François Ier, la Bulle d'or et la paix d'Osnabrück ${ }^{359}$. L'exemple qu'il suit délibérément en organisant les différents aspects de son sujet est celui qui est fourni par Boecler dans ses »Notitia Sacri Romani Imperii $\ll^{360}$.

Quelle est la vision de l'Empire que Scheid développe dans cet ouvrage? Tout d'abord, il dit que l'Empire est un État ou, pour reprendre le mot qu'il emploie, »une seule République «, et non pas »composé de plusieurs Républiques unies«. II allègue deux arguments: »le premier, que les Etats [de l'Empire] peuvent être assignés \& jugés à la Cour de l'Empereur, ce qui est tout à fait contraire à la nature des Républiques libres \& confédérées. Le second, qu'ils peuvent commettre le crime de Léze Majesté, or un allié ne peut pas être coupable de ce crime à l'égard de l'autre allié «361. Ce sont en effet, avec la possibilité de la mise au ban d'un état de l'Empire, qui traduit aussi sa sujétion juridique, les arguments de poids dont disposent les auteurs qui défendent le caractère d'État du Saint-Empire. Des publicistes comme Mauvillon et Necker n'arrivent à écarter ces objections qu'en transformant le véritable sens de certains éléments de la Constitution impériale, dont notamment la mise au ban.

Tout en rejetant le système des trois formes de gouvernement enseigné par la philosophie grecque, et la définition pufendorfienne de la Constitution de l'Empire comme "monstrueuse«, Scheid admet parler de l'Empire au titre d'une monarchie limitée »si l'on entend par cette dénomination un Etat principalement gouverné par un seul Chef, et où ce Chef exerce privativement tous les Droits de Souveraineté, qui ne sont pas communiqués, en vertu des Loix fondamentales,

359 Pour sa traduction de la paix d'Osnabrück, qui est d'une »précision et d'une rigueur méthodologiques « jusque-là inconnues, cf. nos remarques sur les traductions françaises des traités de Westphalie; BRAUN, Traductions, p. 140; ID., Gazette, p. 293.

360 Cf. ScheID, Traité sistématique, t. I, p. 8; ibid., p. 8-9, on trouvera le plan complet des trois premiers volumes. Son choix de suivre Boecler est encore souligné par PüTTER, Litteratur des Teutschen Staatsrechts, t. II, p. 81.

${ }^{361}$ SCHEID, Traité sistématique, t. I, p. 29. 
aux Membres Principaux « ${ }^{362}$. Son esprit d'impartialité lui défend toutefois d'accorder trop d'importance à ces questions d'idéologie. Si Heiss voit dans la capitulation impériale un »contrat « entre l'empereur et l'Empire et Mauvillon une »déclaration [des états de l'Empire] au Roi des Romains, sous quelle condition l'Empire consentoit de l'admettre à son gouvernement en qualité de Chef « ${ }^{363}$, Scheid s'efforce à démontrer ce qu'elle était avant tout, c'est-à-dire une loi fondamentale de l'Empire, un »Ecrit, dressé par les Electeurs, contenant les conditions, sous lesquelles l'Empereur futur promet de gouverner l'Empire, cet Ecrit lui est présenté par les Electeurs, au nom de tous les Etats, d'abord après son Election, pour en jurer l'observation avant que d'être couronné « ${ }^{664}$. Cet écrit ne devient loi, ou en a du moins la force, que par un consentement réciproque, les électeurs n'ayant pas en fait le pouvoir de législateurs, et l'empereur n'étant pas forcé d'accepter leurs conditions. Si Heiss et Mauvillon parlent en outre de "l'Empire « comme d'un seul corps face au futur empereur, Scheid met en relief les discordances entre les électeurs et les autres états qui empêchent l'établissement d'une capitulation perpétuelle, qu'avait prévu l'article VIII du traité d'Osnabrück; les états n'ont, en effet, que le droit d'adresser des »remarques « aux électeurs lors d'une élection impériale, sans titre de droit précis, et vont pour cela souvent jusqu'à remettre en question l'autorité même de la capitulation ${ }^{365}$. Le livre de Scheid est très utile, dans la mesure où il fait l'exposé des idées et jugements divergents qui existent sur certaines questions, laissant le plus souvent au lecteur le soin de trancher; Scheid se révèle en même temps un philologue soucieux de préciser les différentes significations que peuvent avoir certains concepts qu'il utilise. Au sujet de la traduction du terme Landeshoheit par "souveraineté«, il se montre beaucoup moins sévère que Moser, constatant seulement: "La souveraineté renferme proprement l'indépendance, mais comme quelques Auteurs appliquent le premier mot au Pouvoir des Etats de l'Empire, on a trouvé à propos d'y joindre cette épithète [sc. indépendant] «366. Cependant, il juge que ce sont la liberté des états de l'Empire et leur puissance qui »ont introduit beaucoup de confusion \& d'incertitude $\ll 367$ dans le droit constitutionnel allemand.

Celui-ci connaît deux acteurs principaux: l'empereur, d'un côté, et les états de l'Empire de l'autre; parmi ces derniers, les électeurs sont les plus éminents ${ }^{368}$.

362 Ibid., t. III, p. 261-262, n. b).

363 Cf. ibid., p. 584.

364 Ibid., t. II, p. 216.

365 Cf. ibid., p. 219-221.

366 Ibid., t. III, p. 275-276, n. a).

367 Ibid., t. I, p. 7.

368 Scheid traite de l'empereur ainsi que du roi des Romains et des vicaires de l'Empire au livre quatrième (t. I), des états de l'Empire au livre cinquième (ibid.) et des électeurs au livre sixième (t. II). Mais leurs droits et obligations respectifs font évidemment aussi l'objet d'autres parties, par exemple celles sur la législation dans l'Empire, les contributions, la juridiction impériale, le droit d'ambassade, etc., et notamment du livre XVIII $»$ Du Droit de Souveraineté, nommé en Latin Dominium Eminens, de quelle manière il peut avoir lieu dans l'Empire « (t. III). 
L'empereur est le successeur des empereurs romains; Scheid reprend sans aucune hésitation la théorie de la translatio Imperii ${ }^{369}$. En tant que "premier Prince de l'Univers«, il a droit au titre de "Majesté«, comme les autres têtes couronnées. Mais, appliquée à l'empereur, la majesté »ne marque pas le pouvoir \& l'autorité souveraine $\&$ despotique, mais la grandeur et dignité personnelle«, qui se manifestent notamment dans la magnanimité du souverain ${ }^{370}$. C'est une preuve de sa supériorité, à tel point qu'aucun autre membre de l'Empire, du moins en tant que tel ${ }^{371}$, n'a droit au titre de »Majesté«. C'est de la manière traditionnelle, partiellement médiévale, que Scheid conçoit la dignité impériale.

Or, son exposé des droits attachés à cette dignité et du pouvoir de l'empereur témoigne de son souci de s'en tenir aux réalités constitutionnelles, notamment régies par les capitulations impériales et les traités de Westphalie, et de chercher une voie médiane, seule capable de traduire ces réalités ${ }^{372}$. Scheid insiste donc, d'un côté, sur le caractère souverain de l'empereur, et, de l'autre, sur les limitations que lui imposent lesdites lois fondamentales de l'Empire, le respect de la »Supériorité territoriale« dont jouissent les princes à l'intérieur de leurs territoires et la part qu'ils ont »au gouvernement général de l'Empire «373. Citons le passage clé de son chapitre sur cette question:

L'Empereur est un Prince, qui tient, par le moïen de l'élection, sa dignité de Dieu sans autre dépendance; par conséquent il n'a point de juge dans ce monde, non plus que tous les Souverains, \& la seule différence, qu'il y a, c'est que son pouvoir est plus limité par les Loix fondamentales, que celui de quelques uns d'entre eux. Car il est très naturel, que quand une Nation a le droit de se choisir un Chef, elle ait aussi celui de lui proposer des conditions, sous lesquelles elle lui veut conférer le gouvernement, étant libre à celui-ci d'y consentir, ou de renoncer à son élection: au lieu que les peuples, qui ont cédé à leur Souverain la puissance absoluë, \& l'ont attaché à sa famille, n'y sauroient plus contrevenir sans crime de rébellion, étant obligés de la reconnoître toûjours sur ce même pied, \& de s'y soumettre aussi à l'égard de ses successeurs ${ }^{374}$.

Ce passage doit soulever au moins deux objections: primo, il y a une certaine contradiction si l'on dit, d'un côté, que l'empereur ne dépend que de Dieu et si, de l'autre, l'on affirme que la nation, conçue comme source de la souveraineté, ne lui a pas cédé la puissance absolue; secundo, cette dernière affirmation pose le pro-

369 Ibid., t. I, p. 119-120 et n. a). La validité juridique de cette théorie est, presque au même moment, remise en cause par un autre auteur français, cf. GuYON, Essai critique.

370 SCHEID, Traité sistématique, t. I p. 123-124.

371 Si certains électeurs l'ont cependant, c'est à cause d'un royaume qu'ils possèdent ailleurs, comme l'électeur de Brunswick-Hanovre, qui est en même temps roi d'Angleterre (ibid., p. 124).

372 Scheid se propose lui-même de garder »le milieu entre »les Auteurs, dont une partie éléve trop le pouvoir de la Cour impériale au préjudice de la liberté des Etats de l'Empire; \& l'autre partie, animée par une passion intéressée \& quelquefois malicieuse, veut limiter la Puissance Impériale plus qu'elle ne l'est par les Loix, ou tâche même de faire passer l'Empereur pour un simple administrateur« (ibid., p. 170-171).

373 Ibid., p. 170, n. a).

374 Ibid., p. 171. 
blème de savoir si, l'élection une fois accomplie, la nation garde le droit de déposer l'empereur au cas où celui-ci contreviendrait aux conditions sous lesquelles elle lui a conféré le gouvernement - problème passé ici sous silence par Scheid. Ce sont des questions que les publicistes allemands ont traitées depuis le XVII siècle ou même avant, et il ne suffit pas d'accuser de partialité les auteurs qui ont proposé des solutions à cette contradiction. La relation entre l'empereur et la nation, telle que la présente Scheid, demeure ainsi incohérente surtout si l'on considère que l'auteur refuse explicitement le principe selon lequel »l'Empereur ne sauroit exercer d'autres droits, que ceux qu'il pourroit montrer (prouver) avoir réservés \& gardés expressément«. Il tient en effet pour »maxime générale«: „l'Empereur peut faire tout ce qui dépend de la Puissance souveraine, à l'exception seulement de ce qu'il a communiqué aux Etats de l'Empire, \& où il est obligé, par les Loix fondamentales, d'avoir le consentement des Electeurs ou de tous les Etats pour l'exercer « 375 . C'est la théorie de la communication des pouvoirs aux états de l'Empire, qui ne les possèdent pas iure proprio, théorie défendue au XVII siècle notamment par les publicistes qui se tournaient contre celle de la souveraineté populaire. Le tableau que Scheid, réaliste plutôt que théoricien, dresse ensuite des droits respectifs de l'empereur et des états est toutefois très nuancé, et ne laisse presque rien à désirer.

Rien d'étonnant alors à ce que les »Göttingische Gelehrte Anzeigen« approuvent fortement sa démarche. Consécration s'il en est pour un auteur rédigeant en français un ouvrage sur le droit allemand que d'être applaudi par les Allemands eux-mêmes. Surtout que ce compte rendu reprend exactement (presque littéralement) la critique que Scheid a faite de ses prédécesseurs, soulignant ainsi le caractère indispensable de sa démarche. La partie négative du compte rendu ne renferme que quelques objections »mineures ( ("Kleinigkeiten « ${ }^{376}$ ) concernant notamment le plan de l'ouvrage, le fait d'avoir trop ou, au contraire, pas assez approfondi un certain sujet - un litige juridique particulier opposant les catholiques aux protestants - et certaines erreurs mineures qui ne peuvent manquer dans un ouvrage de cette ampleur (en particulier sur ses allusions au droit médiéval). Selon les apparences, le »Traité sistématique « a été universellement applaudi ${ }^{377}$. Le fait de souligner son »impartialité (»Unpartheylichkeit«) est un leitmotiv dans toutes les parties du compte rendu. On voit donc que Scheid a bien suivi la règle qu'il s'était imposée au début, c'est-à-dire »d'éviter avec soin la décision des points contestés \& des prétentions les plus importantes« et de »rapporter seulement les raisons principales pour $\&$ contre $\ll^{378}$. Cet engagement fait à la fois la force et la faiblesse de son ouvrage.

375 Ibid., p. 173.

376 Cf. Göttingische Gelehrte Anzeigen, année 1751, p. 393.

377 Les »Göttingische Gelehrte Anzeigen« évoquent le »Beyfall den gedachter erster Theil [du Traité sistématique] bey verschiedenen hohen Ministern und anderen erlauchteten Personen gefunden hat «, cf. ibid., année 1752, t. I, p. 303.

378 SCHEID, Traité sistématique, t. I, p. [*8]. 
Outre cette modération dont Scheid fait preuve, son ouvrage est de loin le plus complet qui existe en français au milieu du XVIIIe siècle. Et surtout Scheid a raison de souligner que c'est »le seul, qui puisse être employé à une instruction méthodique « ${ }^{379}$. Son véritable apport consiste donc dans des précisions d'une grande qualité et utilité, dans un tableau méthodique des aspects les plus divers de son sujet, et dans le fait d'avoir créé un véritable instrument de travail facile à consulter sur des points précis: bref, un ouvrage de référence. Pourtant, du point de vue de la philosophie politique, ce n'est qu'un auteur médiocre. Autant que nous puissions en juger, il n'y a dans son traité aucune idée nouvelle, même pas de synthèse originale. C'est par rapport à l'échiquier des idées politiques qu'on voit que Scheid a commencé son ouvrage avant 1740, ou du moins qu'il a gardé l'esprit de cette époque. Tout en reprenant des idées antérieures, certains auteurs qui ont publié aux alentours des années 1740 , tel un Mauvillon ou un Necker, se sont avérés des penseurs beaucoup plus originaux.

Jean-Frédéric Scheid est certainement l'auteur du meilleur ouvrage ${ }^{380}$ systématique sur le droit public allemand jamais publié en français ${ }^{381}$; il est d'autant plus surprenant qu'il ait jusqu'à présent échappé à la renaissance de la réflexion historique sur la Constitution du Saint-Empire telle que la voyaient les auteurs de langue française. Son apport est considérable bien que, comme nous l'avons vu, l'état des connaissances ait déjà été, avant lui, bien meilleur que Scheid ne le suggère lui-même. Du temps de la parution de son ouvrage, la critique l'a vivement salué. S'il n'a pas ensuite obtenu tout le succès qu'il put espérer, et ne connut notamment aucune réédition, c'est probablement parce que, dès 1755 , d'autres ouvrages sur le même sujet virent le jour ${ }^{382}$, sans oublier Pfeffel, qui lui fit concurrence dès 1754 .

\section{Un classique de la littérature française sur l'Empire: Pfeffel}

En 1754, Chrétien-Frédéric Pfeffel publia l'editio princeps de son célèbre »Abrégé chronologique de l'histoire et du droit public d'Allemagne «383. Cette première

379 Ibid., p. [*6'].

380 Le reproche que lui fait Pütter, disant que son ouvrage sent le style de la langue maternelle de Scheid, paraît un peu sévère, cf. PÜTTER, Litteratur des Teutschen Staatsrechts, t. II p. 81. Les »Göttingische Gelehrte Anzeigen« soulignent que le style de Scheid est »größtentheils rein und ungezwungen«, cf. Göttingische Gelehrte Anzeigen, année 1753, t. I, p. 135. ${ }^{381}$ Du moins jusqu'au XXe siècle; signalons la publication, en 1999, d'une traduction française, établie par Michel Senellart, de l'ouvrage fondamental de SToLleIs, Histoire du droit public.

382 À commencer par le "Tableau du gouvernement actuel de l'Empire d'Allemagne«, de Johann Jacob Schmauss, qui était la version française de son »Compendium juris publici«, traduit de l'allemand, avec des notes historiques par Louis Gabriel du Buat-Nançay.

383 PFEFFEL, Abrégé (1754). Ce volumineux livre comporte plus de 720 pages. 
édition est dédiée au comte de Brühl ${ }^{384}$. Le succès que Pfeffel connut se manifeste dans plusieurs rééditions de son ouvrage ${ }^{385}$.

Chrétien-Frédéric Pfeffel était diplomate, juriste et historien. Il était le fils d'un autre célèbre juriste et diplomate alsacien, Jean-Conrad Pfeffel, né à Mündingen, en Bade, en 1682. et mort à Colmar, comme stettmestre de la ville ${ }^{386}$, en 1738. Après ses études de droit, le père avait d'abord représenté le margrave de BadeDurlach à Vienne, avant de s'installer à Strasbourg. Recommandé par le prêteur royal de la ville, Klinglin, et par l'intendant d'Angervilliers, il passa au service de la diplomatie française en 1723. En effet, le cardinal Dubois avait demandé à Schœpflin de lui signaler un Alsacien connaissant à fond le droit public du SaintEmpire. En 1726, on créa pour Jean-Conrad, naturalisé Français en 1725, la charge de jurisconsulte du roi pour le droit public germanique. Ce poste fut rattaché au ministère des Affaires étrangères ${ }^{387}$.

Chrétien-Frédéric Pfeffel naquit à Colmar, en 1726, et mourut à Paris, en 1807, la même année que Johann Stephan Pütter. Les meilleurs connaisseurs du droit public du Saint-Empire décèdent peu après sa dissolution. Pfeffel avait étudié le droit à Strasbourg sous la direction de Schœpflin. Sur la recommandation de ce dernier, il entra au service de la cour de Saxe en 1749, secondant son ambassadeur à Paris, le comte de Loss. Après son rappel, Pfeffel fut chargé de l'éducation à Paris des fils du comte Heinrich von Brühl, qui était le principal ministre de l'électeur de Saxe. Par l'entremise de la dauphine Marie-Josèphe de Saxe, Pfeffel entra au service de la France lorsque l'on cherchait un secrétaire bilingue pour la délégation française auprès de la diète de l'Empire à Ratisbonne. En 1758, il assista à la diète, puis eut un poste dans la délégation française à Munich, où il entra dans la classe d'histoire de l'académie. Il passa au service du duc de Deux-Ponts, qu'il représenta également à Munich. Pfeffel fut aussi nommé stettmestre de Colmar. En 1768, le duc de Choiseul, alors ministre des Affaires étrangères, le rappela à Versailles en qualité de jurisconsulte du roi. Dans un premier temps, Pfeffel était chargé de problèmes concernant les frontières du royaume (droits du roi sur Avignon, question des limites en Flandre). À partir de 1772, à Versailles, il fut intégré dans la division chargée de la correspondance avec l'empereur et les princes de l'Empire. En 1774, il fut nommé principal commis aux Affaires étrangères. Pfeffel collaborait également à la »Gazette de France« et continuait en même temps à travailler pour le duc de Deux-Ponts, auquel il rendit de précieux services, surtout au moment de la crise de la succession de Bavière. Après la Révolution, Pfeffel

${ }^{384} \mathrm{Cf}$. ibid., ici l'»Epitre Dédicatoire« au comte de Brühl, qui, à l'époque, était le premier ministre d'Auguste III, roi de Pologne et électeur de Saxe, quatre pages non paginées, après le frontispice.

385 En 1758, en 1766, sous la direction du père Barre, et enfin en 1776 et en 1777, intitulé "Nouvel Abrégé «.

386 À ce sujet, cf. AE, MD Alsace 37 fol. 383-391' (plusieurs lettres concernant la candidature de Pfeffel, en partie citées par ULBERT, Les Affaires étrangères françaises, p. 223 [notes]).

${ }^{387}$ Cf. Gabriel Braeuner, article "Pfeffel, Jean Conrad», dans: NDBA, t. 29 (1997), p. 2982. La création du poste remonte à 1723 selon ULBERT, Les Affaires étrangères. 
s'installa à Deux-Ponts, puis à Mannheim. En 1801, Talleyrand le rappela au ministère des Affaires étrangères et Pfeffel continua à servir Napoléon. Il mourut en $1807^{388}$.

Quand, en 1754, Pfeffel publia son »Abrégé«, il était encore au début de sa grande carrière ${ }^{389}$. Néanmoins, cet ouvrage est sa principale publication. Cela s'explique, entre autres raisons, par son activité diplomatique intense, qui lui laissait peu de temps pour ses occupations littéraires. Malgré cela, Pfeffel s'était constitué une bibliothèque très importante et surtout utile pour les questions du droit public allemand. Le ministère des Affaires étrangères acquit des ouvrages provenant de cette bibliothèque en partie du vivant de Pfeffel, en 1768, en partie après sa mort, de sa veuve, en $1807^{390}$.

La deuxième édition de l'»Abrégé" parut quatre ans après la première, cette fois-ci à Mannheim ${ }^{391}$. Cette édition contient une dédicace, signée Nicolas de Pierron, qui est adressée à l'électeur. Pierron se dit lui-même "Conseiller à la Chambre des finances «392. Il prétend n'avoir »rien négligé pour rendre cette nouvelle édition digne de l'ouvrage qu'on regarde comme un des meilleurs en ce genre ${ }^{393}$. Il fait à la fois, le louange, du livre de Pfeffel et de Mannheim comme lieu privilégié et florissant de l'édition, au moment même où la guerre de Sept Ans ravage de nombreuses contrées en Allemagne et en Europe.

Un »Avertissement« qui n'est pas signé, mais qui doit être attribué à Pfeffel, explique les différences qu'il y a dans cette édition par rapport à la première. L'auteur dit avoir scrupuleusement revu le texte et les dates de l'édition de Paris et

388 Cf. Gabriel BraEunER, article »Pfeffel, Chrétien Frédéric«, dans: NDBA, t. 29 (1997), p. 2982-2983; cf. également Ludwig BERGSTRÄSSER, Christian Friedrich Pfeffels Tätigkeit im französischen Dienste, 1758-1784, Heidelberg 1906; Jacques HENRI-RoBERT, Chrétien Frédéric Pfeffel, stettmeister de Colmar, jurisconsulte et diplomate de Louis XV à Napoléon, dans: Annuaire de la Société historique et littéraire de Colmar XXVII (1978), p. 69-74.

389 Très certainement, la rédaction du livre fut terminée au plus tard début 1754 , puisque l'approbation date du 31 mars 1754 et le privilège royal du 1er mai. Cf. PFEFFEL, Abrégé (1754), approbation et privilège du roi, deux pages non paginées, avant la p. [1].

390 Malheureusement, il n'existe aucun inventaire de ces acquisitions. Nous remercions la bibliothèque du ministère des Affaires étrangères de nous avoir permis, en 2004, de consultater des livres qui proviennent certainement ou éventuellement de l'ancienne bibliothèque de Pfeffel. Les ex-libris permettent de les identifier avec certitude dans certains cas seulement. Malgré ces difficultés, nous pouvons conclure que très certainement des dizaines, plus probablement des centaines d'ouvrages allemands et latins concernant le droit et l'histoire d'Allemagne sont entrés dans la bibliothèque du ministère grâce à Pfeffel.

${ }^{391}$ PFefFel, Abrégé [...], Mannheim ${ }^{2}$ 1758. Selon l'»Avertissement « de l'édition de 1766, cette deuxième édition daterait de 1759, et non pas de 1758; le frontispice de l'exemplaire consulté (voir bibliographie) confirme cependant la datation avancée par les catalogues de la BNF et du British Museum (cf. le Catalogue général des livres imprimés de la Bibliothèque nationale, t. 135 [1936], col. 668-669, ici col. 668), qui est encore confirmée par l'édition de 1777 de l'ouvrage, cf. PFefFel, Abrégé (1777), p. V.

392 Pfeffel, Abrégé (1758), dédicace, p. [vj]. Malheureusement, nous ne disposons pas de connaissances biographiques plus précises.

393 Ibid. 
avoir »retouché le stile dans les endroits qui en avoient le plus besoin « 394 . Mais à part ces corrections mineures, Pfeffel dit surtout avoir »retranché [...] bon nombre d'articles, qui ne m'ont plus paru appuyés d'une autorité irréprochable « et y avoir »substitué d'autres dont j'étois plus certain «, et enfin avoir »multiplié considérablement les remarques relatives au Droit public d'Allemagne «395. Pfeffel répond en particulier à la critique que les auteurs du »Journal de Trévoux " ont faite de l'édition de $1754^{396}$. Ces remarques ne concernent toutefois que des points précis du droit et de l'histoire médiévale. Il s'agit surtout d'interrogations sur la fiabilité de certaines sources. Parfois, Pfeffel admet des erreurs, par exemple d'avoir repris »une piece forgée par un faussaire « de Goldast ${ }^{397}$. Parfois, il insiste sur les positions qu'il a défendues dans la première édition; c'est le cas du terme "ministerialis « qu'il a traduit, chez Otton de Freising, par »petite noblesse" tandis que le »Journal de Trévoux « veut qu'il le traduise par »artisans«. Se fondant sur Albert Krantz, historien allemand du XVe siècle, et sur d'autres témoignages, il prouve que »le terme de ministerialis n'a jamais eu d'autre sens en $\mathrm{Al}$ lemagne que celui d'arriere-Vassal ou de Serf-Noble «398. En revanche, Pfeffel s'est »conformé avec bien du plaisir au sentiment de M. Schoepflin [...] dans les leçons \& le commerce duquel je fais gloire d'avoir puisé toutes les connoissances, que je puis avoir de l'Histoire \& du Droit public d'Allemagne $\ll 399$.

Comme nous l'avons déjà dit, cet ouvrage connut plusieurs rééditions. Nous analyserons ici la première édition de l'»Abrégé « (la seule parue avant 1756) ${ }^{400}$. Les trois premières périodes vont jusqu'à Pépin le Bref: la première période contient les »Antiquités Germaniques« et se termine par la victoire de César sur Arioviste $^{401}$; la deuxième, qui commence avec César, se termine au milieu du III ${ }^{e}$ siècle; la troisième période va de l'établissement des Francs en Gaule à Pépin. La quatrième époque est celle des "Rois de France \& d'Allemagne, de la race des Carlovingiens«. La cinquième, celle des rois et des empereurs de la maison de Saxe. La sixième regarde les empereurs de la maison de Franconie. La septième

394 Cf. ibid., p. vij-xij, citation p. vij.

395 Ibid.

396 Les Mémoires ou le Journal de Trévoux, plus exactement »Mémoires pour servir à l'histoire des sciences et des arts«, périodique français créé par les jésuites, en 1701, et connu pour ses critiques d'ouvrages français et étrangers, notamment dans le domaine de l'histoire et de la théologie, avec une préférence pour les publications latines, cf. Marc MARTIN, article "Trévoux «, dans: François Bluche (dir.), Dictionnaire du Grand Siècle, Paris 1990, p. 1535-1536. Pour certains comptes rendus concernant l'Allemagne, cf. le dernier chapitre. 397 PFEFFEL, Abrégé (1758), p. ix; tout en reconnaissant que la pièce n'est pas authentique, Pfeffel pense quand même ne pas devoir changer son opinion à l'égard des donations faites au Saint-Siège. Il s'agit d'une constitution du pape Léon VIII qu'il avait rapportée dans sa première édition, cf. PFEFFEL, Abrégé (1754), p. 117.

398 PFefFel, Abrégé (1758), p. X.

399 Ibid., p. xj.

400 Comme les autres éditions ont paru bien après 1756, nous nous limiterons à certaines remarques sommaires à ce propos.

401 PFEFFel, Abrégé (1754, comme dans tous les cas où l'année de l'édition à laquelle nous nous référons n'est pas précisée), p. 1. 
concerne ceux de la maison de Souabe. La huitième période est celle des empereurs des maisons de Habsbourg, de Luxembourg et de Bavière; elle commence en 1273, avec le règne de Rodolphe Ier, non seulement premier souverain de ce nom, mais aussi premier comte de Habsbourg à accéder à l'Empire, et se termine à la fin du règne de Sigismond, en 1437. La neuvième période est entièrement consacrée aux empereurs de la maison d'Autriche ${ }^{402}$, depuis Albert II (élu empereur en 1438) jusqu'à la mort de Charles VI. L'histoire du droit public allemand après 1740 n'est pas abordée par Pfeffel.

On peut tirer plusieurs conclusions à propos de l'organisation de l'œuvre du célèbre historien et juriste alsacien: l'»Abrégé« de Pfeffel est un ouvrage qui suit scrupuleusement la chronologie, d'abord les règnes des souverains, puis les années de ceux-ci; souvent, le texte est réparti sur plusieurs colonnes qui fournissent des informations sur différents aspects. Par exemple, il donne les noms, avec des informations supplémentaires, des archichanceliers, des vice-chanceliers, des ducs et des historiens ou autres hommes illustres ${ }^{403}$. Son $\gg$ Abrégé $\ll$, si riche en informations présentées d'une manière si claire ${ }^{404}$, se révèle ainsi, notamment, une initiation aux sources historiographiques de l'Allemagne médiévale et moderne $^{405}$.

En rédigeant son ouvrage, Pfeffel suivait le modèle de l'histoire de France par Hénault, comme il l'explique lui-même dans l'»Avertissement« de son »Abrégé chronologique ${ }^{406}$. Mais Pfeffel ne renonce pas pour autant à un examen analytique des différentes époques, et, notamment, il réunit systématiquement des informations sur un certain problème du droit tel que la condition juridique des états de l'Empire ou la position de l'empereur à une certaine époque.

Cependant, il faut bien noter que presque chaque changement de dynastie coïncide avec la transition d'une époque à une autre, et notamment que le temps présent commence, pour Pfeffel, très précisément en 1740, l'année où la lignée tricentenaire des empereurs de la maison d'Autriche s'interrompt et où Pfeffel termine son »Abrégé«. La pensée historique de Pfeffel s'oriente plus vers les dynasties que vers les siècles ${ }^{407}$. Dans une monarchie élective mais attachée depuis très

${ }_{402}$ Pour les titres des différentes parties, cf. ibid., p. 3, [7], [17], [67], [115], [169], [246], [332].

${ }^{403}$ Cf., par exemple, ibid., p. 105.

${ }^{404}$ Cependant, plus Pfeffel s'approche de sa propre époque, plus l'information devient dense et plus la répartition synoptique tend à disparaitre. Si le récit des événements retenus comme remarquables s'allonge de plus en plus, Pfeffel n'abandonne pourtant pas complètement la manière commode de la répartition des autres informations sur plusieurs colonnes. ${ }^{405}$ En effet, pour le Moyen Âge, non seulement Pfeffel énumère les historiens médiévaux qui ont écrit sur cette période, mais il signale, quand il parle par exemple des événements des années 1259-1261, outre les historiens plus ou moins contemporains des faits (Matthieu Paris et la Chronique de Padoue), aussi un historien moderne, comme Gundling, cf. PFEFFEL, Abrégé, p. 235. Durant la période moderne, Pfeffel cite assez exhaustivement les historiens modernes (cf. les nombreux historiens et jurisconsultes cités p. 555), ne se restreignant point aux seuls Allemands, mais citant aussi un Français, comme de Thou (ibid., p. 451).

$406 \mathrm{Cf}$. ibid., avertissement, deux pages non paginées au début du volume.

${ }^{407}$ Sur l'origine des siècles comme référence historiographique, cf. Johannes BURKHARDT, 
longtemps à une seule maison, cela sert à comprendre pourquoi les auteurs allemands aussi bien que français perçurent l'avènement d'un empereur non autrichien comme une rupture majeure dans l'histoire de l'Empire.

Parmi les événements les plus remarquables, on trouve bien évidemment la paix de Westphalie ${ }^{408}$. Il va sans dire qu'elle revêt aussi aux yeux de Pfeffel un intérêt majeur dans l'histoire constitutionnelle du Saint-Empire et de l'Europe tout entière, puisque ces traités »sont aujourd'hui le Code politique \& la principale des loix fondamentales de l'Empire Germanique «409.

Contrairement à une grande partie des historiens et des juristes de langue française qui ont écrit sur le Saint-Empire, Pfeffel ne reproduit pas de documents intégraux en annexe de son »Abrégé«; il donne toutefois un extrait de la capitulation impériale de Charles VI (1711) 410 . Il n'y énumère cependant que très brièvement les trente-huit promesses que l'empereur fait à tous les états de l'Empire en général, au collège des électeurs en particulier, et au corps des états de l'Empire assemblés à la diète. Cependant, cet auteur résume de manière précise les principales clauses des lois fondamentales du Saint-Empire (telles que la Bulle d'or, la Paix publique de l'Empire de 1495, les capitulations impériales depuis Charles Quint, l'Interim d'Augsbourg de 1548) ainsi que les traités de paix (de Westphalie, de Ryswick, etc.). Par ailleurs, on note que Pfeffel est conscient des problèmes terminologiques que la rédaction d'un ouvrage français sur le droit public allemand peut poser. Tiraillé entre la précision terminologique et le bon usage de son siècle, Pfeffel choisit de respecter scrupuleusement les tournures employées dans les sources, au détriment de la beauté de son style ${ }^{411}$. Tout en traduisant en bon français certains termes du droit public germanique, il cite également le concept spé-

Die Entstehung der modernen Jahrhundertrechnung. Ursprung und Ausbildung einer historiographischen Technik von Flacius bis Ranke, Göppingen 1971 (Göppinger akademische Beiträge, 43); pour le concept du »siècle« à l'âge baroque et au siècle des Lumières, cf. aussi Braun, Von der politischen zur kulturellen Hegemonie, p. 126-128.

408 Cf. PrefFel, Abrégé (1754), p. 530-536. Dans l'édition de 1758, l'année 1648 et les traités de Westphalie sont rapportés p. 756-763.

409 Cité d'après l'édition de 1754, p. 530-531; texte identique dans l'édition de 1758 , p. 757.

410 Cf. PfeFrel, Abrégé (1754), p. 670-672; dans l'édition de 1758, p. 921-924.

411 Cf. Pferfel, Abrégé (1754), avertissement, deux pages non paginées au début du volume: "J'ai indiqué dans une colonne particuliere [les écrivains] que j'ai consultés sur chaque Empereur: si l'on veut se donner la peine de les conférer, on remarquera que m'étant assujéti à prendre leurs propres paroles, j'ai été, pour ainsi dire, contraint de commettre bien des fautes contre la pureté du langage. Il eut été difficile à un Auteur François de ne pas s'écarter de la justesse de sa Langue, si, comme moi, il se fut appliqué à traduire le Latin barbare des anciens Annalistes, \& l'Allemand diffus \& embrouillé des Historiens modemes: ma qualité d'Etranger mérite donc quelqu'indulgence«. Cf. également PFEFFEL, Abrégé (1766), "Avertissement«, deux pages non numérotées au début du premier tome: "il ne m'auroit pas été possible, dans les circonstances où je me trouve, de remédier aux négligences $\&$ aux fautes de langage, quand même j'en eusse été capable. Cet aveu ingénu mérite sans doute quelqu'indulgence; \& ma qualité d'Alsacien, élevé \& continuellement employé en Allemagne, me donne un titre de plus pour la demander $\ll$. 
cifique utilisé par les juristes allemands, par exemple quand il parle des »droits de la Souveraineté appellée en Allemagne supériorité territoriale «12.

À la fin de chaque période, ou presque, Pfeffel ajoute des remarques qui montrent l'évolution des droits respectifs qui revenaient soit à l'empereur soit aux états de l'Empire durant la période concernée ${ }^{413}$. C'est ainsi qu' au cours du règne des Othons, Pfeffel met encore au nombre des droits de l'empereur celui de »confirmer \& de casser l'élection des Papes«. Les empereurs pouvaient aussi »disposer en Souverains de l'Italie«, conférer les fiefs, et avaient »généralement parlant tous les autres droits de Souveraineté, à l'exercice desquels les Etats ne pouvoient concourir «. Toutefois, Pfeffel considère que, à cette époque, les états de l'Empire jouissaient déjà du droit de légiférer, de déclarer la guerre et de conclure la paix, d'envoyer des ministres aux princes étrangers, etc. ${ }^{414}$, en somme des droits qui ne leur furent confirmés que par la paix de Westphalie. Par contre, Pfeffel pense que, vers 1410 , Robert Ier avait déjà achevé »d'établir la souveraineté des Princes d'Allemagne«, puisque, les empereurs ayant "conservé le droit de haute justice dans les terres de plusieurs Seigneurs«, cet empereur »leur céda ce droit par des priviléges particuliers $\aleph^{415}$.

Enfin, selon Pfeffel, la période des empereurs de la maison d'Autriche, qui commença à la mort de Sigismond, »vit monter à son comble la souveraineté des Princes d'Allemagne, \& la liberté du Corps Germanique«. Cependant, l'auteur croit qu'en 1437 les ordres avaient déjà joui des mêmes droits qu'ils exerçaient encore au milieu du XVIII siècle, »les Capitulations des Empereurs \& la paix de Westphalie n'ayant fait que légitimer \& rendre universels les droits que les Etats de l'Empire avoient usurpés ou reçus des Empereurs « ${ }^{416}$. Pour Pfeffel, la véritable nouveauté de cette période des empereurs de la maison de Habsbourg était la constitution des trois collèges des électeurs, des princes et des villes. Durant cette période (du moins dans un premier temps), le rapport de force fut modifié par les électeurs au détriment des autres états, alors que la formation des États territoriaux profitait aux princes. La puissance des villes augmenta également jusqu'à ce qu'elles obtinssent le droit de vote décisif à la diète. Pfeffel rappelle aussi que même chaque membre de la noblesse de l'Empire, qui n'est pas représentée à la diète, »exerce dans ses terres à peu près les mêmes droits de souveraineté dont l'Electeur le plus puissant peut jouir dans son Electorat $\ll^{417}$.

412 Pferfel, Abrégé (1754), p. 70. Ce concept est mis en italique par Pfeffel. Cf. aussi son résumé de la Bulle d'or, ibid., p. 296-297, ici p. 296: „On confirme aux Electeurs tous les droits de la souveraineté, appellée Supériorité territoriale«. On peut également constater que, dans l'index de son livre, s.v. „Supériorité territoriale«, Pfeffel renvoie son lecteur à "Souveraineté des Princes d'Allemagne« (ibid., p. 716).

413 Cf., par exemple, ibid., p. 113-114, 392-393, 434-435, 514-515.

414 Cf. ibid., p. 113 (citations) et 114.

415 Ibid., p. 317.

416 Ibid., p. 330.

417 Cf. ibid., p. 330 et 331 (citation). 
Tout en concédant que jusqu'au règne de l'empereur Maximilien ler le SaintEmpire n'avait presque pas de lois fondamentales, à l'exception de la Bulle d'or et des concordats, et qu'avant Charles Quint aucun empereur n'avait dû signer une capitulation impériale "resserra[nt] la puissance [impériale] en des bornes fixes«, Pfeffel estime qu'au moment de sa mort, en 1519, les états de l'Empire disposaient de »Tous les droits de la Souveraineté, excepté celui d'établir des péages nouveaux «, et que »dès le regne de Rodolphe de Habsbourg, il ne manquoit plus rien ou très-peu de chose à la supériorité territoriale des Etats«, l'empereur se trouvant »réduit dès lors au rang de Président d'une assemblée de Souverains $« 418$.

Selon Pfeffel, les droits des électeurs et des autres états de l'Empire pendant le règne de Charles Quint »montre[nt] à la fois la décadence de l'autorité impériale \& l'aggrandissement de celle des Electeurs «. Comment Pfeffel peut-il aboutir à ces conclusions? On s'aperçoit qu'il explique littéralement la capitulation impériale de Charles Quint, alors qu'on savait, au milieu du XVIII siècle, que de nombreuses clauses de cette capitulation n'avaient pas été respectées par cet empereur. C'est la raison pour laquelle Pfeffel interprète mal l'autorité de Charles Quint. En revanche, il a raison de souligner la montée en puissance des électeurs. Pfeffel estime même que la période de l'histoire du droit public en Allemagne qui finit à la mort de Ferdinand II peut être nommée »la Période des Electeurs«. En effet, au cours de la guerre de Trente Ans, de facto, les assemblées du collège électoral avaient décidé seules, avec l'empereur, des grandes orientations de la politique dans l'Empire, alors que la diète ne fut plus convoquée, si ce n'est qu'après la mort de Ferdinand II. Par la paix de Westphalie, la position des états de l'Empire en général fut renforcée au détriment de celle des électeurs en particulier, notamment dans le domaine de la législation. Pfeffel estime que, depuis Charles Quint, les électeurs »avoient été les Législateurs suprêmes de l'Empire: ils prescrivoient seuls aux Empereurs leurs capitulations, \& n'oublioient pas d'y stipuler en leur faveur les prérogatives les plus brillantes. Leur consentement étoit nécessaire dans toutes les affaires, \& souvent il suppléoit à celui de tous les autres Etats « ${ }^{419}$. Toutefois, ces derniers purent recouvrer successivement au moins une partie des prérogatives que les électeurs s'étaient arrogées ${ }^{420}$.

En général, on constate que Pfeffel surestime la valeur des capitulations impériales. $\mathrm{Si}$, en 1711, au début du règne de Charles VI, les capitulations étaient respectées plus scrupuleusement qu'en 1519, elles ne fixaient toujours que la norme juridique, qui, le cas échéant, pouvait différer de la réalité constitutionnelle. Pourtant, Pfeffel estime que la capitulation de Charles VI lui »fournit les traits principaux « du droit public de l'Allemagne sous cet empereur ${ }^{421}$.

418 Citations ibid., p. 391, 393. Cf. p. 392-393 pour un tableau des différents droits des empereurs, des électeurs ainsi que des princes et des villes.

419 Cf. ibid., p. 434, 435 (première citation) et 514 (citations suivantes).

420 Cf. ibid., p. 435.

421 Ibid., p. 669. 
En remplaçant l'analyse des droits respectifs des différentes institutions constitutionnelles du Saint-Empire par un catalogue contenant seulement les obligations de l'empereur, Pfeffel fut induit à décrire le Saint-Empire comme une confédération d'États souverains et l'empereur comme le simple président de la république qu'ils formaient.

\section{Les traductions françaises des auteurs allemands: l'exemple du »Tableau du gouvernement actuel de l'Empire«, de Schmauss}

Parmi les traductions françaises de publicistes et d'historiens allemands, il faut signaler la version publiée, en 1755, du »Tableau du gouvernement actuel de l'Empire d'Allemagne «, de Johann Jacob Schmauss ${ }^{422}$. En effet, Schmauss est un des grands publicistes de l'Empire de la seconde moitié du XVIII' siècle; il fut notamment professeur à l'université de Göttingen, qui jouissait d'une très bonne renommée 423 .

Dans le domaine de l'histoire de l'Empire, Schmauss, qui avait enseigné le droit de 1721 à 1734 , »représentait la figure la plus en vue «24. Après 1734 , il se mit à enseigner l'histoire de l'Empire et celles des États européens, le droit constitutionnel germanique et le droit public territorial ainsi que le droit des gens. Sa philosophie du droit s'accordait avec Thomasius, mais s'opposait à Christian Wolff. Ses écrits témoignent des positions politiques libérales de l'auteur ainsi que de son indifférence religieuse et de son positivisme juridique. Stolleis estime que »Schmauss était assez proche du portrait idéal du professeur de droit tracé par Münchhausen ${ }^{425}$ : il alliait en effet la théorie et la pratique, possédait une solide culture historique, cultivait le droit naturel et - ce qui attirait sans doute le plus les étudiants - enseignait >le nécessaire et l'utile< avec un grand talent pédagogique, ainsi que le droit des gens et l'histoire des États européens, disciplines particulièrement intéressantes pour les nobles « 426 .

En 1746, Schmauss publia pour la première fois son »Tableau du gouvernement actuel de l'Empire d'Allemagne«, en langue allemande, sous le titre de »Compendium iuris publici Sacri Romani Imperii . Dans l'Empire, le livre fut réédité en 1751, en 1754, en 1766 (édition mise à jour par J. H. Ch. von Selchow)

422 Schmauss, Tableau du gouvernement.

423 Pour sa biographie et son cuvre, cf. PüTrER, Litteratur des Teutschen Staatsrechts, t. II, p. 5-9; STOLLEIS, Geschichte des Öffentlichen Rechts, t. I, p. 311-312 et passim; ID., Histoire du droit public, p. 468-469 et passim.

424 Ibid., p. 468.

425 Gerlach Adolph Freiherr von Münchhausen (1688-1770), l'un des fondateurs du droit public à l'université de Göttingen.

426 STOLleIS, Histoire du droit public, p. 469. 
et en $1782^{427}$. La version originale était aussi connue en France ${ }^{428}$. Mais, sans aucun doute, le public français consulta surtout la traduction française de $1755^{429}$.

Un deuxième frontispice précise les trois principaux objets de l'ouvrage; il est divisé en trois livres, qui contiennent respectivement un tableau général du SaintEmpire »considéré dans son Chef \& dans ses Membres«, un tableau du »Gouvernement général de tout l'Empire « et un autre du "Gouvernement particulier des Provinces de l'Empire par les Etats «. Cet ouvrage comprend, en outre, treize appendices, qui donnent différentes listes des états de l'Empire ${ }^{430}$. L'ouvrage de Schmauss s'adresse au public universitaire, en particulier aux jeunes étudiants de droit, que cet auteur veut initier à leurs études ${ }^{431}$; ce »Tableau« lui doit servir dans ses cours. Cet objectif lui impose à la fois la clarté et la brièveté, au détriment de l'exhaustivité et de l'érudition; son but, qui doit strictement respecter le curriculum universitaire, est de fournir à ses étudiants (et à ses lecteurs) les moyens de poursuivre indépendamment leur étude du droit public allemand ${ }^{432}$. L'ouvrage composé par Schmauss n'est donc pas une œuvre qui répond à toutes les questions des spécialistes, mais un livre à l'usage des étudiants, qui cherche à leur apprendre les principes du droit plutôt que les détails de chaque problème particulier ${ }^{433}$. Afin de donner un fil directeur à son ouvrage, l'auteur »établit pour fondement du Gouvernement général de l'Empire la Majesté Impériale \& les Droits qui découlent de la Majesté«. Il observe le même principe à l'égard de »la Régence particuliere des Seigneurs Territoriaux «, considérant leur »supériorité Territoriale « comme "l'Emule de la Majestéর. Fidèle à l'esprit des juristes allemands de l'époque, Schmauss a pris soin de fonder son argumentation sur l'interprétation des lois de l'Empire, en particulier la capitulation de François Ier, qu'il qualifie d'»Abrégé authentique de Droit public « ${ }^{434}$.

La version française de ce »Compendium «, publiée en $1755^{435}$, a été établie par

${ }^{427}$ Cf. ID., Geschichte des Öffentlichen Rechts, t. I, p. 311-312, n. 110; ID., Histoire du droit public, p. 469, n. 110.

428 L'original allemand a paru sous le titre: Johann Jacob Schmauss, Hofraths und Professoris Juris Ordinarii zu Gơttingen Compendivm ivris pvblici S.R.I. zum Gebrauch der academischen Lectionen verfasset. [...] Mit kurzen Anmerkungen versehen von Johann Christian von Selchow, Göttingen ${ }^{4} 1766$.

429 Le même auteur publia un autre ouvrage très important: Corpus juris publici S. R. Imperii academicum [...], Leipzig 1745; autre édition ibid., 1774. Au sujet de cet ouvrage (sept éditions successives de 1730 à 1794), cf. STOLLEIS, Geschichte des Öffentlichen Rechts, t. I, p. 309; ID.. Histoire du droit public, p. $464-465$.

430 Schmauss, Tableau, p. 379-402.

431 Cf. la préface de l'auteur, reproduite au début de la version française, ScHMauss, Tableau, p. [V]-XIV, à la fin datée »A Gottingen le 25. Mars 1746«.

432 Cf. ibid., p. VJ-VIJ.

433 Pour ses objectifs, cf. ibid., p. VIIJ-IX: il s'intéresse seulement aux »principes« du droit public et à leurs "principales conséquences«.

434 Cf. ibid., p. XIJ-XIV, citation p. XIJ-XIIJ.

435 La rédaction de cette version française était évidemment déjà terminée en 1754; cf. l'»Approbation «, datée »à Versailles le 22. Mai 1754«, et signée »Tercier«, ibid., p. [XLIV]; le privilège du roi, p. [XLIV]-[XLVIII], en date du 25 novembre 1754; et les autres pièces 
le comte Louis-Gabriel du Buat-Nançayy ${ }^{436}$. Cet auteur est aussi connu pour d'autres travaux. Il publia plusieurs livres sur l'histoire ancienne des peuples de l'Europe, en particulier sur l'origine de la France, de l'Allemagne et de l'Italie. Du Buat travaillait également sur les principes du gouvernement monarchique et sur l'administration des finances en France. Son activité littéraire commença en 1755 avec sa première publication, la traduction du »Compendium «, et se termina en 1785.

Louis-Gabriel du Buat-Nançay naquit en 1732 à Tortisambert, dans le Calvados. Comme Le Coq, il était donc Normand. À la fin des années 1740, il entama une carrière de diplomate. En 1749, il assista à la diète de Ratisbonne comme attaché d'ambassade. Revenu à Paris, en 1752, il fut chargé des affaires des cours du Nord. En 1755, il fut nommé ministre résident à Munich, puis auprès de la diète de l'Empire, et épousa une Allemande. Il termina sa carrière comme résident auprès de l'électeur de Saxe, à partir de 1772 , et prit sa retraite en 1775 , pour s'installer à Nançay, près de Vierzon, sur une terre achetée en 1765 . Il mourut à Salbris, en Loir-et-Cher, en $1787^{437}$.

Dans l'»Avertissement« du traducteur du »Compendium«, du Buat-Nançay explique les principes qui ont guidé sa traduction ${ }^{438}$. Son idéal est la traduction littérale, quitte à employer des termes techniques qui ne sont pas usuels en français ${ }^{439}$. En effet, on voit qu'il utilisait de temps en temps des expressions qui n'étaient pas consacrées par le bon usage. Par exemple, il parle de »droit privatif «, de »Seigneurs Territoriaux «, de »supériorité Territoriale «, etc. 440 . Ce traducteur a aussi inventé une bonne traduction du terme allemand »Kreisausschreibende Fürsten «, qui posait souvent problème aux traducteurs français; du Buat-Nançay le traduit par »Princes Convocateurs «441. Cependant, il a enlevé une partie des citations de la capitulation impériale que Schmauss avait fréquemment insérées dans

concernant l'enregistrement du privilège et sa cession à la veuve Bordelet, p. [XLVIII], qui datent toutes de la fin novembre 1754.

436 Catalogue général des livres imprimés de la Bibliothèque nationale, t. 165 (1943), col. 1086: »Une main contemporaine a ajouté le nom du traducteur: Le chevalier de Buat. - Par le comte L.-G. Dubuat Nançay, d'après Barbier «.

437 Cf. CIORANESCU, Bibliographie de la littérature française du dix-huitième siècle, t. I, p. 712; Roman D'AMAT, article »Du Buat-Nançay (Louis-Gabriel)«, dans: Dictionnaire de biographie française, t. XI (1967), col. 1098.

438 Pour sa traduction, cf. l'avertissement du traducteur dans Schmauss, Tableau, p. XVXXXVJ, notamment p. XXXIV-XXXVJ. Sa datation "A Paris ce premier Janvier 1745« (ibid., p. XXXVJ) est très certainement erronée, étant donné que le livre parut en 1755.

439 Cf. ibid., p. XXXIIJ-XXXIV: »peu s'en faut qu'elle [sa traduction] ne soit littérale, \& le Lecteur aura lieu de s'en appercevoir. Pour conserver à mon Original toute sa précision, $\&$ ne pas m'embarrasser dans des circonlocutions continuelles, j'ai employé plusieurs mots consacrés dans le François que parlent les Allemans \& les Négociateurs: tels sont ceux d'Alterner, Comitial, Publiciste \& Réversale, \&c. «.

440 Ibid., passim (par exemple, dans la table des matières, p. XLJ).

441 Ibid., p. 398. 
son ouvrage ${ }^{442}$. En traduisant les autres citations, du Buat-Nançay a suivi la traduction de la »Capitulation harmonique«. Malgré son souci de précision, il s'est permis "quelques légers changemens", estimant que dans un ouvrage didactique la traduction partielle d'une loi n'avait pas la même valeur que dans une édition intégrale ${ }^{443}$. Du Buat-Nançay considère la version française de la »Capitulation harmonique« de Müldener comme »un modele parfait« du deuxième type de traduction, modèle »qui peut-être ne sera jamais suivi« ${ }^{444}$.

Si Schmauss fut traduit en français, cela ne veut pas dire que les Français étaient toujours d'accord avec son interprétation de la Constitution impériale. Même son traducteur, du Buat-Nançay, manifeste parfois son désaccord avec les idées de Schmauss. C'est notamment le cas du droit des sujets à s'engager dans le service de princes étrangers: "Les Seigneurs Territoriaux, selon Schmauss, peuvent à bon droit ôter aujourd'hui à leurs Sujets l'ancienne liberté Allemande, qui consistoit à aller servir chez les Puissances Etrangeres«. À cette assertion, du Buat-Nançay réplique: »Je ne crois pas qu' aucune Puissance de l'Europe tombe d'accord de ce principe, ni consente à son application «, contraire (selon lui) au droit public de l'Empire 445 .

Mais, malgré ce désaccord partiel, le fait que l'ouvrage de Schmauss ait été traduit en français indique que sa lecture était jugée utile par les lecteurs français, que la manière didactique de Schmauss de présenter son sujet correspondait à leurs besoins et que les Français appréciaient son interprétation du système juridique du Saint-Empire.

Schmauss défend résolument l'idée de l'unité du Saint Empire romain germanique. En effet, dans le troisième chapitre de son ouvrage, il définit la Constitution générale de l'Empire de la manière suivante:

Toutes les Provinces qui appartiennent à l'Empire, si l'on en excepte le Cercle de Bourgogne, lui sont incorporées, \& font ensemble un seul Etat \& un seul Corps. Ce Corps est composé d'un Chef \& de plusieurs Membres. La Majesté suprême \& indivisible de l'Empereur comme Chef est le lien qui en fait une seule Cité régie par un seul Gouvernement ${ }^{446}$.

Mais Schmauss concède que les états de l'Empire exercent dans leurs territoires une autorité particulière, bien qu'ils dépendent de l'Empire et de l'empereur:

Sous cette autorité suprême \& générale que l'Empereur exerce sur l'Empire en Corps, il s'exerce dans les Provinces ou Territoires une autorité particuliere, dont sont dépositaires les Etats de l'Empire en qualité de Supérieurs Territoriaux. Rélativement à l'Empereur \& à l'Empire en Corps, ils sont Sujets, Etats \& Membres. Rélativement aux Pays qui leur sont

442 Cf. ibid., p. XXXIV: elles »rendoient son Traité languissant sans le rendre plus instructif«.

443 Cf. ibid., p. XXXV: »Quand on traduit des Loix originales, le moindre mot, une inversion, doivent être transportés de l'Original dans la Traduction, parce que tout y porte coup, tout peut être appliqué de mille manieres différentes; au-lieu qu'un passage transporté dans un Traité Didactique n'y a d'application que celle à laquelle il s'y trouve déterminé «.

444 Cf. ibid., p. XXXV-XXXVJ.

445 Ibid., p. 378 et n. a.

446 Ibid., p. 16-17. 
soûmis, ils sont Princes régnans. Rélativement à leur Etat, leur Religion, leur dignité \& leur puissance, ils reçoivent un grand nombre de modifications différentes ${ }^{447}$.

Le droit public allemand est donc divisé en plusieurs branches, puisque le SaintEmpire a une particularité qui fait que, outre le droit public de l'Empire, »il s'y trouve plusieurs Territoires qui ont leurs Souverains particuliers, \& ces Souverains ont aussi un Droit public particulier «448. Or, les états de l'Empire participent aussi au gouvernement général, puisque l'empereur ne peut pas exercer tous les droits qui lui reviennent sans le concours des ordres ${ }^{449}$. Nous pouvons donc constater qu'en France, encore à la fin de la période que nous étudions, on pouvait avoir une connaissance de l'Empire, qui était plus proche de l'idée du »ReichsStaat«, soutenue de nos jours par Georg Schmidt, que des thèses des souverainistes, qui considéraient les États territoriaux comme véritablement souverains ou quasi-souverains.

\section{Premières conclusions: l'image de l'Empire chez les auteurs français ou écrivant en français de 1740 à 1756}

L'hétérogénéité des auteurs analysés dans ce chapitre nécessite un premier résumé des conclusions auxquelles nous sommes arrivés. Nous avons estimé que Jean-Frédéric Scheid est l'auteur du meilleur ouvrage systématique sur le droit public allemand publié en français, mais que, pour plusieurs raisons, il n'a probablement pas exercé d'influence majeure sur la vision de l'Empire chez ses contemporains français, bien que, au moment de la parution de son ouvrage, la critique l'ait vivement salué. Necker est, dans sa manière d'interpréter la Constitution impériale, aux antipodes de Scheid et, pour citer l'auteur d'un manuscrit que nous allons analyser par la suite, Dupal occupe une place intermédiaire. Trois figures différentes, témoins à la fois du vif intérêt porté à la Constitution de l'Empire et de la diversité des opinions qu'elle inspire. Leur point commun est de juger positivement cette Constitution, et de ne faire preuve d'aucun dédain, tout en soulignant certaines faiblesses (surtout de la part de Necker).

À travers les ouvrages français, on voit ainsi que l'Allemagne n'est nullement perçue comme »une république de princes, une vaste anarchie sous le protectorat de la France«, ainsi que l'a prétendu Salomon à l'égard de l'Allemagne telle

447 Ibid., p. 18-19.

448 Ibid., p. 2.

449 „L'Empereur exerce librement une partie des droits attachés à la Majesté, \& c'est ce qu'on appelle ses Droits réservés, ou sa prérogative. Dans tout ce qui en fait partie, il agit de sa pleine puissance Impériale. Pour exercer les autres qui sont bien le plus grand nombre, il doit prendre l'avis des Etats de l'Empire; mais il faut encore distinguer. Pour l'exercice des uns, il doit prendre l'avis de tous les Etats assemblés en Diette: pour l'exercice des autres, il lui suffit de l'avis de quelques-uns d'entre eux, par exemple, des Electeurs. Quelques-uns appellent ces derniers Droits, droits communiqués; \& les Etats, Corrégens, par cette raison, mais c'est mal à propos«; ibid., p. 17-18. 
qu'elle se présentait vers 1749450 ; du moins ce n'est point l'idée qui prévaut. Le but que Scheid s'est proposé »d'éfacer l'Idée désavantageuse, de l'état du gouvernement de l'Empire, formée par quelques-uns, qui ne savent pas les Langues « 451 allemande et latine n'était donc pas aussi urgent que l'auteur le prétendait ${ }^{452}$. De toute façon, l'on peut bien constater, entre 1740 et 1756 , des divergences considérables d'interprétation; certains auteurs, en particulier Necker, défendant les libertés des états de l'Empire, au point de renier son caractère même d'État, d'autres insistant, tel Scheid, sur son caractère monarchique. Mais Necker, lui non plus, ne considère point l'Empire comme une anarchie, et fait même preuve de patriotisme vis-à-vis de l'Empire (Reichspatriotismus). La littérature française sur le droit public allemand reflète donc parfaitement les contestations qui s'élèvent au sujet de l'interprétation de celui-ci, en Allemagne même, sur l'échiquier politicojuridique.

Comme dans les chapitres précédents il a souvent été question de la documentation française, il paraît intéressant de privilégier dans ce chapitre les manuscrits qui existent en langue française à l'étranger. En effet, la langue française étant devenue, depuis le milieu du XVIII ${ }^{e}$ siècle, la langue universelle par excellence, toute l'Europe lisait à cette époque des mémoires rédigés en français au sujet de la Constitution du Saint Empire romain germanique.

\section{L'histoire de l'Empire par Choffat}

Ce ne sont pas seulement les bibliothèques et les archives françaises qui conservent des histoires manuscrites et des mémoires en langue française sur l'histoire et sur le droit public du Saint Empire romain germanique. On en trouve aussi ailleurs en Europe. Nous avons consulté les catalogues de plusieurs institutions en Autriche et en Angleterre (les deux principaux adversaires de la France au XVIII siècle) pour mesurer l'étendue géographique de la connaissance des écrits français sur ce sujet en Europe centrale et occidentale.

Les archives de Vienne, en Autriche, possèdent une histoire manuscrite du Saint-Empire, divisée en dix périodes. Il s'agit du manuscrit 1022 dans l'inventaire de Böhm ${ }^{453}$, aujourd'hui coté Band Blau $327^{454}$. Ce gros manuscrit, qui

450 SALOMON, Les Alsaciens, p. 452.

451 SCHEID, Traité sistématique, t. I, p. [*8]-[*8'].

452 Schrader prouve que l'organisation politique de l'Allemagne était même, pour les penseurs français (nommément Saint-Pierre et Rousseau), un modèle d'inspiration, cf. SCHRADER, L'Allemagne; cf. aussi Klaus MALETTKE, Les manifestations de la conscience européenne aux XVIIe et XVIII e siècles, dans: ID. (dir.), Imaginer l'Europe, p. 124-128, en particulier p. 127 (sur l'Allemagne comme modèle d'organisation politique pour les États européens). Voir également ci-dessus sur les philosophes français et la Constitution du Saint-Empire.

453 Constantin Edler von BöHM (éd.), Die Handschriften des kaiserlichen und königlichen Haus-, Hof- und Staats-Archivs, Wiesbaden 1968 (réimpression de l'édition originale de Vienne 1873-1874), p. 281. 
compte presque mille pages, porte le titre: »Histoire de l'Empire d'Allemagne, divisée en dix périodes, tirée de plusieurs auteurs contemporains, cités par Struvius. Par Antoine Louis Hyacinte Choffat, prêtre sécullier «455. Malheureusement, nos recherches biographiques sur ce personnage se sont révélées infructueuses ${ }^{456}$. À en juger par son nom, qui est bien attesté comme nom de famille en France dans la période en question, il s'agit probablement d'un auteur français ou originaire d'un pays francophone. À la fin du texte, l'auteur a clairement indiqué la période de la rédaction de son traité: »Fin de l'histoire de l'Empire commencée le $9^{e}$ de juillet 1748 et finie le 12 d'avril $1749 \ll 457$.

La division du texte en dix périodes est conforme à celle de Struvius ${ }^{458}$, c'està-dire que la dixième période, qui comprend les empereurs qui intéressent le plus le droit public moderne, correspond à l'époque des souverains autrichiens allant d'Albert II à Charles VI ${ }^{459}$. Chaque période comporte des chapitres sur chacun des empereurs et sur les interrègnes ${ }^{460}$. En principe, cette histoire n'est qu'un résumé de l'ouvrage de Struvius, où Choffat a inséré, selon ses propres allégations, des informations tirées d'autres auteurs contemporains cités par Struvius.

Struvius est la forme latinisée de l'auteur connu en Allemagne sous le nom de Burkhard Gotthelf Struve. Celui-ci était polygraphe. En particulier, il acquit une très bonne renommée grâce à ses travaux historiques. Originaire de Weimar, où il naquit en 1671, comme deuxième fils du juriste Georg Adam Struve, qui était depuis 1673 professeur de droit à Iéna, Burkhard Gotthelf commença ses études à la même université, et, après un certain nombre de voyages, devint bibliothécaire à la bibliothèque universitaire de Iéna, en 1697. Il dispensa aussi des cours d'histoire, d'abord à titre privé, puisqu'il n'avait aucun grade académique, puis, après avoir fait son doctorat à Halle, devint professeur ordinaire d'histoire à Iéna, en 1704. Lorsque, en 1712, l'université de Kiel lui offrit une chaire de droit féodal et

454 Vienne (Autriche), Haus-, Hof- und Staatsarchiv, Handschriftensammlung (= XV), Band Blau 327 (HHSTA XV B 327). Le manuscrit comporte 486 folios; cependant, il nous semble plus commode de citer l'ancienne pagination du manuscrit (963 pages).

455 Titre d'après l'inventaire.

456 Il n'apparaît ni dans le Dictionnaire de biographie française ni dans les anciens dictionnaires biographiques inventoriés dans: Archives biographiques françaises, ici la partie Index, t. 2 (32004), p. 957.

457 HHSTA XV B 327 p. 960.

458 Burkhard Gotthelf STRUVE, Corpvs historiæ germanicæ [...], 2 vol., Iéna 1730. En effet, une grande partie des traités, imprimés ou manuscrits, sur l'histoire d'Allemagne préfèrent une répartition en dix périodes. Mais il y a aussi d'autres périodisations. Par exemple, un auteur français distingue »trois grandes périodes «, la troisième (depuis 843 ) se divisant »en huit autres « périodes; cf. l'»Histoire de l'Allemagne depuis les tems les plus reculés jusqu'à nos jours. 1772 « (bibliothèque-médiathèque d'Évreux, ms. 6; volume de $320 \mathrm{p}$. in-40; titre, fol. b; citations, p. 1).

459 Cf. la table »des Empereurs divisés en périodes selon Struvius«, HHSTA XV B 327 p. 961-962; le traité est complété par une table »des Empereurs selon l'alphabet«, ibid., p. 963. Il commence au temps des Germains avant la domination romaine (première période). 460 Ces chapitres ne sont pas numérotés; souvent, le sujet des paragraphes respectifs du texte est indiqué par des notes marginales. 
canon, Struvius se décida à rester à Iéna, où on lui accorda, outre sa chaire d'histoire, le titre de professeur extraordinaire en droit. En 1730, il fut nommé professeur ordinaire de droit d'État et de droit féodal. Il mourut brutalement en 1738, également à Iéna.

Struvius fut un auteur fructueux; on lui doit une centaine de publications en allemand, en latin et en français. À côté de ses ouvrages juridiques et de biliothécaire, il est surtout connu pour ses travaux historiques. Struvius publia d'abord, en 1716 , à léna, un petit livre en latin, intitulé »Syntagma historiae Germanicae a prima gentis origine ad annum usque 1716 , qui fut traduit en allemand par Zschackwitz ${ }^{461}$. Partant de ce travail préparatoire, Struvius publia, également à Iéna, en 1730, un manuel d'histoire allemande en deux volumes, qui porte le titre de "Corpus historiae Germanicae a prima gentis origine ad annum usque 1730«: c'est l'ouvrage sur lequel Choffat se fonda en rédigeant son traité en langue française sur l'histoire d'Allemagne. Buder augmenta cet ouvrage, qui connut une deuxième édition, à léna, en 1753 , et une troisième édition, à Dresde, deux ans plus tard. Struvius publia aussi une version allemande de cet ouvrage, intitulée »Vollständige teutsche Reichshistorie«, en deux volumes, à Iéna, en $1732^{462}$. Cette histoire d'Allemagne était encore estimée au XIX ${ }^{e}$ siècle, bien que l'on jugeât que Struvius s'était limité à une simple narration des faits, sans analyse politique; mais son ouvrage passait pour très bien écrit et pour très précis ${ }^{463}$.

Le résumé fait par Choffat de l'ouvrage de Struvius est entièrement rédigé en français; toutefois, Choffat reprend certaines expressions techniques latines du droit public allemand, telles que "reservatum Ecclesiasticum ${ }^{464}$. Si Choffat n'évite pas les problèmes de droit public dans la mesure où ils intéressent l'histoire générale d'Allemagne - par exemple les disputes survenues entre la Bavière et le Palatinat au sujet du vicariat de l'Empire, après la mort de Ferdinand III, et celles qui sont nées entre les électeurs de Cologne et de Mayence concernant le couronnement de l'empereur, durant le même interrègne ${ }^{465}-$, son exposé historique n'offre pas d'analyse systématique de ces questions.

L'aspect important de ce manuscrit est qu'il témoigne de la réception de Struvius en France ou du moins par le public francophone. Or, des écrits non seule-

461 Johann Ehrenfried Zschackwitz (né en 1669, mort à Halle, où le roi de Prusse l'avait nommé professeur ordinaire de droit et de philosophie, en 1738); sur sa vie et son œuvre, cf. PÜTTER, Litteratur des Teutschen Staatsrechts, t. I, p. 363-364.

462 Koch traduisit en français l'Histoire d'Allemagne de Struve; sa traduction se termine par la conclusion de la Quadruple Alliance en 1731; cf. BNU Strasbourg, ms. 3587: »Histoire de l'Empire d'Allemagne traduite d'après l'Abrégé de Struve par Jean Frédéric Achace Koch «. La traduction comprend 586 p. in- $4^{\circ}$; de plus, ce manuscrit contient les annotations de Schopflin.

463 Sur cet auteur, ses publications et la critique du XIX ${ }^{\mathrm{e}}$ siècle à son égard, cf. MrTZSCHKE, art. »Struve: Burkard Gotthelf $«$, dans: Allgemeine deutsche Biographie, t. 36 (Leipzig 1893), p. 671-676. Sur la critique de PÜTTER, voir ID., Litteratur des Teutschen Staatsrechts, t. I, p. 364-369. À part cela, il y a de nombreux articles biographiques sur cet historien, cf. Deutsches Biographisches Archiv, ici la partie Index, t. 7 (32004), p. 5757.

464 HHSTA XV B 327 p. 743.

465 Cf. ibid., p. 750. 
ment historiques mais aussi juridiques traitant de l'Allemagne en langue française furent rédigés ou conservés hors de France.

\section{Dupal ou le regard britannique}

Nous avons vu que, dans les années 1730 à 1750, Scheid, qui est Allemand, écrit en français et qu'il s'adresse à un public qui comprend, outre les Français, les jeunes nobles allemands ses compatriotes et tous ceux qui maîtrisent la langue française. Ainsi, comme nous l'avons déjà souligné ci-dessus, la France, en tant qu'entité linguistique et communauté culturelle de tous ceux qui parlent sa langue et qui pensent en français, ne se limite pas à la France géographique, administrative et politique. Si ce choix linguistique de Scheid est aussi celui d'un grand nombre de ses contemporains, la question se pose de savoir si, dans d'autres pays que la France et l'Allemagne, l'on rédige des textes en langue française sur la Constitution du Saint-Empire et, le cas échéant, si l'on peut y constater différentes manières de percevoir et d'interpréter cette Constitution. Dans l'objectif de donner une réponse au moins partielle à cette question ${ }^{466}$, nous avons choisi d'étudier de plus près le cas britannique. Ce choix semble en effet s'imposer. D'abord parce que la théorie politique, très développée en Grande-Bretagne comme en France, a abouti à des conclusions tantôt analogues, tantôt divergentes dans ces deux pays ${ }^{467}$. Cela s'explique en outre parce que, dans la période considérée, le roi de Grande-Bretagne est l'un des électeurs du Saint-Empire et qu'il porte donc un intérêt particulier aux affaires de celui-ci468, qui ne correspond pas toujours à celui du roi de France, garant des traités de Westphalie, mais sans territoires en Allemagne, et donc exclu de toute forme de participation directe au gouvernement de ce pays (abstraction faite du droit d'intervention réclamé en vertu de ces traités). Dans ce contexte, il paraît indispensable d'étudier un deuxième problème, à savoir l'éventuel reflet de cette situation particulière sur la façon dont les droits et prérogatives des électeurs, et notamment de celui de Hanovre, sont défendus dans les écrits britanniques sur le droit public allemand.

466 Pour la connaissance de l'Allemagne dans d'autres pays européens, par exemple en Italie, cf. également SCHNeTTGer, Imperium Romanum; Braun, Die Wahrnehmung der Reichstage; ID., Ein italienischer Blick; ID., Kaiserhof, Kaiser und Reich; pour l'Angleterre: Emst ScHÜтZ, Die Gesandtschaft Großbritanniens am Immerwährenden Reichstag zu Regensburg und am Kur(pfalz-)bayerischen Hof zu München 1683-1806, Munich 2007 (Schriftenreihe zur bayerischen Landesgeschichte, 154).

${ }_{467}$ Pour les différences fondamentales entre l'évolution des constitutions en France et en Grande-Bretagne, notamment dans le domaine des compétences des parlements et dans celui de la théorie de la souveraineté du roi depuis le XVIe siècle, cf. George H. SABINE, A History of Political Theory, Londres ${ }^{3} 1961$, p. 372-373. Il insiste sur la fin de l'harmonie entre le roi et le Parlement au sujet de la distribution des pouvoirs, qui s'est fait sentir au XVII siècle, mais en même temps sur le mouvement de centralisation qui s'est manifesté en France aussi bien qu'en Angleterre, cf. ibid., p. 449-454 et la bibliographie.

${ }^{468}$ Ce fait est explicitement souligné par Dupal, dans son manuscrit que nous étudierons par la suite. 
En Grande-Bretagne, on s'intéresse dès la naissance de la Reichspublicistik, donc depuis au moins la deuxième moitié du XVIe siècle, à la Constitution impériale ${ }^{469}$. Parmi les ouvrages imprimés, on trouvera, dès le début du XVII siècle, des traductions du français: en 1606, Richard Knolles publie celle des »Six livres de la République « de Jean Bodin ${ }^{470}$, qui fait une large place à l'étude de l'Allemagne et qui, malgré une interprétation réductrice de l'organisation politique complexe de cette dernière, due à un théorème de la souveraineté et de l'État mal adapté à une bonne compréhension, fait preuve d'une connaissance profonde des détails de sa Constitution. Au cours du XVIIe siècle et au début du XVIII ${ }^{e}$ suivent les traductions, notamment, des ouvrages de Louis Du May ${ }^{471}$, de Samuel Pufendorf ${ }^{472}$ et de Jean Heiss ${ }^{473}$. À part les traductions, il existe aussi, évidemment, des livres d'auteurs anglais sur la question ${ }^{474}$. Mais ce qui nous intéresse plus particu-

469 Il est impossible d'offrir un aperçu des études qui y furent entreprises jusqu'au milieu du XVIII ${ }^{e}$ siècle; sur l'évolution de la science politique en Angleterre au XVI ${ }^{e}$ siècle et les échanges qui existent entre ce pays d'un côté et la France ou l'Allemagne de l'autre, cf. l'ouvrage fondamental de Quentin SKINNER, The Foundations of Modern Political Thought, 2 vol., Cambridge et al. 1978.

470 Cf. ibid., vol. II, p. 355; DenZER (dir.), Jean Bodin, ici la bibliographie, p. 495, no 7.43.

471 Cf. ci-dessus.

472 Samuel PUFENDORF, The Present State of Germany. Written in Latin by the Learned Samuel Puffendorff, Under the Name of Severinus de Monzabano Veronensis. Made English and Continued by Edmund Bohun, Esq[uire], Londres 1696. Lachs cite un ouvrage anonyme qui porte le même titre et qui fut publié, d'après elle, à Londres, en 1690; comme l'auteur évoque un séjour à Ratisbonne, elle croit qu'on pourrait l'attribuer à Sir George Etherage, qui fut effectivement résident anglais à la diète de Ratisbonne de 1685 à 1689 , cf. Phyllis S. Lachs, The Diplomatic Corps under Charles II \& James II, New Brunswick (N. J.) 1965, p. 153-154. Or, non seulement son titre, mais aussi sa définition de l'Empire (»An irregular Body, and like some mis-shapen Monster, if it be measured by the Common Rules of Politics and Civil Prudence «) nous incitent à penser qu'il s'agit soit d'une traduction anglaise de Pufendorf, soit d'un livre fondamentalement imprégné de ses idées; sans que nous puissions avancer aucune réponse définitive à cette question, l'ouvrage dans l'édition que Lachs a utilisée ne nous étant pas accessible, nous tenons la première hypothèse pour plus vraisemblable. En effet, la traduction de la définition de l'Empire dans l'édition de Pufendorf de 1696 correspond littéralement à celle qui est citée par Lachs; seulement, la mise en page de l'édition utilisée par elle pourrait être différente, mais il s'agit plus vraisemblablement d'une erreur de sa part (la citation, dans l'exemplaire que nous avons consulté, se trouve à la p. 152, au lieu de 52; mais la pagination d'une deuxième citation avancée par Lachs correspond bien à la nôtre: c'est le paragraphe où l'auteur du »Present State«, p. 84, dit avoir passé un certain temps à Ratisbonne).

473 Cf. ci-dessus.

474 Sur les livres et mémoires écrits par les diplomates anglais pendant la période allant de 1660 à 1689, et consacrés à divers pays d'Europe, cf. LACHS, The Diplomatic Corps, p. 141157. Citons notamment une dissertation sur les institutions politiques de l'Empire, »A Description of Germany«, envoyée de Vienne au roi d'Angleterre, vers 1672, par Bernard Gascoigne, et imprimée à Londres, en 1702; cf. ibid., p. 153 et p. 241, n. 42. Pour l'Allemagne vue par les diplomates anglais, voir également ScHÜTZ, Die Gesandtschaft. Il n'en reste pas moins que la production de titres en français sur ce sujet fut sans aucun doute beaucoup plus importante que celle qu'on peut observer en Angleterre. 
lièrement ici, ce sont les manuscrits ${ }^{475}$ français ${ }^{476}$ probablement rédigés en Grande-Bretagne durant la période considérée dans ce chapitre ${ }^{477}$. Nous avons déjà étudié le cas de Necker, qui a laissé une première version de son ouvrage sur le droit public germanique dans la British Library de Londres. Pour conclure, nous allons maintenant découvrir un autre exemple extrêmement intéressant.

Il s'agit d'un manuscrit intitulé "Introduction au droit public germanique ou

475 Nous n'avons trouvé, du moins jusqu'à présent, aucun titre français imprimé en GrandeBretagne.

476 Les changements qui affectent les préférences linguistiques des cours et des savants européens se manifestent en Grande-Bretagne comme dans quasiment toute l'Europe; la situation particulière de l'exil des huguenots favorisa déjà depuis le milieu du XVII siècle considérablement, mais pas forcément de manière durable, l'essor du français, cf. les parties consacrées à l'Angleterre chez BRUNOT, Histoire, t. V et VIII/1. En revanche, durant la Renaissance et tout le $\mathrm{XVI}^{e}$ siècle, »Italian [...] seems to have been almost as current at the Austrian Habsburg Court as Spanish, and more Elizabethans learned it than learned French «, Garret MatTingly, Renaissance Diplomacy, Londres 1970 (The Bedford historical series, 18) [11955], p. 237. Or, ces préférences ont aussi une influence sur les langues des manuscrits où l'on traite du droit public allemand. Le premier janvier 1564, par exemple, le Florentin Petruccio Ubaldino (d'après la dédicace du manuscrit, fol. 1-2, datée »Di corte, il primo dell'anno M.D.LXIIII«, fol. 2) avait offert à la reine Élisabeth (»Alla magnanima et pia Elisabetta Serenissima Regina d'Inghilterra, di Francia, e d'Hibernia etc., mia sourana Signora«, fol. 1), un très beau manuscrit calligraphique, rédigé dans la langue maternelle de l'auteur, l'italien, où il traite de l'élection et du couronnement de l'empereur, BL, Royal Manuscript 14.A.VIII (la dédicace se trouve fol. 1-2). Dans l'un des deux sonnets qui précèdent l'ouvrage, intitulé »Del contenuto dell'opera« (fol. 3) et constituant un très bel exemple d'une manière littéraire de traiter un sujet juridique, l'auteur définit ainsi son sujet (nous suivons scrupuleusement l'orthographe de l'original): „Come i principi illustri, alti, e sourani / Riceuin la corona, il manto, e i fregi / Dell'Imperio Romano dagli egregi / sette baroni eletti fra i Germani; // Come chimati sien, s'ei son lontani; / E quanto iui l'un l'altro stimi, o pregi; / En qual maniera alcun tal'hor si spregi / Nella pompa real con modi strani; // Leggendo in queste poche, uere carte, / Vedrer potrassi diligentement / La pompa, e'l fasto de i Cesari Agusti; // Quai per ordini antiqui, saggi, e giusti / Eletti sono a noi da quella gente / In nome altrui; ma ch'altri non u'ha parte «. Le choix linguistique de l'auteur ne semble point fortuit, ainsi qu'il l'explique dans la dédicace, puisqu'il dit avoir rédigé son manuscrit "nella nostra lingua Italiana; che vostra Serenità ama tanto« (fol. 1'). En revanche, nous disposons, dans l'ouvrage de Dupal, d'un bel exemple de manuscrit sur la Constitution allemande offert à un membre de la famille royale, au XVIII ${ }^{e}$ siècle, et écrit en langue française. Pour celui d'Ubaldino et son explication, cf. Braun, Scheid, Necker et Dupal, p. 237, n. 161 (où il faut pourtant lire "nobil « au lieu de »nobile« et »trouato « au lieu de "trovato«).

477 Pour le XVIIe siècle, les catalogues de la British Library mentionnent des pièces intitulées »Estat des affaires de l'Empire «; toutefois, il ne s'agit pas d'analyses de la structure politique de l'Empire (telles qu'on les trouve dans la vieille tradition des »relazioni« vénitiennes et dans »L'Estat de l'Empire « de Du May, par exemple), mais du récit de certains événements politiques récents. Ces pièces ont certainement été jointes aux dépêches (rédigées elles aussi en français) de Sir William Curtius, résident britannique à Francfort de 1649 à 1654 et de 1665 à 1673, que celui-ci avait adressées à Robert Long, secretary of State du roi, en 1650, cf. BL, Additional Manuscript 37047, en particulier fol. 74-75, 147-147'. En Angleterre, au XVII siècle, on lit apparemment aussi les lois fondamentales de l'Empire en français, du moins BL, Additional Manuscript 35832 contient-il, fol. 61-61', 62-62' (titre fol. 63') des extraits français de la capitulation impériale de 1620. 
Abrégé des Constitutions de l'Empire d'Allemagne « ${ }^{778}$. Cette introduction, rédigée entre 1740 et $1748^{479}$, est dédiée au prince de Galles ${ }^{480}$ et destinée à l'éducation de ses enfants ${ }^{481}$, comme en témoigne la dédicace ${ }^{482}$, signée Dupal ${ }^{483}$. Le texte comporte cent quatre-vingt-une pages in $-4^{\circ}$, avec une Table des chapitres « ${ }^{484}$, mais sans index. L'auteur a divisé sa matière en trente chapitres. Dans le chapitre premier, il offre des »Notions préliminaires de l'Empire et des électeurs«. Après la »Distinction des états de l'Empire « (chapitre 2) et la »Division de l'Empire en cercles« (chapitre 3), il traite »Des principales loix de l'Empire« en général (chapitre 4) et en particulier (chapitres 5 à 13). S'ensuivent des remarques générales sur »La forme du gouvernement de l'Empire (chapitre 14) et sur "La puissance de l'Empereur et [...] celle des etats« (chapitre 15), une analyse des principales institutions impériales (la diète, les assemblées particulières, la Chambre impériale, le Conseil aulique, les diètes provinciales; chapitres 16 à 19), de l'élection et du rôle du roi des Romains (chapitre 20). Une place importante est faite aux électeurs, avec un chapitre sur leurs privilèges en général (chapitre 21) et un consacré à chaque électorat en particulier (chapitres 22 à 29) ${ }^{485}$; le traité se termine par une étude »Des privilèges de la maison d'Autriche« (chapitre 30).

Au début du chapitre premier, qui comprend une vingtaine de pages, essentiellement consacré aux fondements juridiques et aux cérémonies de l'élection d'un empereur ainsi qu'au rôle et aux droits des électeurs au moment de cet acte, l'auteur définit ainsi le Saint-Empire et son chef: „L'Empire est une république qui consiste dans l'Empereur qui en est le chef et les états qui en sont les membres. L'Empereur est un prince élu légitimement par les électeurs pour gouverner l'Empire « ${ }^{486}$. Notons d'abord que Dupal accorde à l'Empire le caractère d'une république, donc la qualité d'un État; ce constat n'est point gratuit puisque c'est cette qualité même que lui conteste Charles-Frédéric Necker. La définition de la forme

478 BL, King's Manuscript 161 (titre fol. 2).

479 Selon le catalogue du British Museum: George F. WARner, Julis P. GILson, Catalogue of Western Manuscripts in the old Royal and King's Collections, vol. III, Londres 1921, p. 33; les raisons de cette datation n'y sont malheureusement pas alléguées. Il est toutefois certain que le manuscrit n'est pas antérieur à 1740 , puisqu'une note de bas de page précise que le roi de Bohême: »C'est aujourd'huy la reine d'Hongrie«, Marie-Thérèse (BL, King's Manuscript 161 fol. 6', n. *); tout porte d'ailleurs à penser qu'il fut écrit avant la paix d'Aix-la-Chapelie (1748). Selon une note au crayon ajoutée au bas du fol. 2, le manuscrit daterait de 1741 .

$480 \mathrm{Si}$ la datation du manuscrit est correcte, il s'agit de Frédéric Louis, prince de Galles (1707-1751).

481 Dont le futur roi Georges III (1738-1820), qui succéda en 1760 à son grand-père Georges II (1682-1760) comme roi de Grande-Bretagne et électeur de Hanovre, dont il deviendra roi en 1814. Le précieux manuscrit (écriture calligraphique, frontispice fleuri, reliure en maroquin rouge, tranche dorée) porte d'ailleurs ses armes.

482 BL, King's Manuscript 161 fol. 3-5, ici fol. 4'.

483 Dupal, dont le prénom est inconnu, ibid., fol. 5. Des recherches biographiques menées en France et en Angleterre ne nous ont pas permis d'identifier cet auteur, ni même de connaître son prénom.

484 Ibid., fol. 94-95'.

485 Un seul chapitre pour les électeurs de Trèves et de Cologne.

486 BL, King's Manuscript 161 fol. 6-6'. 
de gouvernement du Saint-Empire qu'offre Dupal dans le chapitre 14 n'est point sans équivoque; la difficulté de cette tâche tient du procédé que Dupal adopte en cherchant dans un premier temps à définir ce que l'Empire n'est pas:

L'Empire n'est point un État monarchique puisque la puissance souveraine ne réside point dans une seule personne. Ce n'est point non plus un État aristocratique, puisque les grands de l'État hors des diettes ne sont que des personnes privées par raport au corps de l'Empire, et cependant jouissent des droits régaliens dans leurs territoires. Il est encore moins démocratique, car le peuple n'y a point de pouvoir. On ne peut pas dire qu'il est mêlé de monarchique et d'aristocratique, puisque chaque État a ses droits différents et forme une république particulière, qui peut faire la guerre ou la paix pour son propre intérêt, pourveu que ce ne soit point contre l'Empire ${ }^{487}$.

L'embarras de l'auteur se fait sentir quand il en tire les conclusions, se contredisant (du moins en apparence) lui-même: »C'est donc une forme de gouvernement singulière qui n'a point de nom propre qui puisse l'exprimer, ny d'exemple dans tout l'univers. L'on peut dire seulement qu'il est composé d'une monarchie limitée et d'un système de plusieurs États ou républiques unies par différents nœuds $\ll \mathbf{4 8 8}$.

Si Dupal semble se contredire en affirmant dans un premier temps que l'Empire n'est pas une monarchie, puis en le qualifiant ensuite de monarchie limitée, c'est qu'il emploie ces concepts dans des acceptions et des contextes divergents. Le refus de qualifier l'Empire d'»État monarchique « est fondé sur une conception bodinienne de la puissance souveraine et de la monarchie. Si Dupal refuse ensuite l'interprétation que Bodin fait de l'Empire quand ce dernier le déclare »État aristocratique « où la souveraineté réside dans la seule diète, c'est que cette conception reflète mal le fédéralisme allemand, caractérisé par l'exercice par les ordres qui composent l'Empire des droits attachés à leur Landeshoheit ${ }^{489}$. Quand, enfin, Dupal n'admet pas non plus de parler de l'Empire en tant que démocratie, il n'attache pas à cette notion le sens plus traditionnel d'une participation des villes libres de l'Empire au gouvernement de l'État, mais bien le sens plus fondamental d'un gouvernement du peuple. L'école du status mixtus, selon laquelle l'Empire constitue un État mixte où se mélangent des éléments monarchiques et aristocratiques, est contestée pour la même raison que l'interprétation aristocratique offerte par Bodin ${ }^{490}$; ces approches différentes souffrent en effet du même défaut: elles ne traduisent pas le fait que chaque État allemand constitue une sorte de »république particulière " à l'intérieur de la république qu'est l'Empire. Le souci de Dupal diffère donc sensiblement de celui de la plupart des auteurs écrivant en français sur le droit public allemand. Contrairement à ceux qui étudient le problème de la répartition horizontale des pouvoirs (à savoir quels droits reviennent respectivement à l'empereur et aux états) pour déterminer la participation de cha-

${ }^{487}$ Ibid., fol. 53-53'.

488 Ibid., fol. 53'.

489 Dupal opte, nous l'avons vu, pour le terme de »droits régaliens «.

$490 \mathrm{Au}$ sujet des formes de gouvemement enseignées par Bodin, cf. Horst DENZER, Bodins Staatsformenlehre, dans: ID. (dir.), Bodin, p. 233-244. 
cun au gouvernement central de l'Empire et définir ensuite la forme de ce gouvernement, Dupal insiste sur le fait que la distribution verticale des pouvoirs (donc le fédéralisme) révèle la forme même de gouvernement de l'Empire. Or, ce faisant, il n'a plus recours au concept de souveraineté de Bodin, car cette notion est indivisible. La singularité de la Constitution impériale, relevée par Dupal, se rapproche évidemment des idées de Pufendorf que Scheid, nous l'avons vu, ne partage pas. Cependant, tout en ayant rejeté chacune des trois formes classiques enseignées par la philosophie grecque et tout particulièrement par Aristote, Dupal en vient enfin à accepter le qualificatif de »monarchie limitée«; or, ce n'est plus la monarchie dans le sens de la monarchie absolue définie par Bodin, c'est une notion de la monarchie qui n'exclut pas catégoriquement la restriction et le partage de la puissance souveraine. Peu originale et encore attestée par Scheid, cette notion acquiert toutefois, chez Dupal, un sens particulier, car il ne l'oppose pas, dans sa définition, aux autres pouvoirs centraux, mais il l'intègre dans un système fédéral »de plusieurs États ou républiques unies par différents nœuds«, donc non pas indépendants stricto sensu. C'est l'originalité de Dupal par rapport aux autres auteurs étudiés de considérer comme parfaitement compatibles la monarchie limitée et le caractère fédéral de l'État, et de n'y voir aucune contradiction ${ }^{491}$. La difficulté qui consiste à suivre l'enchaînement logique qui mène à cette définition découle du fait que Dupal, en refusant d'autres interprétations, sous-entend le sens particulier qui revient aux notions de monarchie et de souveraineté chez les auteurs dont les théories sont implicitement remises en cause. Dupal conclut, en soulignant de nouveau la nécessité d'intégrer le fédéralisme allemand dans une définition exacte de la forme de gouvernement de l'Empire:

Cette définition [que Dupal vient de proposer] paroît la plus claire et la plus juste, en ce que l'on voit dans l'Empire plusieurs États particuliers, qui se gouvernent à leur modes [sic] et qui n'agissent que pour leurs propres intérêts, sans être appuiés que de ceux dont ils veulent bien rechercher l'alliance, et qui cependant par raport aux affaires qui concernent tout le Corps germanique sont obligés de délibérer en commun avec le chef, et de soutenir tous ensemble ce poids commun ${ }^{492}$.

Cette Constitution, toujours selon Dupal, est le résultat d'une évolution historique, non »un ouvrage médité «493, et découle de l'ambition dont ont fait preuve, depuis les Carolingiens, les princes les plus puissants pour acquérir de nouveaux droits et territoires, ainsi que de leur souci de garder un chef puissant pour les protéger dans leurs nouvelles acquisitions; de »crainte de tomber dans un État monarchique«, ils essaient de restreindre sa puissance par les capitulations ${ }^{494}$.

491 Nous ne disons pas par là que Dupal a élaboré ou seulement défendu le premier cette idée; on devrait suivre la piste ouverte par d'autres auteurs, notamment anglais et allemands. Néanmoins, dans nos études plus approfondies sur les auteurs français, pareille manière de voir, du moins avec cette clairvoyance et cette facilité, n'a pu être répertoriée.

492 Ibid., fol. 53'-54.

493 Ibid., fol. 54.

494 Ibid., fol. 55. 
Or, quelles sont les répercussions de cette Constitution particulière du SaintEmpire sur l'exercice du pouvoir souverain? Dupal admet l'existence d'une souveraineté partagée, catégoriquement rejetée par Bodin, Le Bret et Loyseau. De sa définition de l'Empire, Dupal conclut »que la suprême puissance est partagée entre l'Empereur et les états de l'Empire «95; il accorde à l'empereur »des droits qui lui sont réservés« (c'est ce que la Reichspublicistik latine appelle »iura reservata«), mais aux États territoriaux »un[e] espèce de pouvoir despotique sur leurs sujets«. Cette dernière formule peut paraître un peu hasardeuse, mais ce que Dupal veut seulement dire, au fond, c'est que ni l'empereur ni les autres états de l'Empire ne sont en droit d'empêcher l'exercice de ce pouvoir ${ }^{496}$. Il y a donc, d'après Dupal, trois catégories de droits: la première renferme les droits réservés à l'empereur, au niveau fédéral de l'Empire; la deuxième comprend ce que l'on qualifie, dans l'Empire, de Landeshoheit, et regroupe les droits que les états exercent chacun sur les territoires particuliers qui forment l'Empire; la troisième catégorie est celle des droits exercés conjointement par l'empereur et les états. En revanche, Dupal remet en cause une quatrième catégorie de droits admise par d'autres publicistes, en particulier par Heiss, et qui reviendrait seulement à l'empereur et aux électeurs ${ }^{497}$; il allègue comme exemples certains droits douaniers. Ce refus d'exclure nettement de l'exercice de ces droits la totalité des états de l'Empire, exclusion qui apporterait pourtant un avantage notable aux électeurs en renforçant leur position vis-à-vis des autres états, ce refus, disions-nous, montre clairement que si Dupal offre une place de prédilection au rôle et aux fonctions des électeurs, il ne cherche pas à défendre outre mesure leurs prérogatives dans des cas litigieux du droit public allemand. Ce n'est pas un avocat qui plaide leur cause, mais un savant scrupuleux, dont le souci primordial est de fournir une image objective des données constitutionnelles de l'Empire aux enfants du prince de Galles.

Les iura reservata, dans la liste qu'en dresse Dupal, ne diffèrent pas sensiblement du catalogue qu'en proposent d'autres publicistes. Il est toutefois à noter qu'il se montre toujours très prudent, signalant les contestations qui s'élèvent au sujet de certains droits. Probablement dans l'intention de ne pas surcharger la mémoire des enfants du prince de Galles, il ne donne pas les noms des auteurs entre lesquels il constate ces divergences, disant seulement »quelques auteurs« et »d'autres auteurs«. Plus intéressante que la liste des iura reservata est cependant sa définition du pouvoir commun, exercé par l'empereur et les états de l'Empire réunis en diète; cette définition est profondément imprégnée des stipulations des traités de Westphalie ${ }^{498}$. Il »se raporte au bien général de l'Empire« et non aux territoires en particulier, et renferme le pouvoir

495 Ibid., fol. 55 '.

496 Cf. ibid.

497 Dupal dit que »quelques auteurs prétendent« l'existence de ces droits, mais que »la plupart des princes soutiennent que ces droits leur appartiennent pareillement« (ibid., fol. 56' et fol. 57).

498 L'historique des négociations et le résumé des stipulations que Dupal offre des traités de 
d'établir des loix générales, de les interpréter ou de les abroger, celuy de recevoir quelqu'un dans la qualité d'état de l'Empire, de luy accorder voix et suffrage dans les diettes, de l'en exclure ou de le suspendre, et de changer même les tribunaux souverains de l'Empire. C'est encore un droit commun de déclarer et de faire la guerre ou la paix, en corps.

Et d'y ajouter encore celui „d'imposer les collectes impériales, celuy d'avoir des troupes, de faire construire des fortifications, d'y mettre des garnisons, de faire des traités tant au dedans qu'au dehors de l'Empire « ${ }^{499}$. On ne s'étonnera pas de la facilité avec laquelle Dupal accepte l'idée de l'exercice commun par l'empereur et les états réunis dans la diète d'Empire de certains droits primordiaux pour le fonctionnement de l'État et qui en constituent l'essence même. L'idée de la souveraineté du King-in-Parliament était une conception trop bien ancrée dans la pensée politique anglaise pour que l'on insiste sur ce point. En revanche, la compréhension parfaite du fédéralisme allemand chez Dupal est tout à fait remarquable. Si la plupart des auteurs étudiés partent du partage du pouvoir entre l'empereur et les états pour en déduire la soumission de ces derniers à l'Empire ou leur indépendance (quasi) complète, en fonction de la position défendue, Dupal n'hésite point à accepter la participation et de l'Empire comme entité étatique et de ses ordres au droit international. Soulignant que le droit de déclarer la guerre ou de conclure la paix est un droit commun du »corps« de l'Empire, il attire l'attention sur le fait que ce même droit appartient »aussi aux États particuliers, lorsque le corps de l'Empire n'y est point interressé «500. Comme il applique un procédé identique à d'autres questions du droit public allemand, la fameuse question de l'indépendance ne se pose même pas.

Dans la mesure où la Constitution anglaise ne connaît pas de loi(s) fondamentale(s) au sens continental du terme, il serait intéressant de voir si Dupal en fait de même, ou s'il refuse de reconnaître leur bien-fondé, comme le fait Rousseau en France ${ }^{501}$. Effectivement, Dupal n'emploie pas le terme de "loi fondamentale«; mais il connaît bien la chose, en admettant l'existence de »loix [...] principales«, parmi lesquelles il classe "les recès de l'Empire, la Bulle d'or, les capitulations des Empereurs, la Paix publique, la Paix de religion, les traités de Westphalie, de Nimègue, de Munster [sic], de Risvick et de Rastad «502. Il n'y a là rien d'étonnant, bien que la plupart des autres auteurs ne nomment, pour ce qui est des traités, que celui de Westphalie, et qu'ils ne mettent souvent pas les recès au nombre des lois fondamentales, ce qui obscurcit en fait un peu la distinction entre la loi ordinaire et la loi fondamentale. Il est d'ailleurs à noter que Dupal évite la comparaison entre les institutions impériales et celles d'autres États, notamment les institutions anglaises. Sa description de l'Empire nous semble en fin de compte mieux traduire les réalités constitutionnelles de celui-ci que ne le fait Necker dans

Münster et d'Osnabrück est toutefois assez sommaire; en revanche, il s'étend sur »les guer[r]es « qui ont précédé ces traités (cf. ibid., fol. 43'-49).

${ }^{499}$ Citations ibid., fol. 56-56'.

500 Ibid.

501 Rousseau, Euvres complètes, III, p. 362-364.

502 BL, King's Manuscript 161 fol. 28. 
sa »Description du gouvernement present du Corps germanique «, en 1741, ou dans l'étude préliminaire de celle-ci sous forme d'un autre manuscrit, conservé de même à Londres.

La littérature française sur le droit public germanique, qui reflète, comme nous avons déjà pu le constater, presque parfaitement les contestations qui s'élèvent au sujet de l'interprétation de celui-ci en Allemagne même, sur l'échiquier politique et juridique, cette littérature française, disions-nous, échappe, au milieu du XVIII siècle, à la France et aux auteurs allemands qui ont depuis longtemps écrit pour un public francophone; mais les Allemands d'origine, propageant leur culture de l'État de droit à l'étranger, sont aussi au service d'autres puissances, tel un Necker chez les Britanniques, et c'est du français qu'ils se servent maintenant, même s'ils ne visent pas un public (uniquement) francophone. Si Dupal est un auteur dont l'origine est fort douteuse, il est incontestable qu'il écrit pour une dynastie germano-britannique, et même si l'on fait abstraction de son cas, la littérature française sur l'Empire dépasse indubitablement les limites du continent même pour conquérir l'Angleterre, en subissant parfois certains changements non mineurs dans la manière de percevoir l'Empire, mais, à une particularité près que nous avons relevée ${ }^{503}$, sans mutations majeures du point de vue terminologique.

\section{Conclusion}

Les controverses que nous venons d'aborder, dans ce chapitre, ne représentent qu'une partie de celles qui ont éclaté après 1648 , en particulier depuis 1740 , sur les rapports entre l'empereur et les états, sur le statut constitutionnel de ces derniers et sur la Constitution même de l'Empire. Elles ne sont pourtant pas une particularité de l'époque postérieure à 1648 . Leur persistance prouve que la paix de 1648 n'a point définitivement fixé le rapport entre l'empereur et les ordres, que ce rapport restait toujours en suspens. Les ouvrages en langue française ne se limitent pas à une description de ces discordances, mais y prennent part d'une façon active. Quelles que soient les idées qu'ils propagent, les traductions de l'article VIII du traité d'Osnabrück et les versions françaises des autres lois fondamentales (Bulle d'or et capitulations) sur lesquelles ils s'appuient sont en principe identiques. Les Heiss, les Necker, les Mauvillon ${ }^{504}$, les Scheid, les Pfeffel peuvent se fonder sur les mêmes termes en en tirant des conclusions divergentes.

Dans les ouvrages français, ces controverses se font particulièrement vives après 1740 , quand le bipolarisme austro-prussien et la remise en cause de la domination des empereurs autrichiens commencent à modifier les rapports de force dans l'Empire. Malgré la persistance d'interprétations traditionnelles de la Constitution du Saint-Empire chez un certain nombre d'auteurs, un retour aux idées de

503 À propos du terme de »loi fondamentale«, qui manque, d'après notre lecture du manuscrit, chez Dupal.

504 Rappelons que Mauvillon a repris la traduction de Heiss. 
Jean Bodin est indéniable. Certains auteurs, parmi lesquels d'excellents connaisseurs du droit public germanique, comme Chrétien-Frédéric Pfeffel, vont même plus loin que Bodin et interprètent le Saint-Empire comme une confédération d'États entièrement souverains. Cependant, en étudiant les mémoires sur l'histoire et le droit du Saint-Empire conservés au dépôt des Affaires étrangères, on s'aperçoit de la persistance d'idées plus traditionnelles au sujet de l'interprétation de la Constitution allemande, dans les milieux diplomatiques français par rapport aux auteurs des ouvrages imprimés, tels que Mauvillon et Necker. En général, on constate que, dans la diplomatie, un certain nombre d'idées traditionnelles, comme celle de la puissance de l'empereur, ont persisté après 1740505; mais les idées divergentes, par exemple celles de Jean Bodin, regagnent du terrain, en particulier depuis cette date. En 1763, Pfeffel constate: "La face de l'Allemagne a totalement changé «506.

505 L'auteur d'un »Mémoire sur le droit public d'Allemagne et sur les intérêts politiques de la France dans l'Empire«, daté de 1764, préconisait le rétablissement de l'ancien système, c'est-à-dire l'alliance entre la France et la Prusse: "Si l'Empire étoit réuni sous un seul chef qui pût gouverner l'Allemagne à son gré, cette puissance pourroit en peu de tems devenir l'arbitre de l'Europe, ou y jouer du moins le premier rôle. Tant que la puissance de la maison d'Autriche sera balancée par celle de la maison de Brandebourg, l'Allemagne ne pourra donner aucun véritable sujet d'inquiétude à ses voisins. L'Empire ne peut être regardé que comme une grande masse, formée de parties incohérentes, très difficiles à assembler «, copie: AE, MD All. 111 fol. 263-274, citation fol. 268.

506 Cf. le mémoire de Pfeffel, daté à Munich, le 9 août 1763, copie: ibid., fol. 364-367, citation fol. 364 . 
